\title{
Emploi les activités théâtrales dans l'enseignement de Flé en vue de développer l'expression orale et écrite et les savoir-être chez les étudiants[es] du cycle secondaire.
}

Préparée par.

\section{Dr. Abdel Nasser Chérif Mohammed}

Professeur-adjoint à l'université du Fayoum

مستخلص البحث.

هدف البحث الحالى الى استخدام الانشطة المسرحية فى تدريس اللغة

الفرنسية كلغة اجنبية فى تتمية التعبير الثفهى و التحريرى وأيضا فى تتمبة الاتجاهات المرتبطة بالتعبير الثفهي و التحريري لاى طلاب وطالبات المرحلة الثانوية. ولتحقيق اهداف البحث الحالي قام الباحث بإعداد مجموعة من الادوات (ادوات دراسة وأدوات قياس) حيث قام الباحث بإعداد قائمة بمهار ات التعبير الثفهى و التحرير وي وأيضا قائمة بالاتجاهات المرتبطة بالتعبير و الضرورية لطلاب المرحلة الثانوية من وجهة نظر المتخصصين بالمجال. وهاتين القائمتين بمثابة ادو ات اجر ائية لتحديد تلك المهار ات و الاتجاهات و اخذ رأي المتخصصين فى تعليم وتعلم اللغة الفرنسية فيها. كما قام الباحث ببناء اختبار فى مهار ات التعبير الثفهي و الكتابي و أيضا بطاقة ملاحظة لقياس اتجاهات الطلاب وبطاقة لتقويم الاداءات الثفهية لدى افر اد مجموعة الدراسة. وقام الباحث بيناء كر اسة انشطة باستخدام الانشطة المسرحية. وتم عرض الادوات على المتخصصين لتقنينها قبل التطبيق (قبل التجربة). وبعد المعالجة الاحصائية اكدت النتائج فعالية استخدام الانشطة المسرحية فى تتمية مهار ات التعبير الثفهى و الكتابى و الاتجاهات المرثبطة بها لدى طلاب وطالبات المستوى الثانوي.

الكلمات المفتاحية: الانشطة المسرحية - مهارات التعبير الثفهي والكتابي -

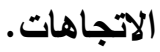




\section{Résumé en langue française.}

La recherche actuelle a eu pour objectif l'emploi des activités théâtrales dans l'enseignement de FLÉ en vue de développer l'expression orale et écrite et les savoir- être relatifs à ces compétences chez les étudiants(es) du cycle secondaire. Afin d'atteindre les objectifs de cette recherche, le chercheur a élaboré des instruments de mesure et des instruments de recherche. Il a élaboré une liste de compétences de l'expression orale et écrite et une autre liste des savoir-être vue nécessaires aux étudiants(es) du niveau secondaire. Ces deux listes constituaient comme des outils procéduraux pour déterminer les compétences de l'expression orale et écrite et les savoir-être nécessaires pour les sujets de l'étude du point de vue des spécialistes dans le domaine de la didactique de FLÉ. Il a également élaboré un test de compétences de l'expression orale et écrite, une grille d'observation et une grille d'évaluation pour les employer dans le cadre de la recherche. Il a aussi préparé un cahier d'activités en employant les enjeux théâtraux pour développer les compétences et les attitudes visées. Il a présenté ces instruments à un jury de spécialistes pour les valider. Après avoir appliqué les instruments déjà mentionnés, il a employé les techniques statistiques appropriées pour traiter les notes brutes obtenues quantitativement et qualitativement. Les résultats ont assuré l'efficacité de l'emploi des activités théâtrales en vue de développer les compétences de l'expression orale et écrite et de développer les savoir-être chez les étudiants(es) au niveau secondaire.

\section{Mots clés:}

Activités théâtrales - compétences de l'expression orale et écrite - les savoir-être.

\section{2}




\section{Introduction.}

Appendre une langue cible se fait, sans doute, de façon différente que celle de la langue maternelle. Dans la langue maternelle, on forme l'enfant dans un objectif de communiquer et d'interagir avec son environnement en entourage et dans cet environnement cet enfant devient apte à développer sa langue écrite et son langage parlé. Ce processus se fait inconsciemment de la part de cet enfant; il fréquente l'établissement scolaire en appuyant sur des schèmes cognitifs déjà acquis. Tout au long des années de scolarité, il développe ses compétences nécessaires de lecture, de compréhension orale et écrite, de production orale et écrite, ainsi ses compétences culturelles. Mais la situation est beaucoup plus différente voire complexe avec la didactique de la langue étrangère. L'apprenant(e) est ici en apprentissage permanent pour développer ses compétences langagières. Il doit déployer beaucoup plus d'efforts pour maîtriser les différentes compétences de la langue; par exemple sa lecture est très lente au début de l'apprentissage à cause du manque du vocabulaire, également son écriture est illisible et insignifiante. Peu à peu, il commence à apprendre cette langue cible et le(la) formateur(rice) joue ici un rôle primordial pour faciliter son enseignement/apprentissage. (Barth B.-M., 2006).

On essaie, au fur et à mesure, de développer des compétences langagières variées chez les apprenants(es) de tous les niveaux d'apprentissage en FLÉ (à partir du niveau d'A1 jusqu'au niveau de $\mathrm{C} 2$ ou plus.) parmi lesquelles, selon Goullier et à travers le 
CECRL, on trouve les compétences de la compréhension orale, celles de la compréhension écrite, celles de l'expression orale en situations interactionnelles, celles de l'expression écrite. (Goullier F., 2005).

D'après Maurie F., (Maurie F., 1992), ces compétences (les compétences de compréhension orale et écrite et celles de l'expression orale et écrite) constituent les quatre savoir-faire langagiers essentiels dont les apprenants(es) de FLÉ ont besoin. Selon la même chercheuse, ces quatre savoir-faire témoignent que l'oral précède l'écrit et en même temps associe à lui (à l'écrit) dans les deux compétences de la langue; compétence de la compréhension et compétence d'expression. Cette réalité s'est accordée avec des études antérieures telles dans la recherche d'(Amel Oual, 2010). Selon cette recherche d'Amel, l'enseignement/ apprentissage de n'importe quelle langue étrangère nécessite la perfection de ses différentes règles (notamment règles phonologiques et règles morphosyntaxiques) afin que les apprenants(es) puissent communiquer en l'employant dans les différentes situations de réception au même titre de production.

L'expression s'est définie par le ministère de l'Éducation de l'Ontario, comme étant le pont entre la lecture d'un texte donné avec fluidité et expressivité et modelée par le(la) maître(esse)enseignant(e) et l'exploitation de la voix et du langage par les apprenants(es) lors d'improviser, d'imiter, ou(et) d'interpréter des personnages. Selon le ministère de l'Éducation à l'Ontario, l'expression n'est qu'une situation de communication orale 
nécessaire pour développer les compétences langagières et celles de la réflexion créative chez les apprenants(es). Ces compétences font appel à l'imaginaire de ces apprenants(es) et les invitent toujours à participer à des scènes du discours au même titre à interpréter des textes pleins d'illustrations variées. (Ministère de l'Éducation de l'Ontario, 2008).

Il est à noter que l'oral tient une place importante dans l'instruction de la langue (n'importe quelle langue) notamment les langues étrangères. D'après les spécialistes et les didacticiens(nes), lorsqu'on se met à apprendre l'aspect oral de la langue, on doit faire des améliorations constantes sur les conditions du dialogue pédagogique, prendre en considération les points ci-dessous (Blanche-Benvéniste C., 1998) :-

- L'exécution des consignes doit être remise en question pour bien enseigner l'oral. Or, les consignes doivent être claires par des mécanismes variés; on doit doubler oralement les consignes. Ces consignes doivent être adressées aux apprenants(es) par un écrit au tableau, aussi les consignes ne doivent pas rapidement être exécutées .

- L'encouragement des apprenants(es) d'expliciter leurs démarches suivies pour s'entraîner à l'oral. Autrement dit, ils(elles) doivent verbaliser leurs stratégies adoptées dans les ateliers de pratiquer l'oral; les groupes composés par eux(elles) doivent bien oraliser pour faire un commentaire oral, présenter un exposé oral ...etc. 
- La nécessité d'encourager les apprenants(es) d'oraliser devant leurs collègues lors du processus de la didactique de l'oral; ils(elles) doivent verbaliser les activités de l'oral par suivre la stratégie de «question-réponse», doivent s'exprimer et s'engager de façon individuelle ou collective dans d'autres activités conçues sous la forme de problèmes à résoudre ...etc.

- L'entraînement guidé par les enseignants(es) et les inspecteurs de la langue étrangère, des apprenants(es) à discriminer les phonèmes par des mécanismes graphophonologiques; les apprenants(es) doivent améliorer leur oral par les exercices de dictée et doivent développer leur niveau oral par la lecture des textes à haute voix ...etc.

S'exprimer oralement et par écrit constitue les deux compétences non seulement visées et majeures mais également recherchées dans le domaine de la didactique de FLÉ. Le processus de la didactique de langues; langue maternelle, langue étrangère, vise donc en permanence au développement de quatre compétences : la compréhension orale et écrite au même titre l'expression orale et écrite chez tout(e) apprenant(e) dans tous les niveaux langagiers. Lorsque l'on parle, il (elle) ne cherche pas uniquement à produire des énoncés discursifs, mais également à prendre part à une conversation pour bien compléter le discours en manipulant la langue. A ce propos, les dialogues produits à travers ces situations dialoguées et parlées donnent 
l'occasion aux interlocuteurs de construire des répliques ayant un(des) sens en mettant les termes et les expressions langagiers les uns par rapports aux autres. Le sens se reproduit donc à travers les enchaînements contextuels et discursivement produits en employant ces termes et ces expressions langagiers. (Lilia Boumendjel, 2005).

Concernant l'aspect oral de l'expression, ses compétences consistent à combiner des composantes que les apprenants(es) doivent perfectionner pendant leur parcours du processus de l'enseignement/ apprentissage de toute langue enseignée. Il s'agit de, non seulement, avoir des savoirs et des savoir-faire de leur part, mais également de pouvoir mettre ces savoirs et savoir-faire à la disposition des discours produits par eux(elles); ils(elles) doivent avoir la capacité à manipuler le vocabulaire, la façon de parler, les formes structurales, les gestes, la prononciation, l'intonation, le rythme...etc. Alors l'expression orale n'est pas la simple connaissance des formes linguistiques mais également c'est l'aptitude à bien structurer les répliques employées et à bien exploiter ces répliques dans les différentes situations et avec les différents interlocuteurs pour bien continuer le discours. (Barth, 2006).

D'après un nombre énorme des méthodologues et des didacticiens(nes), l'expression orale constitue une relation indiscrètement établie entre un émetteur et un destinataire à travers un contexte de communication ou d'échange donné. Bien connu, l'oral inclut un travail sur la prononciation correcte des 
sons, sur l'intonation et sur le rythme et le rôle de chacun des apprenants(es), dans ce cas, c'est la familiarisation avec ces différents procédés déjà mentionnés (la prononciation des sons, l'intonation et le rythme) pour les pratiquer, ensuite les perfectionner peu à peu. On doit noter que le message oral est immédiat transportant des idées accompagnées des interactions non-verbales comme la gestualité, la mimique, les signes de sourire, et le regard d'un locuteur et produisant des effets sur des auditeurs. L'expression orale est donc un moyen de transmettre des messages entre des locuteurs et des auditeurs en employant la voix et le corps des premiers (les locuteurs) pour couvrir des situations de communication.

Hélène Sorez (Sorez H., 1995) voit que l'expression orale est un moyen de transmettre des messages aux autres en employant, de façon principale, la parole comme moyen de communication. Sorez met l'accent, donc, sur la parole comme outil essentiel de communication. On doit montrer que la compétence de l'expression orale est basée sur des interactions verbales et des interactions non-verbales. Sorez met en relief les interactions verbales dans sa définition de cette compétence en disant «s'exprimer oralement, c'est transmettre des messages généralement aux autres, en utilisant principalement la parole comme un moyen de communication»».

Selon des recherches antérieures telles dans la recherche d'Abdelaziz M. Latreche (Abdelaziz M. Latreche, 2015), le fait d'avoir l'aptitude à s'exprimer librement et inconsciemment dans les différentes situations en employant la langue enseignée, c'est 
d'avoir les mêmes caractéristiques de surfer librement sur les hauteurs des larges des personnels natifs de cette même langue car d'après le chercheur, la compétence de l'expression orale reste toujours la compétence la plus marquante pour les apprenants(es) de ces langues étrangères et en même temps elle n'est pas facile à acquérir. Par cette compétence l'on peut mesurer la capacité langagière de tous les parleurs des langues étrangères; par cette compétence, on peut juger que tel message est bien transmis et tel autre n'est pas bien transmis. Autrement dit, plus les apprenants(es) deviennent aptes à transmettre leurs messages oralement destinés, plus leurs niveaux en expression orale deviennent favorables. Or, cette compétence d'expression orale tire sa force à travers l'emploi correct des mécanismes tels que la fluidité du locuteur pendant les situations d'échanges, la structure correcte des répliques, l'aptitude à compléter les conversations tenues sans aucune difficulté, et sans aucun recours à des phrases artificielles.

Selon la recherche de Karima Cheriet (Karima Cheriet, 2014), l'expression orale constitue une compétence obligatoirement acquise par les apprenants(es); cette même compétence aide ces apprenants(es) à s'exprimer correctement de façon orale dans les différentes situations de la communication. Comme un critère du travail dans le domaine de l'expression orale, un rapport doit être établi entre un émetteur et un récepteur. Celui-ci doit avoir l'aptitude à comprendre l'autre pour que la communication soit efficace et pour que le message oral 
passe correctement. D'après la chercheuse, ce message oral est immédiat et on mesure son effet sur un récepteur.

Plusieurs autres recherches antérieures notamment la recherche d'Amina Souhila Hadjar (Amina Souhila Hadjar, 2015), ont montré que la perfection de l'expression orale joue un rôle primordial dans la didactique de FLÉ. Pour cette raison et d'après la chercheuse, les maîtres(ses)-enseignants(es) organisent en permanence des ateliers consacrés à ce propos. Les objectifs de la communication linguistique constitue la tâche essentielle derrière ces ateliers. Pendant ces tâches, le(la) maître(sse)enseignant(e) doit :

- Concevoir des situations d'échanges et de concurrences dont l'objectif essentiel est de créer une atmosphère d'échanges en vue de pousser les apprenants(es) à s'exprimer pour installer des compétitions parmi ces apprenants(es).

- Faire la correction des erreurs de ces apprenants(es) et leur donner l'occasion de refaire les énoncés incorrects pour bien continuer dans les situations d'échanges.

D'après la recherche d'Halima Saadia Charif (Halima Saadia Charif, 2015), l'expression orale constitue une compétence visant à s'exprimer dans toutes les situations de communication par la voie de la parole. Selon la chercheuse, la parole demeure le procédé de communication orale par excellence. Cette chercheuse a montré, à travers sa recherche, que la réussite de l'apprenant(e) dans l'expression orale compte sur son aptitude à 
relier l'aspect physique de la parole comme la voix, l'intonation, les signes de sourire, la mimique et la gestualité avec l'aspect linguistique de la parole. Or, cette compétence d'expression orale est, d'après elle, difficile à acquérir puisque cette compétence inclut des composantes variées; composante phonétique, lexicale, linguistique, discursive et stratégique.

Continuer dans ces situations d'échanges n'est pas une tâche facile au contraire c'est un travail difficile nécessitant des efforts de la part des apprenants(es) pour apprendre à perfectionner le langage oral.

En ce qui concerne l'aspect écrit de l'expression, il est à noter que tous les précurseurs dans le domaine de la didactique des langues vivantes en général et de la didactique de FLÉ en particulier se mettent d'accord sur l'importance de l'aspect écrit de la langue (soit la compréhension écrite, soit l'expression écrite). l'expression écrite était considérée comme l'objectif majeur dans la didactique des langues dès les années soixante jusqu'à nos jours. C.-à-d., les didacticiens(nes) focalisent sur cet aspect écrit dès l'emploi de l'approche traditionnelle (grammairetraduction) passant par l'approche communicative jusqu'à l'emploi de l'approche actionnelle. Avec l'approche traditionnelle ou classique, la langue étrangère était enseignée par les exercices écrits de grammaire, les exercices de traduction, les exercices de rédaction des articles, et les exercices de dissertations. Avec les méthodes audio-orales et audio-visuelles, on a négligé l'aspect écrit de peur de l'interférence de la prononciation des sons avec 
l'orthographe de l'écrit. Mais actuellement avec l'approche communicative et celle de l'approche actionnelle, on a remis en question l'aspect écrit.

Il faut signaler que l'écriture n'est pas de copier ou bien de recopier quelques phrases mais une activité intellectuelle nécessitant des savoir-faire multiples commençant par une stratégie efficace d'écriture bien choisie passant par la rédaction des phrases pour composer un paragraphe ou un texte donné, la révision de ce qu'on a écrit et finissant par l'évaluation du contenu produit par écrit. (Karima Majouba, 2012).

L'écriture constitue un activité sociolinguistique et plusieurs études antérieures dans le domaine de l'expression écrite comme la recherche de (Karima Majouba, 2012) ont montré qu' à l'école, l'apprenant(e) écrit pour:

- Présenter des exposés et des recherches documentaires;

- Communiquer avec ses pairs soit dans l'établissement scolaire, soit ailleurs;

- Raconter des évènements;

- Donner des consignes;

- Décrire des expériences personnelles, des recettes,...etc.;

- Donner des informations.

À ce propos, (Lartigue R., 1992) a confirmé que la production d'écrits correspond à des besoins et à des désirs vrais qu'on élabore dans des situations authentiques. L'expression 
écrite fait partie intégrante de la communication en général et de la communication écrite en particulier. La communication par écrit suppose essentiellement qu'un scripteur adresse un texte ou un document à un récepteur (un lecteur). Ces personnels (le scripteur et le/les récepteur(s)) n'ont pas les mêmes intentions lors des situations de la communication; le/les scripteur(s) a/ont l'intention de pratiquer puis développer l'écriture, tandis que le/les récepteur(s) a/ont l'intention de pratiquer puis développer la lecture. (Karima Majouba, (2012). Or, lors des ateliers consacrés à développer les compétences de l'expression de l'écrit chez l'apprenant(e), celui(celle)-ci doit produire des phrases, des paragraphes, ainsi des petits textes sur une gamme de thèmes relatifs à ses besoins et à ses intérêts; cet(te) apprenant(e) peut s'entraîner à rédiger par exemple un essai, une dissertation, un article ou un rapport pour transmettre une information, pour commenter un évènement donné, pour manifester une attitude envers des incidents sociaux,...etc.

Pour bien développer les compétences de l'expression orale et écrite chez les apprenants(es) de tous les niveaux langagiers de la langue française, il nous faut, au fur et à mesure, employer des stratégies, des approches, et des méthodes nouvelles. Grégory Lepoutre (Lepoutre G., 2007) a mentionné que ce sont aux apprenants(es) qui doivent apprendre en voix les textes de la langue. C.-à-d., ils(elles) doivent développer leurs compétences orales et écrites par eux(elles)-mêmes. Ils(elles) doivent donc être autonomes et conduisent par eux(elles)-mêmes leur apprentissage. Il a mentionné que le théâtre et les enjeux 
théâtraux jouent là des rôles primordiaux. Cela veut dire que les apprenants(es) ajoutent d'autres dimensions aux travaux langagiers comme les ressources corporelles, qui sont des enjeux théâtraux, pour faciliter la compréhension des textes et pour donner l'occasion aux apprenants(es) en même temps de pratiquer les compétences de l'expression langagière. Or, ces activités basées sur les enjeux théâtraux constituent une vision d'avant-garde pour développer les deux facettes de l'expression langagière (l'expression orale et écrite).

Il faut signaler que l'exploitation des activités et des pratiques théâtrales dans le processus de l'enseignement/apprentissage des langues (dans les classes de langues) sont remarquablement développées depuis quelques années. D'après des documents diffusés électroniquement par les centres pédagogiques parmi lesquels on trouve ceux du centre international d'études pédagogiques (Centre International d'études pédagogiques, 2015), ces activités et ces pratiques théâtrales constituent des outils efficaces pour rendre l'apprentissage de la langue française favorable et motivant. Selon ces documents, ces activités peuvent donner l'occasion aux apprenants(es) d'ouvrir à des dimensions nouvelles de la langue étrangère; la dimension culturelle, la dimension sociale et la dimension émotionnelle.

Pratiquer les enjeux théâtraux donne aux apprenants(es) un aspect vivant concernant les compétences langagières car ces activités donnent l'occasion à ces apprenants(es) de s'exprimer librement en associant la parole au corps. L'association de la 
parole au corps permet à l'apprenant(e) d'accéder facilement au sens. (Halima Saadia Charif, 2015).

Des spécialistes nombreux en didactique de FLÉ comme (Lepoutre G., 2007), (Halima Saadia Charif, 2015) ont montré que les pratiques théâtrales permettent aux apprenants(es) de bouger sur la scène en parlant la langue française. D'après eux, ces pratiques théâtrales aident les apprenants(es) de prendre conscience des fonctionnements de la voix et de faire des corrections et des améliorations des défaillances phonétiques, et celles de l'intonation. C'est à travers le théâtre et les enjeux théâtraux à l'établissement scolaire que les enseignants(es) et l'aspect administratif peuvent transmettre des éléments socioculturels de la langue et du langage.

En outre, Gisèle Pieera (Pierra G., 2001) a vu que la mise en place des séances basées sur l'activité théâtrale constitue une sorte d'ouverture à un monde de création où l'apprenant(e) peut non seulement représenter les petites œuvres mais également se placer dans une position d'agitateur de sens.

À ce propos, Chen Wel (Wel Ch., 2009) a confirmé que le théâtre et la pratique théâtrale en classe de langue constitue un support pédagogique pour enrichir l'enseignement/ apprentissage de FLÉ. D'après lui, le théâtre et les enjeux théâtraux offrent des ressources naturelles pour enrichir et développer l'aspect linguistique (notamment le lexique, la syntaxe et le stylistique) de FLÉ. 
Des ouvrages et des recherches antérieurs variés se sont présentés sur l'idée d'employer la pratique théâtrale dans l'enseignement des langues; l'ouvrage d'(Alix Ch., et al., 2013) intitulé «Didactique du français langue étrangère par la pratique théâtrale». Cet ouvrage a présenté une étude théorique assemblant les travaux et les expériences des didacticiens, des professeurs ainsi des linguistes qui ont utilisé la pratique théâtrale dans leurs méthodes d'enseignement de FLÉ et de français langue seconde (FLS).

D'autres ouvrages et recherches antérieurs variés se sont présentés sur l'idée d'exploiter le corps, la voix et le texte comme mécanismes d'origine théâtrale dans l'enseignement des langues; l'ouvrage de (Pieera G., 2006) intitulé «Le corps, la voix, le texte : arts du langage en langue étrangère». Cet ouvrage a présenté l'élaboration d'un programme d'instruction adressé à des apprenants(es) de français venus(es) de différentes origines pour établir une sorte de transversalité autour des notions de parole, de culture, et de corps comme outils de l'expression du sujet parlant.

Dans le même cadre, il existe d'autres œuvres et études antérieures telles l'œuvre de (Louys G., et Leeman D., 2013), celle de (Mongenot Ch., et De Peretti I., 2013), et celle de (Pieera G., 2001). Ces études et ouvrages mettent l'accent sur l'exploitation de la pratique théâtrale dans l'enseignement/ apprentissage de FLÉ. Elles suggèrent et discutent en même temps comment passer d'un corps à l'autre avec les autres aspects 
(sémantiques, culturels, relationnels, émotionnels ...etc.) pour développer soit la compréhension soit la production langagières.

D'autres études et ouvrages récemment achevés mettent l'accent sur l'emploi des activités théâtrales comme démarches et outils pédagogiques. Ces recherches sont comme la recherche de (Balazard S., Gentet-Ravasco E., 2011), celle de (De Bouter P., 2015), celle de (Marjolaine P., et Treffandier F., (2012), et celle de (Payet A., 2010). Ces recherches présentent en gros les avantages des activités théâtrales dans les classes de langue de tous les niveaux langagiers et les types de telles activités exécutées, réalisables et pratiquées dans ces mêmes classes. La recherche de (De Bouter P., 2015), par exemple, a mentionné comment les maîtres(resses)-enseignants(es) de toutes les disciplines développent-ils(elles) des compétences soit langagières soit autres par la pratique du jeu théâtral?.

Ces activités et cette pratique théâtrales peuvent contribuer également à développer les comportements et les attitudes positives (ce qu'on intitule les savoir-être) chez les apprenants(es) des langues vivantes étrangères et notamment de FLÉ.

Des études antérieures (par ex: (Kopiac M., et Howden J., 2000), (Cuq J.-P., 2003), (Gauvin C., et Laforge É., 2006), et (Fatiha Boudebouda, 2010) ont confirmé l'importance essentielle de ces savoir-être pour tel(le) ou tel(le) apprenant(e) des langues en général et pour celui(celle) de FLÉ. 
D'autres études précédentes (par ex: (Péris E., 2009) et (Smuk M., 2014)) ont focalisé sur l'importance centrale de ces savoirêtre soit pour les apprenants(es), soit pour l'enseignement/ apprentissage des compétences de la langue en général et parmi lesquelles on trouve les compétences de deux facettes de l'expression (expression orale et expression écrite).

Suivant ces études déjà mentionnées, les apprenants(es) des langues vivantes étrangères (LVÉ) et plus particulièrement de (FLÉ) maitrisant ces comportements et ces attitudes (les savoirêtre) sont en mesure de /d' :

- Déterminer, nommer et identifier ses atouts d'apprentissage de la langue et de ses compétences et dans notre cas celles de l'expression (orale et écrite);

- Déterminer, nommer et identifier ses points faibles concernant le processus d'apprentissage de la langue et de ses compétences et dans notre cas celles de l'expression (orale et écrite);

- Intégrer des connaissances sur le soi dans la conception de son processus d'apprentissage et du choix des stratégies adoptées pour atteindre ses objectifs;

- Déterminer et saisir les traits personnels constituant une entrave à la perfection de telle ou telle compétence et dans certains cas l'accepter.

Or, on peut dire que le développement des savoir-être chez les apprenants(es) fait d'eux(elles) des gens aptes à identifier ses 
atouts d'apprentissage, à déterminer leurs objectifs, à choisir leurs stratégies du travail, à choisir leurs parcours méthodologiques, à bien exploiter leurs procédés et modalités de l'évaluation ...etc. Ils(elles) deviennent autonomes pour ce qui concerne l'enseignement /apprentissage des compétences de l'expression orale et écrite.

\section{Position du problème.}

Le problème de la recherche actuelle se pose à travers les points ci-dessous :

- Des programmes et des recherches antérieurs conçus dans le cadre de la complémentarité de deux facettes de l'expression (expression orale et écrite); ces recherches ont confirmé que ces deux facettes d'expression (expression orale et écrite) se complètent et que l'enseignant(e) et l'apprenant(e) ne sont pas capables de traiter l'aspect oral sans l'aspect écrit de l'expression. Autrement dit, il ferait mieux de travailler les deux facettes d'expression de façon complémentaire en classe de langue. Ces recherches sont : la recherche du (Ministère de l'éducation nationale, 2009). La recherche en cours s'identifie avec la même vision de la nécessité de travailler les deux facettes de l'expression (orale et écrite) de façon intégrale. Les deux facettes de l'expression (expression orale et expression écrite) semblent être comme un aller / retour d'un même parcours. C.-à-d., l'on ne peut pas traiter une compétence sans l'autre. 
- Des recherches et des études antérieures dans le domaine de l'emploi de la pratique théâtrale dans l'enseignement/ apprentissage de FLÉ en général, comme la recherche d'(Alix Ch., et al., 2013), celle de (Pieera G., 2006), celle de (Louys G., et Leeman D., 2013), celle de (Mongenot Ch., et De Peretti I., 2013), et celle de (Pieera G., 2001), et ces recherches et œuvres ont assuré l'efficacité de cette technique dans le processus de l'enseignement/ apprentissage de FLÉ.

- D'autres recherches et études, comme la recherche de (Balazard S., Gentet-Ravasco E., 2011), celle de (De Bouter P., 2015), celle de (Marjolaine P., et Treffandier F., (2012), et celle de (Payet A., 2010) ont assuré l'efficacité de l'emploi des activités théâtrales comme démarches et outils pédagogiques. Ces recherches et études ont recommandé la nécessité d'employer ces activités théâtrales dans la classe de langue avec les apprenants(es) de tous les niveaux langagiers.

- Des recherches et des études antérieures, telles la recherche de (Balazard S., Gentet-Ravasco E., 2011) ont présenté des conseils aux maîtres(resses)-enseignants(es) et ont proposé sous forme de fiches opérationnelles une stratégie et une approche (claire et fixe) pour développer les compétences de l'expression orale chez leurs apprenants(es). 
- D'autres recherches et études antérieures, telles la recherche de (Nesma Mohammed, 2015), celle de (Doaa Sayed, 2011), celle de (Hagar khalil, 2005), celle de (Naglaa Fathi, 2006), ont recommandé la nécessité de mettre l'accent sur le développement des compétences de la communication orale en général et des compétences de l'expression orale en particulier chez les apprenants(es) du niveau secondaire au même titre chez les futurs(es) enseignants(es).

- Des recherches et études antérieures dans le domaine de l'expression orale et écrite, comme la recherche d'(Aliaa Mohammed, 2003), celle d'(Asma El-Dib, 2015), celle de (Taje El-Dine Mohammed, 2013), celle de (Passant Kamal, 2018), et celle de (Mohammed Fathi, 2018) ont recommandé qu'on doit développer l'expression orale en permanence chez les apprenants(es) de FLÉ.

- Des études antérieures et précédentes, (par ex : (Kopiac M., et Howden J., 2000), (Cuq J.-P., 2003), (Gauvin C., et Laforge É., 2006), (Fatiha Boudebouda, 2010), (Péris E., 2009) et (Smuk M., 2014)), ont mis l'accent sur l'importance du développement des savoir-être chez les apprenants(es) de la langue étrangère et notamment ceux(celles) de la langue française comme langue étrangère (FLÉ).

- De tout ce qui précède, le chercheur s'est assuré que les apprenants(es) débutants(es) de FLÉ ont besoin de 
développer leurs niveaux en expression orale et écrite, et pour s'assurer davantage, le chercheur a mené une étude exploratrice sur un groupe d'apprenants(es) de FLÉ composé de (25), autre que le groupe de l'étude et au même niveau d'apprentissage et leurs résultats sont résumés dans le tableau ci-après :

\begin{tabular}{|c|c|c|c|}
\hline No. & $\begin{array}{c}\text { Les } \\
\text { compétences } \\
\text { mesurées. }\end{array}$ & $\begin{array}{c}\text { Pourcentage } \\
\text { total } \%\end{array}$ & Les phases en détail. \\
\hline 1. & $\begin{array}{l}\text { Expression } \\
\text { orale. }\end{array}$ & $\begin{array}{l}\text { Le } \\
\text { pourcentage } \\
\text { des erreurs } \\
\text { est plus de } \\
88 \% \text {. }\end{array}$ & $\begin{array}{l}\text { - } 56 \% \text { des erreurs sont dues à } \\
\text { la prononciation fautive des } \\
\text { sons semblables (les } \\
\text { apprenants(es) ne sont pas } \\
\text { capables de distinguer ces } \\
\text { sons notamment les sons } \mathrm{P} / \mathrm{b} \text {, } \\
\text { les voyelles orales et } \\
\text { notamment les voyelles } \\
\text { nasales. } \\
32 \% \text { des erreurs sont dues à } \\
\text { l'emploi fautif des règles } \\
\text { grammaticales lors de parler, } \\
\text { à l'emploi fautif des mots et } \\
\text { des expressions lors de } \\
\text { parler ...etc. }\end{array}$ \\
\hline 2. & $\begin{array}{l}\text { Expression } \\
\text { écrite. }\end{array}$ & $\begin{array}{l}\text { Le } \\
\text { pourcentage } \\
\text { des erreurs } \\
\text { est plus de } \\
93 \% \text {. }\end{array}$ & $\begin{array}{l}\text { - } 52 \% \text { des erreurs sont dues à } \\
\text { l'emploi fautif des règles } \\
\text { grammaticales lors d'écrire. } \\
\text { - } 41 \% \text { des erreurs sont }\end{array}$ \\
\hline
\end{tabular}




\begin{tabular}{|l|c|c|c|}
\hline No. & $\begin{array}{c}\text { Les } \\
\text { compétences } \\
\text { mesurées. }\end{array}$ & $\begin{array}{c}\text { Pourcentage } \\
\text { total \% }\end{array}$ & Les phases en détail. \\
\hline & & & partagées comme suit : \\
& & & $\begin{array}{l}\text { emploi fautif des règles } \\
\text { orthographique, emploi } \\
\end{array}$ \\
& & fautif des marques de \\
& & ponctuation. \\
\hline
\end{tabular}

- Pour s'assurer du problème de la recherche davantage, le chercheur a opéré une rencontre avec un nombre de maîtres(esses)-enseignants(es) ( $\mathrm{N}=10$ enseignants(es)) au niveau secondaire. Un nombre majoritaire de ces enseignants(es), (80\% d'eux(elles)), ont assuré que les apprenants(es) sont énormément faibles dans les compétences de l'expression en général et notamment dans les compétences de l'expression orale. Tous(toutes) ces enseignants(es) sont d'accord sur la faiblesse de tous(toutes) les apprenants(es) au niveau secondaire dans les savoir-être. Les enseignants(es) ont confirmé que (95\%) des apprenants(es) sont timides, hésitants(es), incapables de préciser leurs besoins, leurs atouts et leurs objectifs lors de se mettre à parler en public.

\section{Problématique de la recherche.}

Le problème de la recherche actuelle s'est limitée à la faiblesse des apprenants(es) au niveau secondaire dans les compétences de l'expression (orale et écrite) et dans les savoir- 
être relatifs à l'expression. Cette recherche s'est souciée de savoir l'efficacité d'«Emploi les activités théâtrales dans l'enseignement de FLÉ pour développer l'expression (orale et écrite) et pour développer les savoir-être chez les étudiants(es) au cycle secondaire».

Pour bien étudier la problématique ci-dessus, on doit répondre aux questions suivantes :

- Quel est le niveau des apprenants(es) de la $2^{\text {ème }}$ année au niveau secondaire dans les compétences de l'expression (orale et écrite) en FLÉ ?

- Quels sont les savoir-être nécessaires pour les apprenants(es) au niveau secondaire?

- Quelles sont les activités théâtrales convenables pour développer les compétences de l'expression (orale et écrite) et les savoir-être vus nécessaires chez les apprenants(es) du cycle secondaire?

- Quelle est l'efficacité des activités théâtrales pour développer les compétences de l'expression (orale et écrite) et les savoir-être vus nécessaires chez les apprenants (es) du groupe de l'étude?

\section{Objectifs de la recherche.}

Cette recherche a pour objectif de :

- Contrôler le niveau des apprenants(es) de la $2^{\text {ème }}$ année au niveau secondaire dans les compétences de l'expression (orale et écrite) en FLÉ; 
- Découvrir les savoir-être nécessaires pour les apprenants(es) de FLÉ au niveau secondaire;

- Vérifier l'efficacité de l'emploi des pratiques théâtrales dans le développement des compétences de l'expression (orale et écrite) en FLÉ contenues dans le manuel de la $2^{\text {ème }}$ année du niveau secondaire et dans le développement des savoir-être nécessaires pour les sujets du groupe de l'étude.

\section{Importance de la recherche.}

Cette recherche peut-être profitable pour :

- Les apprenants(es) de FLÉ de tous les niveaux d'apprentissage dans la mesure de développer leurs compétences de l'expression (orale - écrite); ils(elles) peuvent simuler les pratiques théâtrales présentées dans le cadre de la recherche actuelle dans la visée de développer en permanence leur niveau en expression (orale -écrite).

- Les maîtres(resses)-enseignants(es) de FLÉ en général et notamment ceux(celles) qui travaillent au cycle secondaire et avec les adolescents(es) débutants(es)) dans la mesure d'exploiter les activités théâtrales présentées pour développer les compétences de l'expression (orale - écrite) et les savoir-faire nécessaires chez leurs apprenants(es) de ce niveau d'apprentissage.

- Les inspecteurs et les formateurs de FLÉ dans la mesure de profiter des fiches et des supports employés pendant les 
séances de la tentative lors de l'entraînement des apprenants(es) au même titre les enseignants(es), aux compétences de l'expression (orale - écrite) et les savoirêtre nécessaires.

- Les didacticiens(nes) de FLÉ dans la mesure de profiter des outils, des instruments et des modalités de l'évaluation (évaluation formative et évaluation sommative) présentées dans le cadre de la recherche actuelle.

\section{Délimitation de la recherche.}

Cette recherche s'est limitée à :

* Un groupe d'étude choisi aléatoirement parmi les apprenants de la $2^{\text {ème }}$ année au cycle secondaire; ce groupe s'est composé de (35) étudiants(es). Les sujets du groupe sont des adolescents débutants. Ce groupe a été sélectionné aléatoirement parmi les apprenants de l'école secondaire de jeunes garçons de (Khausos) au gouvernorat du Caire. La tentative s'est déroulée pendant le $2^{\text {ème }}$ trimestre de l'année scolaire 2018 2019.

\section{Instruments de la recherche.}

Lors d'expérimenter la recherche en cours, le chercheur a employé les outils ci-dessous :

\section{Outils de recherche.}

- Cahier d'activités et des exercices destiné à développer l'expression (orale - écrite) et à développer les savoir-être 
nécessaires pour les étudiants de la $2^{\text {ème }}$ année au cycle secondaire. Ces activités et ces exercices sont conçus de façon convenable suivant le niveau des étudiants du cycle secondaire (niveau débutant).

\section{Outils de mesure.}

- Un test de compétences de l'expression (orale - écrite) employé dans le cadre de la recherche comme un test de progrès. Ce test est manipulé dans le cadre de la tentative pour contrôler le niveau des sujets du groupe de l'étude avant et après la tentative. Ce test est employé dans le cadre de l'évaluation sommative.

- Une grille d'observation destinée à contrôler le niveau des apprenants(es) de FLÉ dans les savoir-être nécessaires pour eux avant et après la tentative.

- Des petits tests d'expression (orale - écrite) employés pendant la tentative pour mesurer le progrès des sujets du groupe de l'étude. Ces tests se sont employés régulièrement après les activités et les exercices de chaque leçon. Ces tests sont dans le cadre de l'évaluation formative.

- Une grille d'évaluation élaborée pour évaluer les items des tests consacrés à l'aspect oral.

\section{Hypothèses de la recherche.}

La recherche actuelle s'est souciée de savoir si $/ \mathrm{s}^{\prime}$ : 
- Il existe une différence statistiquement significative entre les moyennes des notes des sujets du groupe de l'étude dans tous les items du test de compétences de l'expression (orale - écrite) entre la pré et la post application du test en faveur de la post application au seuil de 0.01 .

- Il existe une différence statistiquement significative entre les moyennes des notes des sujets de l'étude dans les compétences de l'expression orale contenues dans le test des compétences de l'expression (orale et écrite) entre la pré et la post application du test en faveur de la post application du test au seuil de 0.01 .

- Il existe une différence statistiquement significative entre les moyennes des notes des sujets de l'étude dans toutes les sous-compétences de l'expression orale contenues dans le test de compétences de l'expression (orale et écrite) entre la pré et la post application du test en faveur de la post application du test au seuil de 0.01 .

- Il existe une différence statistiquement significative entre les moyennes des notes des sujets du groupe de l'étude dans les items du test de compétences de l'expression (orale - écrite) en ce qui concerne les compétences de l'expression écrite entre la pré et la post application du test en faveur de la post application du test au seuil de 0.01 .

- Il existe une différence statistiquement significative entre les moyennes des notes des sujets de l'étude dans toutes 
les sous-compétences de l'expression écrite contenues dans le test des compétences de l'expression (orale et écrite) entre la pré et la post application du test en faveur de la post application du test au seuil de 0.01 .

- Il existe une différence statistiquement significative entre les moyennes des notes des sujets du groupe de l'étude dans la pré et la post application des items de la grille d'observation concernant les savoir-être en faveur de la post application au seuil de 0.01 .

\section{Méthodologie de la recherche.}

Lors d'achever la recherche actuelle, on a adopté les méthodologies ci-dessous :

- La méthode descriptive analytique pour ce qui concerne la revue de la littérature éducative et des recherches antérieures relatives au sujet de la recherche pour bien présenter le cadre théorique et pour élaborer parfaitement les outils de la recherche.

- La méthode expérimentale pour ce qui concerne les procédures adoptées lors de la tentative.

- La méthode statistique mixte (quantitative - qualitative) pour ce qui concerne la discussion et l'analyse des résultats de la recherche.

\section{Procédures de la recherche.}

Pour atteindre les objectifs de la recherche actuelle, on a adopté les démarches ci-dessous : 
(A) Afin de répondre à la $1^{\text {ère }}$ question, le chercheur a suivi les étapes suivantes :

- Le chercheur a étudié et a analysé les œuvres, les ouvrages, les références et les études antérieures dans le domaine de la didactique de FLÉ en général et plus particulièrement dans le domaine de la didactique de l'expression (orale - écrite) et de savoir-être pour présenter la partie consacrée à la variable dépendante de la recherche (la partie consacrée aux compétences de l'expression orale et écrite et aux savoir-être).

- Il a étudié et a analysé les œuvres, les ouvrages, les références et les études antérieures dans le domaine de la didactique de FLÉ pour ce qui concerne l'exploitation des activités et des pratiques théâtrales dans le domaine de l'enseignement /apprentissage des langues étrangères pour présenter la partie consacrée à la variable indépendante de la recherche (l'emploi des activités et des pratiques théâtrales).

- Il a élaboré la liste de compétences de l'expression orale et écrite à travers les études précédentes et les références spécialisées. Cette liste a constitué un point de départ pour déterminer les compétences visées. Elle a été une procédure de recherche;

- Il a élaboré les items du test de compétences de l'expression orale et écrite employé dans le cadre de la recherche. Ce test a constitué un outil de recherche pour 
contrôler le niveau du groupe de l'étude avant et après l'intervention;

- Il a présenté ces outils aux juges pour les valider avant l'intervention.

- Après les avoir validés, il a préparé la forme définitive de ces outils;

(B) Afin de répondre à la $2^{\text {ème }}$ question, le chercheur a suivi les étapes suivantes :

- Le chercheur a élaboré une liste de savoir-être vue nécessaire pour les apprenants(es) de ce niveau d'apprentissage à travers les études précédentes et les ressources scientifiques;

- Il a élaboré une grille d'observation pour contrôler le niveau des apprenants(es) dans ces savoir-être avant et après la tentative;

- Il a présenté ces outils aux juges pour les valider avant d'opérer l'intervention;

- Après les avoir validés, il a préparé la forme définitive de ces outils.

(C) Afin de répondre à la $3^{\text {ème }}$ question, le chercheur a suivi les étapes suivantes :

- Le chercheur a déterminé les séquences consacrées à l'expression (orale - écrite) dans le manuel de FLÉ de la $2^{\text {ème }}$ année et les a enrichies par des exercices et des 
activités variés. Ces exercices sont présentés sous la forme des activités et des pratiques théâtrales;

- Il a entraîné les apprenants de ce niveau d'apprentissage à pratiquer ces activités. Il a guidé ces apprenants à faire des répétitions avant de présenter les activités sur la scène (la scène est ici la salle de classe);

- Il a fait toutes les préparations en collaboration avec l'enseignant(e) et les apprenants pour exécuter la tentative;

(D) Afin de répondre à la $4^{\text {ème }}$ question, le chercheur a adopté les démarches suivantes :

- Le chercheur a commencé son intervention par la pré application du test (test de compétences de l'expression (orale - écrite));

- Il a également opéré la pré application de la grille d'observation;

- Il a appliqué les activités du manuel de la $2^{\text {ème }}$ année secondaire reformulées suivant les procédures des activités et des pratiques théâtrales;

- Il a suivi les exercices et les a évalués de façon formative (pendant la tentative) pour suivre le progrès des apprenants. À la fin de chaque leçon, le chercheur a conçu un test formatif à travers lequel il mesure le jusqu'à quel point les apprenants se sont progressés; 
- Il a terminé son intervention par la post application du test de compétences de l'expression (orale - écrite) et la post application de la grille d'observation;

- Il a traité statistiquement les notes brutes obtenues par la pré et la post application du test et de la grille d'observation par les techniques statistiques convenables;

- Il a présenté une analyse mixte (quantitative et qualitative) des résultats;

- Il a présenté une discussion des résultats obtenus;

- Il a avancé les recommandations et a suggéré des recherches futures à la lueur des résultats obtenus.

\section{Terminologie de la recherche.}

\section{Activités théâtrales en enseignement du FLÉ.}

(Pieera G., 2001 : P.30) a défini les activités théâtrales comme suit : «Ce plaisir, de l'activité dans la langue étrangère, naît quand il y a acception de soi, de sa voix dans cette langue, dégagée des résistances produites par le regard et l'écoute des autres, impliqués aussi dans un travail de même nature. Car l'inhibition de la parole n'est pas toujours liée à des carences de compétences linguistiques. Elle dépend de la possibilité, donnée ou non, que s'ouvre un espace sonore. Or, il nous est apparu que le travail créatif dans une langue étrangère pose les conditions de libération de la parole et débloque cette création de peur en tant qu'il ouvre un tel espace». 


\section{Le chercheur a donné sa définition du terme dans le cadre de} cette recherche comme suit :

Les activités théâtrales se sont définies dans la recherche actuelle comme des activités pratiquées en employant la voix (son volume, et son débit), le regard et les gestes en vue de développer les compétences de l'expression orale tout en respectant la prononciation, l'intonation et le rythme au même titre les règles morphosyntaxiques et par un contenu lexical approprié. Elles peuvent être également exploitées afin de développer les compétences de l'expression écrite tout en respectant les règles de la ponctuation au même titre de la morphosyntaxe et par un contenu lexical approprié.

\section{Expression.}

(Galisson R., et Coste D., 1976 : P. 208) a défini le terme comme suit : «Opération qui consiste à produire un message oral ou écrit, en utilisant les signes sonores ou graphiques d'une langue. Expression orale et expression écrite correspondent à ce qu'on appelle parfois les «skills» actifs : parler et écrire. En ce sens «expression» est généralement opposé à «compréhension» (orale et écrite : écouter et lire).

\section{* Expression orale.}

Suivant (Karima Cheriet, 2014), l'expression orale constitue une compétence que les apprenants doivent acquérir progressivement et qui consiste à s'exprimer oralement dans des situations de communication. Il s'agit d'un rapport entre un

\section{4}


émetteur et un récepteur qui doit avoir la capacité de comprendre l'autre.

Selon (Tagliante C., 2006), l'expression orale constitue la compétence derrière laquelle on trouve des éléments concernant le fond et la forme; les éléments du fond comprennent les informations qu'on veut donner avec des exemples de justification, l'argumentation qu'on choisit, les idées qu'on a à structurer, les sentiments, les avis exprimés, le langage et ses caractères. Les éléments de la forme comprennent l'attitude générale, les gestes, la voix ; son volume et son débit, les regards ...etc.

Le terme a été défini selon (Sorez H., 1995 : P. 5) comme suit : «s'exprimer oralement, c'est transmettre des messages généralement aux autres en utilisant principalement la parole comme un moyen de communication $»$.

\section{Le chercheur a présenté sa définition opérationnelle.}

La compétence de l'expression orale s'est définie dans la recherche actuelle comme l'aptitude des apprenants à parler dans des situations basées sur des sujets de la vie familiale, sociale, professionnelle et quotidienne. Lors de parler, les apprenants peuvent choisir le type de discours adéquat à chacune des situations, le lexique, l'intonation, le rythme, et le débit. Ils peuvent également adapter leurs messages aux différentes situations et aux différents niveaux d'interlocuteurs. Ainsi, s'exprimer à l'oral exige un savoir et un savoir-faire allant de la simple connaissance des règles grammaticales, la perfection des 
sons difficiles à prononcer et finissant par le respect des types de phrases (exclamatives, interrogatives, impératives, affirmatives ...etc.).

\section{Expression écrite.}

(Thao N., 2007) a défini le concept en citant : «les apprenants ne composent pas des textes pour que l'enseignant puisse corriger leurs fautes, mais que la production est une activité qui a un but et un sens : les apprenants écrivent pour communiquer avec un ou des lecteurs»».

Bouchard cité dans Pouliot, (Pouliot M., 1993 : P. 120) a défini le concept en disant que l'expression écrite est «une capacité à produire des discours écrits bien formés y compris dans leur organisation matérielle, appropriés à des situations particulières diversifiées».

(Barth B.-M., 2006) a défini le terme en disant : «Écrire est un processus complexe qui implique que l'élève doive se planifier, rédiger, et réviser sa production, aussi bien sur le plan du contenu que de la forme, et ce à tout moment durant le processus d'écriture. [....]. En effet, l'élève doit être capable de tenir compte de l'intention d'écriture, de rassembler ses idées sur le sujet, d'aller chercher des informations, de tenir compte de ses lecteurs dans son texte, d'organiser le tout de façon cohérente, de rédiger et de relire son texte afin d'y apporter les corrections nécessaires». 


\section{Le chercheur a avancé sa définition du terme comme suit :}

La compétence d'écrire ou d'expression écrite est définie dans cette recherche comme la capacité des apprenants à rédiger des phrases, des paragraphes, ainsi des petits textes sur des sujets de la vie familiale, sociale, professionnelle et quotidienne. Lors d'écrire, les apprenants doivent prendre en compte de collecter les informations qui composent leurs idées sur les sujets abordés, d'organiser leurs idées dans un texte cohérent tout en respectant les règles grammaticales, le contenu lexical convenable et relatif à chacun des sujets traités, et les règles de ponctuation.

\section{* Les savoir-être.}

Les savoir-être sont des compétences sociales ou comportementales. Elles sont intitulées des compétences non cognitives renvoyées à des normes sociales obligatoires qu'il faut acquérir pour rentrer dans les apprentissages (Morlaix S., 2015).

La pédagogue Runtz-Christan (Runtz-Christan E., 2000) a déterminé les savoir-être nécessaires pour un individu :

- Capacité de communiquer avec les individus de sa classe;

- Suscitation d'une envie d'apprentissage chez ses apprenants;

- Capacité de valoriser sans juger;

- Aptitude de réguler sans régulariser;

- Compétence d'anticiper sans antécéder. 
Le terme de savoir-être, selon Jean-Pierre Cuq (Cuq J.,-P., 2003), signifie que les apprenants se mettent en relation avec les autres tant du point de vue culturel que linguistique.

\section{Le terme s'est défini dans cette recherche comme suit :}

On désigne ici par le terme de «savoir-être», le développement des comportements et des attitudes des apprenants pour les rendre des gens autonomes dans toutes les étapes du processus de l'apprentissage des compétences de deux facettes de l'expression. Ils deviennent donc aptes à identifier ses atouts d'apprentissage, à déterminer leurs objectifs, à choisir leurs stratégies $\mathrm{du}$ travail, à choisir leurs parcours méthodologiques, à exploiter les activités théâtrales adéquates, à choisir les représentations convenables, à exploiter leurs procédés et modalités de l'évaluation...etc. 


\section{Étude théorique.}

Bien connu, le corps a son propre langage qui est en réalité complémentaire des signes de la langue. Le sens d'un énoncé ou d'un texte reste «caché» ou plutôt «ambigu» jusqu'à un moment de s'exprimer corporellement. Autrement dit, les gestuels aident à interpréter les mots, les phrases et les textes écrits et prononcés en langue en général et en langue française en particulier car plusieurs émotions passent facilement et de façon signifiante par les activités corporelles. Les activités théâtrales consistent à faciliter l'enseignement/apprentissage de presque toutes les compétences langagières de FLÉ; lorsqu'on observe un(e) étudiant(e) francophone parler en français, on peut facilement comprendre le sens à travers les expressions du visage et les mouvements du corps. La recherche actuelle a essayé de profiter des activités théâtrales pour développer les compétences de l'expression (orale - écrite) au même titre développer les savoirêtre vus nécessaires chez les étudiants adolescents de la $2^{\text {ème }}$ année au cycle secondaire. Afin d'atteindre ces objectifs, le chercheur a pour objectif d'étudier et d'analyser les recherches antérieures relatives au sujet de la recherche et d'étudier les œuvres et les ouvrages de la littérature éducative pour avoir des informations sur les variables de la recherche en cours et pour s'en profiter lors d'élaborer les instruments employés au sein de la recherche actuelle.

AXE I : dans cette partie, le chercheur a traité les éléments concernant les activités théâtrales et leur rôle dans 
l'enseignement /apprentissage de FLÉ en général et plus particulièrement leur rôle dans la didactique des compétences de l'expression (orale - écrite), et dans le développement des savoir-être chez les apprenants de FLÉ. il a également mis l'accent sur le rôle de l'enseignant(e) dans les activités théâtrales. il a traité aussi la différence existant entre la simple communication linguistique quotidienne et la communication théâtrale focalisant sur les techniques théâtrales employées dans ce cadre comme la parole, le geste, le texte ....etc.

AXE II : dans cette partie, le chercheur a traité les éléments concernant les compétences de l'expression orale et de l'expression écrite, leur place dans la didactique de FLÉ notamment les compétences vues nécessaires aux apprenants débutants et notamment ceux de ce niveau d'apprentissage (le niveau secondaire). Également les aspects relationnels qui peuvent exister entre les variables de la recherche (les activités théâtrales, les compétences de l'expression (orale écrite) et les savoir-être); ce que les activités théâtrales peuvent présenter pour développer l'enseignement des compétences de l'expression (orale - écrite) et les savoirs-être vus nécessaires pour les apprenants de ce niveau d'apprentissage. 


\section{AXE I.}

\section{La notion de «théâtralisation» et la didactique de FLÉ.}

Les activités éducatives complémentaires contribuant en permanence à développer des savoirs, des savoir-faire, des savoir-être voire des savoirs culturels dans une seule visée, c'est la réussite éducative et scolaire de tous les étudiants(es). Cette réussite se fait grâce à la pratique permanente de ces activités; ces activités complémentaires donnent l'occasion de façon individuelle à chacun(e) de ces étudiants(es) de bien gérer son apprentissage et de s'épanouir personnellement et socialement (Cellier H., et Pourtier P., 2013).

La «théâtralisation» des disciplines scientifiques fait partie intégrale des activités pédagogiques complémentaires suivant des recherches et des ouvrages antérieurs comme la recherche d'(Alix Ch., et al., 2013), celle de (Derkaoui L., et Legros D., 2015), celle d'(Hilton H., 2011), celle de (Pieera G., 2006), celle de (Louys G., et Leeman D., 2013), celle de (Mongenot Ch., et De Peretti I., 2013), et celle de (Pieera G., 2001). D'autres ouvrages et recherches antérieurs comme la recherche de (Balazard S., Gentet-Ravasco E., 2011), celle de (De Bouter P., 2015), celle de (Marjolaine P., et Treffandier F., 2012), celle de (Payet A., 2010), et celle de (Lepoutre G., 2007), vont plus loin et ont recommandé la nécessité d'employer ces activités théâtrales dans la classe de langue pour développer les différentes compétences langagières (soit des compétences de réception soit des compétences de production) chez les 
apprenants(es) de tous les niveaux d'apprentissage de langue française.

La question élémentaire qui se pose là : «Pourquoi les activités théâtrales?». La réponse était toujours : parce que le théâtre et les activités théâtrales constituent des ressources naturelles faciles à exploiter de la part des étudiants(es); ces activités sont des ressources corporelles faciles à employer pour interpréter le sens des mots, des phrases, des expressions et des textes (soit des textes authentiques, soit des textes d'inspiration littéraire). Selon l'étude de (Lepoutre G., 2007), la pratique des activités théâtrales constitue un jeu continuel entre «le faire et le regarder» d'une part et de l'autre part entre «l'agir et l'analyser».

À cet égard, (Lang J., 2000) a confirmé que l'éducation culturelle et artistique constitue le complément nécessaire mais souvent négligé d'une formation aux savoirs abstraits et rationnels. Lang a cité que : " les pratiques artistiques sont constitutives à part entière de la formation de l'esprit». Il a mis ici l'accent sur le rôle pédagogique joué par la pratique de ces activités artistiques.

À la même perspective, Isabelle Bernard (Bernard I., 2010) en collaboration avec un cadreur jordanien ont présenté un projet de recherches à travers lequel ils se sont interrogés sur l'efficacité des pratiques théâtrales dans les cursus de français employés dans les universités du pays de la Jordanie. C'était une expérience basée sur une pédagogie innovante (la pratique théâtrale) présentée en contexte arabophone. Cette même 
expérience s'est présentée suivant un compte-rendu tridimensionnel : la première dimension consiste à décrire, la deuxième dimension explicite la pratique du théâtre et ses bénéfices dans la gestion des difficultés et de l'anxiété linguistiques et la troisième dimension est consacrée à dresser un premier bilan didactique.

Aussi, il est possible, par l'improvisation théâtrale, de mettre en place une réflexion sur des situations de communication et la façon dont telles situations conditionnent la valeur donnée aux savoirs et aux significations que les apprenants(es) construisent. Cette sorte d'activités crée ce qu'on peut intituler «la fonctionnalisation»» des situations de communication.(Roxane G., 2011).

Les compétences de l'improvisation théâtrale, d'après (Berlin C., et Hornbeck K., 2005), se limitent à :

- Apprendre comment accepter des «offres» (des répliques, de «backstory» d'un personnage, des morceaux...etc.);

- Éviter d'arrêter une scène avec des réponses brèves comme (oui, non);

- Maintenir la progression de la scène vers la fin convenable;

- Rechercher des moyens de faire l'inattendu plutôt que le prévisible;

- Focaliser sur les personnages qui sont sur la scène plutôt que sur d'autres personnages; 
- Concentrer sur l'histoire et le message plutôt que sur la comédie.

Dans le même cadre, Alain et Gaël Vercollier (Vercollier A., et Vercollier G., 2013) se sont interrogés : «comment enseigner/ apprendre la langue française comme deuxième langue enseignée et comment motiver les apprenants(es) par les jeux du théâtre». À travers ce travail, ces deux didacticiens ont livré leurs réflexions, ont décrit leur expérience, et ont conseillé les enseignants(es): «comment dérouler les sessions et comment employer les modalités d'évaluation au sein de l'expérience».

Également, (Pieera G., 2001) et (Halima Saadia Charif, 2015) ont mis l'accent sur le même point. Elles se sont d'accord que la mise en place des activités théâtrales constituent une ouverture de l'esprit des étudiants(es). ceux(celles)-ci trouvent à travers ces activités et ces pratiques théâtrales une sorte d'ouverture à l'univers de création où ils(elles) découvrent des auteurs et des textes, se placent dans une position d'agitateur de sens. Ils(elles) attribuent du sens aux mots transmis à travers ces activités. Selon ces chercheuses déjà mentionnées, ces étudiants(es) deviennent créatifs(ves).

Aussi, Alex Cormanski (Cormanski A., 2005) a présenté une œuvre comprenant à peu près soixante activités pour développer l'expression orale chez les apprenants(es). le chercheur a mis l'accent sur le comment exploiter les interactions non-verbales telles que le regard, le ton, la voix, la gestualité, la gestion de l'espace ...etc. dans le développement des compétences de l'oral 
en général et notamment celles de l'expression de l'oral. Cette œuvre met à la disposition de l'apprenant(e) de tous les niveaux de la langue et de l'enseignant(e), des matériaux variés pour développer les interactions à travers les improvisations. Ces matériaux permettent le réinvestissement des acquis.

De plus, Linda Derkaoui, et Denis Legros (Derkaoui L., et Legros D., 2015) ont mis l'accent sur l'effet de la «théâtralisation» d'un texte sur l'interprétation, sur le contenu, et sur la fluidité de l'expression orale. Cette recherche a travaillé sur deux groupes (groupe expérimental et groupe témoin); le groupe témoin a étudié les textes par la lecture et le groupe expérimental a étudié les textes par les jeux théâtraux. Cette recherche a confirmé que la «théâtralisation» des textes est effective dans la mesure de la production d'inférences créatives, du contenu sémantique des textes traités, ainsi de la qualité de l'expression orale chez les sujets du groupe expérimental.

Encore, la recherche de Halima Saadia Charif (Halima Saadia Charif, 2015) a assuré que les activités et la pratique théâtrales contribuent à aider les étudiants(es) à améliorer l'expression orale. Ces activités et cette pratique théâtrales donnent l'occasion à ces étudiants(es) à pratiquer couramment la parole en classe de langue. À travers la recherche, la chercheuse a prouvé que les apprenants(es) manifestent un plaisir lorsqu'ils(elles) deviennent aptes à répondre à un exercice difficile et lorsqu'ils(elles) aperçoivent leur progrès et leur acquisition des savoirs et des savoir-faire dans le domaine de l'expression orale. 
De surcroît, Samira Moutakil (Samira Moutakil, 2012) a exploité l'expérience d'employer le théâtre et les activités théâtrales pour enseigner/ apprendre le français dans des objectifs spécialisés pour former les futurs guides touristiques. Cette expérience est employée dans un objectif de pousser les apprenants(es) à parler correctement le français associant la parole à la gestualité; à la lueur de l'expérience de la «théâtralisation», les apprenants(es) ont été non seulement familiarisées avec la prononciation correcte des sons, l'articulation, l'intonation et l'expression orale, mais également ont perfectionné(es) le contenu lexical, culturel et morphosyntaxique. L'expérience a donné l'occasion aux apprenants(es) de développer leur imagination par la simulation des personnages joués. La chercheuse a confirmé que l'emploi de ce type d'activités est très intéressant dans la mesure d'enseigner/apprendre le français langue étrangère en général et le français pour des objectifs spécialisés (FOS) en particulier.

Runtz-Christan (Runtz-Christan E., 2000) a ajouté que la théâtralité ne mentionne pas un style éducatif propre à certains(es) enseignants(es) doués(es), mais constitue une nécessité. Ce terme cherche à établir ce qu'on intitule le rapport (Enseignant/apprenant) assoyant l'autorité et visant à voir et à entendre les savoirs.

Claire Dubos (Dubos C., 2014) a montré que les activités théâtrales en classe de langue sont employées comme un accompagnement ludique aux programmes d'enseignement. Ces activités ne sont pas dans le cadre d'un projet conçu tout au long 
d'une année scolaire ou d'un semestre, mais dans le cadre d'encourager les apprenants(es) à prendre la parole en français d'une part et de réaliser la cohésion d'un groupe composé d'apprenants(es) d'autre part. Ces activités sont dans le cadre de dynamiser les apprenants(es) et de les aider à sortir du cadre traditionnel et à devenir acteurs de leur apprentissage. Ces activités théâtrales du point de vue de la chercheuse, ne consistent qu'à créer une situation de communication concrète donnant l'occasion aux apprenants(es) à prendre la parole et à faire le point sur l'aspect conceptuel déjà présenté pendant les cours. À travers cette recherche, Claire Dubos a déterminé le déroulement de ces activités comme suit :

- Étape de la détermination des objectifs pédagogiques des activités, des matériaux nécessaires, des participants(es) ...etc.;

- Étape de l'introduction : ici, l'enseignant(e) essaie d'éclaircir les objectifs pédagogiques, les consignes, de fixer le temps consacré à chaque exercice;

- Étape de la révision : ici, l'enseignant(e) focalise sur la révision linguistique (grammaticale et lexicale) d'une part, et d'autre part sur les personnages et leurs rôles;

- Étape de la préparation : ici, l'enseignant(e) met l'accent sur le temps d'exécuter la représentation; 
- Étape de la représentation : ici, c'est la phase de l'exécution de l'activité et le rôle de l'enseignant(e) est de prendre des notes;

- Étape de l'exploitation : ici, c'est l'étape de discuter les points lexicaux et grammaticaux traités pendant le spectacle, de discuter les difficultés envisagées et les conseils aux autres participants(es).

(Lentin L., 1988) a montré que grâce à la simplicité lexicale et syntaxique du théâtre, il peut être employé avec les apprenants(es) de tous les niveaux et il leur permet d'améliorer leurs compétences linguistiques et de perfectionner leur expression orale et leur prononciation à travers les représentations.

En conséquence, Astrid Sepulchre (Sepulchre A., 2018) a ajouté que les activités théâtrales donnent l'occasion aux (acteurs(rices)) d'interférer avec les autres acteurs(rices) pour apprendre à jouer des situations fictives. Ces activités consistent à faire entrer les acteurs(rices) dans la peau des personnages imaginaires et imaginés dont ils(elles) jouent les rôles. Les acteurs(rices) se déplacent sur la scène dans une démarche créative et selon un schéma à progresser.

Bref, le concept de la «théâtralisation» des cours en langue étrangère enseignée n'est qu'une sorte de représentation du contenu d'apprentissage présenté à travers ces cours. Cette expérience pratiquée dans le domaine de la didactique du FLÉ en général et notamment en expression (orale - écrite) peut donner 
l'occasion aux apprenants(es) de manier le vocabulaire, le ton, l'intonation, la morphologie, la syntaxe, la rédaction....etc. La pratique du théâtre, comme a confirmé (Linten L., 1988), peut aborder à tous les niveaux d'apprentissage de la langue, et peut permettre aux apprenants(es) d'améliorer leurs compétences linguistiques. Il a également mentionné que le théâtre se qualifie de la simplicité de son vocabulaire et de sa syntaxe, c'est pourquoi les représentations théâtrales peuvent contribuer au perfectionnement de la prononciation et de l'expression chez les différents(es) apprenants(es) de différents niveaux.

Pour apporter des éclairages nécessaires, il faut distinguer entre le théâtre et les activités théâtrales (Jeux théâtraux). Selon plusieurs spécialistes en littérature, le théâtre n'est pas un genre littéraire mais en réalité une représentation scénique d'un texte écrit par un dramaturge sur un thème quelconque. Ces dramaturges écrivent au fur et à mesure ces textes pour être joués sur la scène. La pratique théâtrale n'est pas en effet une explication ou bien une traduction de ces textes mais une activité complémentaire pour les accomplir. En d'autres termes, la représentation et les jeux de rôles réalisés sur la scène du théâtre ne se considèrent pas une redite de ces textes crées par les dramaturges mais une sorte de présentation du contenu de ces textes. (Lepoutre G., 2007). 


\section{Les activités théâtrales et le dialogue dit théâtral en classe de FLÉ.}

Il est à noter que pratiquer le dialogue en classe de langue en général, et plus particulièrement en classe de FLÉ n'est pas un travail facile entre les apprenants(es) eux(elles)-mêmes, ou entre les apprenants(es) et leurs enseignants(es). Les apprenants(es) ne cherchent que de savoirs déjà connus et déjà vus. Ces apprenants(es) évitent là la recherche et la réflexion. À ce propos, (Vinh S., 2001) a confirmé que dans l'esprit des apprenants(es), l'oral ne constitue que bavardage sans importance. Selon le chercheur, le dialogue en classe semble difficile entre ces genres d'apprenants(es) puisque la parole de l'enseignant(e) constitue la seule source fiable d'information.

Le dialogue naturel se fait habituellement entre deux personnes; une personne (A) s'adresse, dans la plupart du temps, à une personne $(B)$ et chacun peut jouer un double rôle (rôle d'un récepteur et rôle d'un émetteur) dans des situations d'échanges quotidiennes. Le dialogue théâtral se fait entre plusieurs personnes; on ajoute un troisième rôle à ceux des autres déjà mentionnés. Il se déroule entre $\mathrm{A}$ et $\mathrm{B}$ d'une part et $\mathrm{C}$ de l'autre part. il faut mentionner que $((C)$ joue dans ce cadre, le rôle du public).

Il faut signaler que le but majeur, derrière l'emploi de l'improvisation théâtrale en classe au même titre de l'emploi du dialogue dans les activités de classe, est de pratiquer la langue. Autrement dit, on emploi les activités théâtrales (l'improvisation 
théâtrale) et le dialogue dans la classe de langue pour une seule visée, c'est de pousser les étudiants(es) à jouer et en même temps à pratiquer la langue étrangère en classe dans un cadre naturel. D'après plusieurs études antérieures, l'emploi des dialogues théâtraux ont réellement des objectifs comme :

- Passer de l'aspect abstrait de la langue étrangère à un aspect vécu à travers des situations artificielles et conçues.

- Pousser les étudiants(es) incompétents(es) et paresseux(euses) à parler en langue étrangère; ce qui les aident à développer leurs compétences de l'expression orale.

- Aider les étudiants(es) prisonniers(ères) de peur, de la honte et du ridicule à prendre l'initiative, ensuite à prendre part aux activités de classe; ce qui les aident à développer leurs compétences de l'expression.

- Aider un nombre énorme d'écoliers(ères) en général et d'étudiants(es) de FLÉ en particulier à surmonter leur timidité; ces genres d'étudiants(es) deviennent peu à peu des participants(es) actifs(ves).

- Donner l'occasion aux étudiants(es) de la langue étrangère à passer de longues heures dans ces activités et à travers les dialogues (de l'improvisation théâtrale) pour perfectionner l'expression orale.

En réalité, il suffit deux étudiants(es) pour pratiquer le dialogue dans l'improvisation théâtrale en classe de langue. 
lorsqu'on conçoit une situation basée sur les activités théâtrales et le dialogue de l'improvisation théâtrale, on choisit au minimum deux étudiants(es) pour le mettre à exécution. À ce propos, Pascal Charvet et autres (Charvet P. et al., 1986) ont confirmé qu'à travers le dialogue, les étudiants(es) se posent en permanence des questions comme : Qui parle et à qui? Qui pose des questions et qui répond à ces questions? Qui lance la parole le premier? Qui a le droit de parler?. Pascal et ses collaborateurs ont mentionné que les étudiants(es) complètent, lors de la scène, l'établissement d'un modèle dit actanciel afin d'établir un schéma de parler.

On doit montrer que le dialogue peut être verbal ou gestuel. Le dialogue verbal et le dialogue gestuel se complètent pour transmettre le message lingual. Le dialogue gestuel se pratique sur la scène par les gestes, les mouvements corporels et les regards. Les deux genres de dialogue s'associent pour accéder au sens des messages transmis et reçus lors des situations de communication langagière. (Halima Saadia Charif, 2015).

À travers le dialogue pratiqué lors de la pratique des activités théâtrales dans la classe de langue, le sens d'un discours peut s'expliquer facilement. À cette perspective, Henri Besse et autres (Besse H., et al., 1975) ont certifié que la méthode efficace de manifester le sens et la signification est de les traduire par l'emploi d'autres mots de la langue étrangère (des synonymes) ou par des mots d'autre langue (soit langue maternelle, soit autre langue étrangère enseignée). 
En un mot, le dialogue théâtral pratiqué à travers les activités basées sur l'improvisation théâtrale, permet aux étudiants(es) des langues étrangères en général et plus particulièrement les étudiants(es) du FLÉ de développer leur prononciation, leur intonation, leur rythme, d'apprendre certaines formules langagières et d'employer un vocabulaire français convenable pour recouvrir une situation de communication langagière. En d'autres termes, le dialogue théâtral contribue à développer le niveau des étudiants(es) de FLÉ en dehors de la classe et avec leurs collègues plus tard.

\section{Les activités théâtrales/ leurs rapports avec les besoins} psychopédagogiques et sociolinguistiques essentiels pour les apprenants(es) des langues étrangères.

Les activités théâtrales et l'emploi des jeux théâtraux dans le cadre de l'enseignement/apprentissage constituent une réponse immédiate des besoins fondamentaux des apprenants(es) des langues étrangères en général et de FLÉ en particulier. D'après plusieurs linguistes et didacticiens(nes), ces activités théâtrales semblent être un idéal outil pour traiter un nombre énorme de ces besoins. À ce propos, Séverine Hartmann (Hartmann S., 2012) a mentionné qu'il existe trois besoins fondamentaux comme suit :

- Besoin d'appartenance sociale comme : l'appartenance à un groupe, le sentiment d'être vu dans le groupe, la coopération, l'interaction et la participation à un projet commun; 
- Besoin d'être estimé comme : le pouvoir d'entrer en compétition, de se mesurer, d'avoir une responsabilité, de réussir;

- Besoin de se réaliser comme : fabriquer, exprimer sa créativité, produire.

Aussi, Christiane Page (Page Ch., 1997) a pensé que les activités théâtrales conduisent les élèves et les étudiants(es) à déployer des efforts pour se développer et maîtriser les apprentissages nécessaires à leur vie sociale actuelle et future. Page a mis, donc, l'accent sur l'efficacité des activités théâtrales dans le développement des modes d'apprentissage nécessaires pour ces apprenants(es) pour fréquenter facilement la vie sociale. Elles peuvent offrir aux apprenants(es) un champ d'expérimentation de plus en plus complexe et élaboré. Également, Page a montré que les activités théâtrales correspondent à la maturité des enfants et ces activités théâtrales, d'après lui, peuvent recouvrir chez eux plusieurs besoins comme:

- Besoin psychologique et besoin physique pour être capables d'agir;

- Besoin de se sentir en groupe;

- Plaisir de la fiction;

- Plaisir de pratiquer un jeu collectif dirigé par des règles;

À cette perspective, Gisèle Pieera (Pieera G., 2001) a ajouté que les activités théâtrales contribuent à l'accroissement progressif de l'autonomisation dans l'apprentissage du travail 
consacré à la création de la mise en scène au même titre le travail consacré à la diction.

À ce propos, Hassan Marai (Hassan Marai, 2002) a ajouté que les activités théâtrales peuvent être :

- Des moyens de recréation;

- Des moyens efficaces de communication;

- Des moyens de s'exprimer et d'exprimer une idée, une conception et un sentiment;

- Des moyens pour réduire les cas de peur et d'honte devant un public;

- Des moyens de développer la prononciation des mots chez les élèves;

Helen Bee ( Bee H., 1997) a mentionné, dans le même cadre, que les activités théâtrales constituent pour les enfants un «jeu social théâtral». À travers ce type de jeu, l'apprenant(e) peut jouer à être un autre. Ce genre de jeu peut sensibiliser les enfants et les apprenants(es) aux sensations des autres.

Les capacités et les compétences psychopédagogiques et sociolinguistiques les plus développées par les activités théâtrales sont, du point de vue de Sophie Balazard et Elizabeth Gentet-Ravasco (Balazard S., et Gentet-Ravasco E., 2011) : la découverte de l'autre, l'écoute et ainsi le regard. D'autres recherches comme la recherche d'(Halima Saadia Charif, 2015) ont ajouté le geste comme compétence à développer. Concernant l'écoute, ces recherches antérieures ont assuré que les activités 
théâtrales peuvent développer chez les apprenants(es) la compétence d'écouter les autres. D'après les mêmes recherches, cela peut créer des relations privilégiées entre les participants(es). Cela peut vraiment aider les apprenants(es) à vivre en communauté en entourage malgré la diversité existant dans cette même communauté. Ces chercheuses voient que les activités théâtrales aident les apprenants(es) à développer des compétences comme :

- L'esprit de la solidarité;

- L'esprit de l'interdépendance;

- Le plaisir de construire en groupe;

- La compétence de s'exprimer sur la pensée de quelqu'un d'autre;

- Le sentiment de responsabilité dans un groupe.

À ce propos Dominique Megrier (Megrier D., 2004) a confirmé que ces activités théâtrales et le théâtre apprennent à savoir vivre et à savoir travailler en collectivité. Cela veut dire que la pratique du théâtre et des activités théâtrales dans l'établissement scolaire est un excellent lieu de socialisation.

En ce qui concerne le regard, Page (Page Ch., 1997) voit qu'il (le regard) contribue au développement des capacités et des moyens d'expression chez les joueurs-participants à travers les activités théâtrales; à travers le regard, ces joueurs-participants peuvent instaurer et assumer les situations de communication entre eux et les spectateurs. Autrement dit, le regard joue un rôle 
important dans ces genres d'activités (activités théâtrales), c'est de communiquer avec l'audience pour transmettre des messages importants pendant les spectacles; des messages positifs ou négatifs sur un point discursif donné.

D'après la recherche d'Halima Saadia Charif (Halima Saadia Charif, 2015), le regard constitue un langage créant entre ceux qui se discutent, se parlent et s'écoutent. La chercheuse a ajouté que le regard de l'enseignant(e) peut établir une atmosphère de confiance dans la salle de classe et il peut également créer une atmosphère de peur et d'incertitude dans cette salle.

D'après la même étude, le geste accompagne toujours la parole pour transmettre et renforcer le sens des mots, des expressions et des phrases destinés à s'exprimer oralement. Renard Raymond (Raymond R., 2002) a confirmé ici que l'expression orale nécessite un engagement du corps dans son ensemble pour rendre les énoncés produits oralement compréhensibles. Cet engagement joue un rôle essentiel pour traduire les sentiments et les émotions en train d'être transmis à un locuteur. Or, le geste est un procédé facilitateur de la parole.

Quant à la découverte de l'autre, d'après (Winnicott cité dans Fraile P., 2014) la pratique du jeu théâtral peut faciliter la croissance et donne l'occasion aux étudiants(es) d'établir des relations avec les autres et avec le lieu de l'élaboration du sujet. Pauline Fraile (Fraile P., 2014) a ajouté que les activités théâtrales peuvent donner la possibilité aux enfants de travailler sur eux-mêmes. Selon lui, ces activités les aident à découvrir 
leurs capacités d'expression puis à les développer. Il a également ajouté que ces activités consistent à solliciter globalement l'attention des apprenants(es) d'être inclus(es) dans tous leurs aspects; aspect corporel, aspect mental et affectif.

En un mot, les activités théâtrales contribuent à socialiser les apprenants(es) et à les préparer de vivre efficacement dans une collectivité soit dans l'établissement scolaire soit hors de l'établissement scolaire.

\section{Rôle de l'enseignant(e) dans la pratique des activités théâtrales.}

Plusieurs didacticiens(nes), chercheurs(euses) et concepteurs ont déterminé le rôle joué par l'enseignant(e) lors de la pratique des activités théâtrales. Il est à noter que l'enseignant(e) peut être soit un élément de motivation, soit un élément de démotivation pour les apprenants(es) qui participent aux activités théâtrales (joueurs-participants). Selon la recherche de Pauline Fraile (Fraile P., 2014), l'enseignant(e), qui veut susciter la motivation chez ses étudiants(es), doit être motivé(e) tout d'abord et compétent(e) à pratiquer l'enseignement. Pauline a ajouté que l'enseignant(e) doit conduire ses apprenants(es) vers les activités réalisables et doit les conseiller d'éviter les activités irréalisables pour ne pas perdre le temps. Il doit adopter avec ses apprenants(es) la négociation (le projet) selon leurs aptitudes, leur maturité, leurs profils et leurs capacités à s'autoréguler. Il reste toujours le coordinateur de la négociation (du projet). Il fait 
prendre conscience aux apprenants(es) de leurs compétences individuelles et d'intérêts communs.

D'autres rôles joués par l'enseignant(e) au sein de la négociation (du projet) comme :

$\checkmark$ Il(elle) sert de guide en répondant aux questions posées par les apprenants(es);

$\checkmark$ Il(elle) ne leur donne pas des solutions toutes faites en vue de leur donner l'occasion d'être autonomes.

Selon la recherche d'Halima Saadia Charif (Halima Saadia Charif, 2015), l'enseignant(e) a une grande responsabilité tout au long de la pratique des activités théâtrales; il doit impliquer les apprenants(es) dans le jeu, il doit leur donner la liberté de choisir les personnages et doit leur donner la motivation suffisante. La chercheuse a déterminé les rôles de l'enseignant(e) comme suit :

$\checkmark$ Il(elle) doit faire adapter les apprenants(es) à ce genre d'activité;

$\checkmark$ Il(elle) aide les apprenants(es) à déterminer des objectifs clairs, et précis à atteindre;

$\checkmark$ Il(elle) doit guider les apprenants(es) lors du jeu théâtral;

$\checkmark$ Il(elle) doit aider les participants(es) à éviter les égarements et la perte d'efficacité;

$\checkmark$ Il(elle) doit mettre à la disposition des apprenants(es) des supports authentiques accompagnés d'activités précises; 
$\checkmark$ Il(elle) doit mettre à disposition de ces apprenants(es) des textes, des dictionnaires nécessaires pour compléter le travail;

$\checkmark$ Il(elle) doit délimiter la durée de l'activité pour ne pas perdre le temps;

$\checkmark$ Il(elle) doit favoriser l'autonomie des apprenants(es) lors de l'activité.

\section{Communication quotidienne (verbale/linguistique) comme point de départ pour la communication théâtrale.}

Puisqu'on a pour objectif d'employer les activités théâtrales comme outil pédagogique dans le domaine du développement de l'expression (orale - écrite), il faut comprendre la communication théâtrale. Avant d'entrer dans des détails concernant le concept, il faut tout d'abord comprendre de quoi s'agit-il la communication. Selon des ressources variées et des dictionnaires, la communication constitue une opération compliquée basée sur des outils variés étudiés par des spécialistes de différents domaines; domaine linguistique, domaine didactique, domaine de l'analyse conversationnelle, domaine pragmatique...etc. (Hakima Abdelloui, 2012).

En effet, la communication constitue le véhicule transportant des messages ou des savoirs d'un émetteur (un destinateur) vers un ou plusieurs récepteurs (destinataire(s)). Elle est vraiment un pont de passage entre les humains pour échanger les informations de façon quotidienne. Elle constitue également le passage nécessaire dans le processus de l'enseignement/ 
apprentissage. Selon des études et des recherches antérieures comme la recherche d'(Hakima Abdelloui, 2012), et celle d'(Halima Saadia Charif, 2015), sans la communication, les sciences humaines ne pouvaient pas exister. La communication se compose de types : une communication dite verbale (linguistique) et une autre dite non-verbale.

Les composantes de la communication quotidienne verbale (ou linguistique) sont : le destinateur, le destinataire et le(les) message(s).

D'autres chercheurs(euses), didacticiens(nes) et linguistes voient que la communication verbale constitue la transmission de l'information par la voie de décodage d'un message donné. Ce décodage se fait à travers un système de signes soit phonique (dans le cas de la communication orale), soit graphique (dans le cas de la communication écrite). Autrement dit, la communication verbale n'est qu'une information des savoirs transmise d'un côté à l'autre à travers un message codé. Le travail du destinataire est de décoder ce message par un système de signes. (Dubois J., et al., 1994).

Il faut signaler que le concept de la communication est polysémique; un terme ayant des sens variés. Ce qui nous intéresse dans la recherche en cours est le fait des échanges des humains opérés à travers la langue orale ou écrite.

La communication non-verbale est, tout à fait, complémentaire de la communication verbale. Selon la recherche d'(Hakima Abdelloui, 2012), ce genre de 
communication est basé sur le geste, les expressions de face, la voix (notamment volume, débit, articulation, intonation ...etc.), et plus il existe une concordance entre la communication verbale et la communication non-verbale, plus le message est transmis efficacement. L'aspect verbal de communication renforce, donc, l'aspect non-verbal pour comprendre le contenu du message transmis par le processus de la communication.

En résumé la communication verbale ou linguistique se fait régulièrement entre un sujet établissant une relation d'échange avec un ou plusieurs individus pour transmettre des pensées, des idées, des sentiments, des savoirs ...etc. Cette transmission peut être exécutée soit de façon directe (face à face), soit de façon indirecte (par des médias).

La communication dite théâtrale est en gros une sorte de relation de transmission communicative. Ce genre de communication est intitulé une communication «multimodale»; elle se fait à travers des systèmes de signes variés et à travers des canaux variés. Elle englobe la communication linguistique ou verbale et la communication non-verbale en même temps. Elle comprend donc les différents aspects d'une situation de communication en même temps; elle fonctionne les différents mécanismes comme le langage, le regard, la lumière, le décor, la voix, le geste, les sourires, les mouvements, la mimique, les signes de joie et de malaise ...etc. Tous ces mécanismes se complètent en vue de véhiculer efficacement un message. Cette communication se déroule, bien entendu, sur la scène de façon interactionnelle entre les participants(es) au spectacle eux(elles)- 
mêmes d'une part et entre les participants(es) et les spectateurs d'autre part. Il n'existe pas de séparation entre salle et scène pendant le spectacle, mais la salle constitue un grand lieu où tous et toutes les participants(es) et les spectateurs déambulent à travers des instructions et des buts précis comme a affirmé Alain Boisvert (Boisvert A., 2006). Les informations communiquées de façon non-verbale restent intentionnelles dans la communication linguistique quotidienne mais dans le cadre des activités théâtrales se manifestent par la représentation et le jeu de rôles.(Halima Saadia Charif, 2015).

Dans la communication dite théâtrale se manifeste un concept important, c'est ce qu'on intitule "la sémiose théâtrale». Ce concept signifie que les activités théâtrales consistent à fonctionner un système de signes. Il est bien connu, selon des dramaturges et des spécialistes dans le théâtre, que le théâtre et les spectacles théâtraux ne sont qu'un objet sémiologique. Les représentations théâtrales sont une sorte d'imitation de ce qui se passe dans la vie réelle.

Signalons que la sémiologie, selon De Saussure, (cité dans Kowzan T., 1997) est une science étudiant la vie des signes dans le cadre de la vie sociale. Pour ce, on met en considération de développer les compétences de savoir-être chez nos apprenants(es).

Notons que la communication théâtrale travaille sur quatre spécificités ou mécanismes communs:la parole, le texte, la culture et le corps (à travers le geste). 


\section{Acte du langage (la parole).}

La parole et le corps se complètent pour une communication théâtrale efficace et effective. La pratique théâtrale donne l'occasion à la parole de se regarder, de résonner tel un instrument musical, de vibrer et ainsi de se faire entendre à travers les spectacles exécutés. Lorsqu'on laisse la parole sortir, on lui donne l'occasion de passer et ce passage et ce suspens font du visuel un auditif et d'ici, c'est la naissance du parleur et du personnage parlant. La parole advient pour traiter les différentes situations de discours dans les activités théâtrales par les participants(es) (Pieera G., 2011). Si la langue est un système de signes abstrait, la parole constitue l'expression de ce système de façon concrète (Meunier Ch., 2010). Selon la majorité des phonétistes, trois organes sont les responsables de produire les sons : l'appareil respiratoire, le larynx, et le conduit vocal. À travers les situations de communication quotidiennes, c'est la parole qui est le responsable de tisser les différents liens entre les interlocuteurs. Si la responsabilité de la parole est de tisser les liens pour non pas commencer une situation donnée, l'aspect corporel est conscient et dynamique. Les deux aspects s'associent donc pour que le message passe correctement.

Christine Meunier (Meunier Ch.,(2010) nous a donné quelques réalités concernant la parole en situation comme suit :

- La parole est rarement produite telle qu'elle est décrite de façon réglementaire;

- Les «sons» sont produits toujours en contexte; 
- La parole se produit rapidement (environ 150-300 mots / minute);

- Elle est gérée par des contraintes linguistiques et biomécaniques.

\section{La gestualité (les gestes).}

Joseph Messinger (Messinger J., 2009) a confirmé que chaque sujet constitue un miroir tridimensionnel : dimension affective, kinesthésique et sociale. Il ressent de façon fruste des sentiments d'antipathie, de sympathie..etc. à l'égard de l'autre. L'auteur a ajouté que les règles sociales ne permettent pas de s'exprimer nos sentiments de façon abstraite et directe. D'ici, les gestes traduisent, malgré nous, toutes nos émotions. Or, les gestes ont pour but de transformer des significations abstraites envers des objets ou des sujets dans la société en entourage. Par exemple s'on veut exprimer que rien à faire face à un évènement on dit directement : «rien à faire !». Mais on manifeste par les gestes : «on se soulève les mains ouvertes vers le ciel et les bras sont demi-tendus». Il faut donc noter que les personnes, à qui on s'adresse, ne jugent pas uniquement ce qu'on dit comme discours, mais également, elles jugent notre rigueur et notre sincérité à travers nos gestes. (Toastmasters international, 2013). Les gestes sont les mécanismes des moyens de communication non-verbale par excellence car ces gestes présentent des possibilités de clarté pour les discours. Selon (Toastmasters international, 2013), ces gestes peuvent : 
- Clarifier et étayer les arguments présentés lors du discours et cela peut faciliter la transformation des messages oraux;

- Donner du relief aux idées contenues dans les discours et cela développe et complète l'aspect verbal de la communication dans l'esprit de l'audience;

- Amplifier et accentuer la parole en vue d'exprimer les sentiments et les opinions de façon claire;

- Diffuser la tension nerveuse;

- Agir comme support visuel pour retenir ce qui est entendu par le public;

- Mobiliser l'auditoire pour déterminer la réponse attendue de la part de lui;

- Se voire de loin parce que la parole n'arrive pas facilement à tous les spectateurs notamment ceux du lointain.

On peut clôturer cette partie par la citation de Renard Raymond (Raymond R., 2002) : la production (orale) nécessite l'engagement $\mathrm{du}$ corps dans son ensemble [....] par des battements de la tête et des mains.

\section{Le texte.}

Gisèle Pieera (Pieera G., 2011) a mentionné que le texte est vu comme une ressource subjectivant du langage. Il est en réalité énigme. Si l'acte de parole est consacré à faire face aux problèmes et aux difficultés de l'aspect oral (problèmes de prononciation, d'intonation et de rythme), le texte est mastiqué 
comme un chewing-gum délicieux face aux problèmes et aux difficultés de l'aspect écrit. Pendant les exercices oraux, on fait l'entraînement des apprenants(es) à travers l'exagération et l'articulation des sons, les pauses, la formation des groupes rythmiques...etc. mais pendant les exercices écrits, on fait l'entraînement des apprenants(es) à travers les règles de la ponctuation (point final, deux points, virgule, point virgule, point d'interrogation, d'exclamation ...etc.). 


\section{AXE II.}

Cadre conceptuel de l'expression orale : définitions et importance.

- L'oral comme un point de départ.

Selon plusieurs études et recherches précédentes parmi lesquelles on cite la recherche de (Samira Moutakil, 2012), celle d'(Halima Saadia Charif, 2015), celle d'(Abdelaziz M. Latreche, 2015), et celle d'(Amina Souhila Hadjar, 2015), l'oral constitue un vecteur essentiel dans toutes les activités exécutées dans la classe de langue. Il est vraiment l'objet presque majeur dans la didactique de FLÉ. La tâche de tous les enseignants(es) en classe de langue est d'entraîner leurs apprenants(es) à prononcer et à bien articuler la langue. C'est pourquoi, on a focalisé sur cette partie de recherche consacrée à l'aspect oral de l'expression.

En effet, on a des définitions multiples de l'oral, on se contente ici de présenter quelques unes. Dans le dictionnaire de didactique de français langue étrangère et seconde (Cuq J.,-P., 2003), Cuq a confirmé que : " l'oral est référé à l'écrit». L'aspect oral s'identifie, donc, à l'aspect écrit. Or, les deux aspects sont deux réalités différentes, mais l'aspect oral constitue la manière de la communication entre l'être humain par excellence.

Le dictionnaire de didactique des langues de (Galisson R., et Coste D., 1979) a présenté une définition du terme comme suit : «le code de l'oral et le code de l'écrit ne se confondent pas; aux différences liées au canal correspondent des différences dans 
l'organisation des signifiants: d'autant plus que diachroniquement, pour le français, par exemple, code oral et code écrit n'ont pas évolué de la même manière».

Le terme est défini dans le dictionnaire pratique de didactique du FLÉ de Jean Pierre Robert comme le domaine de l'enseignement de la langue comportant l'enseignement de l'oral à travers des activités auditives et productives.

D'après Michèle Verdelhan-Bourgade (Verdelhan-Bourgade M., 2002), l'oral constitue le socle sur lequel se construisent toutes les autres connaissances langagières.

Le concept suivant Trendel (Trendel E., 2008) n'est qu'un outil à multi-usage que l'individu peut employer en vue d'exprimer ses pensées, ses idées, ses sentiments, et à travers lequel peut communiquer et établir des relations avec les autres.

D'après Coletta (Cité dans la recherche d'Amel Ouel, 2010), l'oral, c'est :

- Parler, reformuler, argumenter un énoncé, réfuter une idée, un savoir en employant soit la langue maternelle, soit la langue étrangère;

- Former de l'individu à travers la confrontation aux autres par la voie d'une discussion, d'un dialogue, d'une conversation ou d'un discours en se soumettant à des normes et à des règles de communication langagière et en se soumettant au jugement des autres. 
On peut, donc, conclure que l'oral a un double objectif; il joue le rôle d'un outil d'enseignement /apprentissage et d'un outil de communication langagière quotidienne parmi les sujets de toutes les communautés humaines. C'est pourquoi l'oral constitue un objectif pédagogique et social en même temps. Cela s'est accordé avec des recherches précédentes notamment la recherche d'Abdelaziz M. Latreche (Abdelaziz M. Latereche, 2015). Cette recherche a vu que l'oral est, tout-à fait, présent dans toutes les activités quotidiennes de l'individu; Il constitue tous ses aspects; aspect cognitif et intellectuel, aspect affectif et aspect identitaire. À travers l'oral, le sujet peut construire sa personnalité et renforcer sa position sociale au sein de la communauté dont il fait partie. D'ici vient l'intérêt de développer cet aspect (oral) chez nos apprenants(es).

\section{- Expression orale.}

Le dictionnaire de didactique des langues de (Galisson R., et Coste D., 1979) a défini le concept de l'expression en général : «opération qui consiste à produire un message oral ou écrit, en utilisant les signes sonores ou graphiques d'une langue. Expression orale et expression écrite correspondent à ce qu'on appelle parfois les «skills» actifs : parler et écrire. En ce sens «expression» est généralement opposé à «compréhension» orale et écrite : écouter et lire».

Le centre canadien des niveaux de compétences linguistiques (CLB, 2012) a vu que l'expression orale, c'est de créer des messages dans des contextes non exigeants et habituels 
d'emploi de la langue dans des situations quotidiennes, courantes et prévisibles en vue de combler des besoins essentiels, d'exercer des activités quotidiennes et de traiter des sujets connus présentant un intérêt personnel immédiat.

L'expression orale est comme la compétence la plus marquante en langue cible. Elle est, sans doute, difficile à acquérir. Cette compétence est toujours influencée par de nombreux mécanismes; l'aptitude à tenir des discussions et des conversations sans difficultés soit des difficultés linguistiques, soit des difficultés paralinguistiques, la capacité de prendre la parole spontanément (c.,-à-d., sans aucun recours à des formulations déjà élaborées), le pouvoir de faire face à un public, la fluidité d'échanges des répliques...etc. (Abdelaziz $M$. Latreche, 2015).

La compétence de l'expression orale consiste, donc, à s'exprimer oralement dans des situations variées de communication. Il s'agit d'établir un rapport abstrait entre un destinateur et un destinataire (entre un émetteur et un récepteur) et c'est au second (le destinataire) de comprendre le premier (le destinateur). (Karima Cheriet, 2014).

Selon la recherche d'Amina Souhila Hadjar (Amina Souhila Hadjar, 2015), l'expression orale constitue une compétence que les apprenants(es) doivent progressivement acquérir pour s'exprimer dans les différentes situations d'énonciation en français langue étrangère (FLÉ). D'après la recherche d'Amina, il existe un rapport interactionnel établi entre un destinateur et un 
destinataire pour que l'apprenant(e) devienne apte à produire à l'oral des énoncés variés dans les différentes situations de communication. Ces apprenants(es) doivent surmonter les difficultés concernant la compréhension comme les difficultés de prononciation, celles d'intonation, celles du rythme, celles de la grammaire; ils(elles) doivent, donc, dépasser ces problèmes pour que le message oral se transmet correctement entre eux(elles).

Dans l'expression orale, on fonctionne tous les mécanismes de la communication verbale et de la communication nonverbale en même temps pour transmettre un message oral; on bénéficie, donc, de la parole en compagnie des gestes, de la mimique, du regard, de la voix. Il est à noter que les messages oraux sont, au fur et à mesure, immédiats et nécessitent des réponses instantanées de la part de l'auditeur. Le but pédagogique derrière ces messages oraux immédiats est de mesurer ses effets sur les récepteurs. Plus ces messages sont assez clairs, plus ils passent facilement et sont renforcés par des réponses directes. Cette clarté des messages se font par le mélange naturel de différents mécanismes de communication (communication verbale et non-verbale). Le message oral est, donc, régi par :

- La gestualité des mouvements coordonnés avec la parole;

- La correcte prononciation des sons composant les mots employés lors de la parole.

- Les mimiques accompagnant les phrases prononcées.

- L'intonation et le rythme. 
- La voix du parleur notamment son volume et son débit.

En un mot, la réussite au sein de la compétence de l'expression orale compte sur l'emploi correct du langage parlé (la prononciation, l'intonation et le rythme) et sur les autres procédés paralinguistiques employés (la gestualité, les mimiques, la voix ...etc.).

\section{- Importance de l'expression orale.}

Le développement des compétences de l'expression constitue, sans doute, un objectif revendiqué non seulement de tout établissent mais également de tout enseignant du FLÉ. Lorsque les apprenants(es) comprennent les messages adressés oralement, il leur faut s'exprimer oralement ou par écrit. Or, afin de réaliser l'expression orale, les apprenants(es) doivent être capables de s'exprimer librement selon leurs aptitudes, leurs personnalités et leurs capacités langagières. Ces apprenants(es) doivent se développer du point de vue des savoirs, des savoirfaire et des savoir-être pour ce qui concerne les différentes situations de communication quotidiennes; ils(elles) doivent savoir comment prendre la parole sans timidité, doivent acquérir le vocabulaire adéquat, doivent maîtriser et pratiquer les règles phonologiques, doivent maîtriser et pratiquer les règles grammaticales, doivent savoir gérer leur apprentissage par eux(elles)-mêmes (autonomie d'apprentissage)...etc.

On doit noter que la maîtrise des compétences de l'expression orale est, sans aucun doute, le point de départ de comprendre les messages auditifs (la compréhension auditive). Par le moyen de 
l'expression orale, l'apprenant(e) est disposé(e) à produire des sons portant des sens et réglementés par des structures grammaticalement correctes. Or, la perfection des compétences de l'expression orale constitue la base épistémologique de toute langue soit maternelle, soit enseignée. Parler une langue étrangère comme a affirmé Michel Billières (Billières M., 1988), c'est de développer des compétences relatives à différents domaines linguistiques (comme : le domaine grammatical, le domaine phonétique, le domaine sémantique, le domaine contextuel...etc.) et des domaines paralinguistiques (les gestes, les mimiques et la voix). Suivant Billières, cela constitue une approche, à la fois phonétique et anthropologique.

Suivant des chercheurs(euses) dans le domaine de la didactique de FLÉ comme (Karima Cheriet, 2014), l'expression orale peut développer chez les apprenants(es):

- Des informations langagières, de l'argumentation, des sentiments et des opinions variés à travers des idées présentées discursivement;

- Ces idées doivent être enchaînées logiquement et correctement en employant des transitions bien choisies;

- Ces idées doivent être adéquates au sein de l'aspect socioculturel; dans les situations de communication, il faut se faire comprendre au même titre exprimer ce qu'on a réellement l'intention de dire.

Parler, donc comme a affirmé (Abdelaziz M. Latreche, 2015), constitue la base de l'enseignement car l'expression comprend 
tout (l'écoute, le langage et la parole). À travers l'expression orale, les apprenants(es) travaillent sur la langue à partir de la recherche des sens pour les mots et les termes employés, jusqu'à les utiliser ultérieurement pour s'exprimer de façon convenable dans les différentes situations de la vie.

Surplus, l'expression orale joue un rôle essentiel dans le perfectionnement de la langue en général et plus particulièrement dans le perfectionnement du français comme langue étrangère. D'après des études et des recherches précédentes comme celle d'Amina Souhila Hadjar (Amina Souhila Hadjar, 2015), les formateurs(rices) doivent tenir des ateliers réguliers ayant des objectifs de pratiquer la communication langagière de façon précise.

À travers ces ateliers, le(la) formateur(rice) peut :

- Établir des situations d'échanges entre les apprenants(es) et créer une atmosphère de compétition entre eux(elles) pour pratiquer une certaine émulation;

- Intervenir au fur et à mesure pour corriger les fautes, et les erreurs commises par les apprenants(es) lors de parler pour les aider à reformuler les énoncés maladroits. Ces mesures sont nécessaires pour la continuité de ces situations de communication.

En un mot, le développement des compétences de l'expression orale consiste à développer tout ce qui concerne le code oral dès la compréhension auditive jusqu'à l'expression 
orale; l'apprenant(e) reçoit préalablement des messages par l'écoute et s'exprime pour répondre à ces messages. Plus ces messages reçus se sont compris distinctement, plus les réponses produites sont correctes. La correction des réponses se mesure à travers les structures correctement employées, le respect des règles de prononciation, d'intonation et de rythme, la présentation des énoncés sémantiquement convenables aux contextes...etc.

- Difficultés de pratiquer l'expression orale en classe de langue.

Tout d'abord, ce qui est à noter, c'est que la plupart des maîtres(esses)-enseignants(es) négligent, au fur et à mesure, l'aspect oral en général dans la classe de langue et lorsqu'ils(elles) commencent à donner importance à l'aspect oral, ils(elles) privilégient la compréhension orale au dépens de l'expression orale. Des motifs nombreux sont derrière cette importance donnée à la compréhension orale; les difficultés envisagées par les apprenants(es) au sein de prendre la parole au public notamment dans les cas des apprenants(es) débutants(es), le manque de vocabulaire chez ces apprenants(es), leur anxiété langagière, le manque d'entraînement au sein de la conception des situations réelles de communication francophones...etc. C'est pourquoi, le temps consacré aux compétences de l'expression orale ne dure que quelques minutes comme a affirmé (Amina Souhaila Hadjar, 2015). 
En fait, prendre la parole au public est toujours organisé et purement initié par l'enseignant(e) et non pas par les apprenants(es). Pour ce faire, l'enseignant(e) adopte des procédures artificielles telles que l'emploi soit des réponses écrites réalisées par les apprenants(es) de façon écrite, soit par la lecture à haute voix. En d'autres termes, l'initiative n'est pas prise par les apprenants(es) mais par l'enseignant(e) sous la forme de ce qu'on a intitulé «l'écrit oralisé». Cette manière du travail est tout à fait gérée par l'enseignant(e) et les rôles des apprenants(es) ne sont pas pris en compte.

L'enseignant(e) doit prendre en considération que les apprenants(es) sont des adolescents(es) débutants(es) et c'est à lui(elle) de les motiver à s'exprimer oralement sans aucune timidité et d'éveiller l'esprit de curiosité chez eux(elles). Il(elle) doit être prudent(e) de bien distinguer les exercices de la compréhension auditive de celle de l'expression orale car un nombre considérable d'enseignants(es) mélangent les deux compétences du raison du mal fonctionnement du temps de la séance en classe de langue.

Plusieurs chercheurs(euses) et didacticiens(nes) comme : (Amina Souhaila Hadjar, 2015) ont énuméré les causes de négligence des compétences de l'expression orale dans les salles de classe pendant le processus d'enseignement/apprentissage comme suit :

- Plusieurs enseignants(es) n'arrivent pas à distinguer les exercices consacrés aux compétences de la compréhension 
auditive des exercices consacrés aux compétences de l'expression orale;

- Ils(elles) monopolisent les exercices de parole et ne laissent pas l'initiative aux apprenants(es) de s'exprimer de façon libre dans des situations naturelles;

- Ils(elles) ne maîtrisent pas le fonctionnement des matériaux pédagogiques (à condition que l'établissement scolaire puisse les fournir) qui aident à développer l'expression orale comme les ordinateurs, les projecteurs...etc.

Cadre conceptuel de l'expression écrite : définitions et importance.

- L'écrit comme un objectif majeur.

Il faut tout d'abord signaler que les compétences de l'expression soit orale, soit écrite sont élémentairement liées et indissociables et que les apprenants(es) de chacune des langues enseignées (étrangères) en général et particulièrement de FLÉ doivent déployer tous les efforts possibles pour les développer. Les concepteurs de la didactique se trouvent, au fur et à mesure, dans un cadre d'aller et retour permanent entre les deux facettes de l'expression pour développer les mécanismes de leur apprentissage.

Ces concepteurs focalisent sur l'autonomie des apprenants(es) pour développer par eux(elles)-mêmes leurs compétences de ces deux modes d'expression. C.-à-d., ils 
encouragent ces apprenants(es) de gérer leur apprentissage par eux(elles)-mêmes; de concevoir des méthodes et des stratégies toujours d'avant-garde pour développer leur expression. L'essentiel n'est pas que les apprenants(es) s'expriment uniquement, mais ils(elles) expriment quelque chose de précieux.

Conformément à la recherche de Magdalena Hernandez Alarcon (Hernandez Alarcon M., 2001), on touche une différence entre les natifs et les non-natifs en ce qui concerne l'abordage de l'écriture. L'acte d'écrire est aussi difficile soit pour l'apprenant(e) natif(ve) soit pour l'apprenant(e) non-natif(ve). Et cette vision s'accorde avec des linguistes nombreux comme : (Catach N., 1988) et (Weber C., 1993).

L'écriture n'est pas une simple rédaction de quelques phrases sur n'importe quel sujet de composition, mais c'est un processus complexe faisant appel à des savoirs cognitifs sur la langue et en employant quelques savoir-faire et en exploitant quelques stratégies discursives pour produire des textes, des récits, des commentaires...etc. sur des évènements de la vie. (Karima Majouba, 2012).

L'écrit fait partie intégrale des compétences sociales vues nécessaires pour chacun des sujets de telle ou telle communauté linguistique, savoir s'exprimer à l'écrit est une nécessité humaine. Les compétences de l'expression écrite constituent non seulement l'objectif majeur mais également une mission essentielle du système scolaire. 
Selon Karima Cheriet (Karima Cheriet, 2014), on écrit pour :

$\checkmark$ Produire des récits complets;

$\checkmark$ Structurer des textes argumentatifs;

$\checkmark$ Étudier de façon organisée la langue.

À cette perspective, Goody (Goody G., 1979) a montré que l'écriture ne constitue pas une simple transcription phonologique des actes de parole dans des conditions sociales ou technologiques variées, mais constitue des activités linguistiques ayant l'objectif de poser et de résoudre des problèmes. Ce point de vue de Goody met l'accent, non seulement, sur le rôle de l'écriture dans le développement des compétences sociales et technologiques chez les apprenants(es), mais également sur l'écriture même comme une activité linguistique visant à la résolution des problèmes. Selon lui, mettre l'apprenant dans une situation de réaction après avoir passé un processus d'apprentissage, c'est de le mettre dans une situation problématique et son rôle est de mobiliser ses savoirs, ses savoirfaire et ses savoir-être pour trouver des solutions efficaces à cette situation. L'essentiel, donc, est de fonctionner les compétences écrites dans des performances rédactionnelles pour répondre à des besoins quotidiens de communication.

Afin d'avoir des travaux rédactionnels linguistiquement corrects et logiques de la part des apprenants(es) débutants(es) en L2 ${ }^{(')}$, comme ont affirmé plusieurs études et recherches

( ) L2 = 2ème langue étrangère. 
antérieures comme la recherche de Veda Aslim-Yetis (AslimYetis V., 2008). Ces recherches ont montré que le scripteur débutant doit prendre en considération quelques pratiques pour accomplir ses tâches rédactionnelles :

- Rappel des règles grammaticales à employer lors de la rédaction; s'il est demandé aux apprenants(es) de rédiger un paragraphe ou un texte au passé, c'est à l'enseignant(e) de clarifier quel passé employé lors de la rédaction (passé simple, passé composé ou imparfait)?, et quels sont les différences qui peuvent exister entre ces types de passé au niveau de l'emploi et au niveau de la forme?

- Emploi de l'expression dirigée; avant de pousser les apprenants(es) à rédiger les paragraphes et les textes donnés, c'est à l'enseignant(e) de préparer avec ces apprenants(es) un canevas des sujets et des listes de vocabulaire relatives à ces sujets proposés à rédiger et de préparer le plan des sujets avec eux(elles);

- Création d'une liste de vocabulaire; avant de donner l'occasion aux apprenants(es) de commencer à rédiger le sujet donné, c'est à l'enseignant(e) de mener une session de remue-méninges autour de ce sujet et les apprenants(es) inscrivent le lexique dans leurs cahiers. Ils(elles) ont recours à ces listes inscrites lors de la tâche rédactionnelle pour produire le sujet;

- Emploi d'œuvres de référence; avant de commencer la tâche rédactionnelle, les scripteurs doivent consulter des 
ouvrages de référence en grammaire, en orthographe et en dictionnaires de lexique; les scripteurs sont, dans la plupart de cas, incapables d'employer ces œuvres de référence. Or, c'est à l'enseignant(e) de les aider comment employer ces ouvrages de référence;

- Intervention constante de l'enseignant(e); l'enseignant(e) constitue pour les scripteurs le support infini lors de la tâche rédactionnelle. Pour les apprenants(es) scripteurs, c'est l'enseignant(e) qui est toujours la ressource des connaissances, des savoir-faire sur la langue et les éléments linguistiques;

Pour clôturer cette partie, ce sont les apprenants(es) en collaboration avec l'enseignant(e) d'exploiter les savoirs, les savoir-faire et les savoir-être relatifs à l'aspect écrit de l'expression pour accomplir des performances rédactionnelles correctes, logiques dans des situations de communication dites fonctionnelles.

\section{- Expression écrite.}

Tout d'abord, il faut mentionner que l'expression écrite fait partie intégrale de la production écrite. Celle-ci se présente comme le cas de savoir-écrire en langue maternelle dans un objectif de construire un sens et également dans un objectif de faire les apprenants(es) acquérir les compétences à produire divers types de textes pour répondre à des visées de communication. Ces apprenants(es) écrivent non seulement pour que l'enseignant(e) corrige leurs fautes, comme a 
confirmé N. Thao (Thao N., 2007), mais également ils(elles) écrivent pour être lus et pour communiquer avec un ou plusieurs lecteurs.

Selon plusieurs concepteurs dans le domaine de la didactique de FLÉ comme : Sophie Moirand (Moirand S., 1982) et Marie-Claude Albert (1998), la compétence de la production écrite en général et notamment celle de l'expression écrite se compose de plusieurs composantes comme suit :

- Composante linguistique : cette composante est basée sur une compétence purement linguistique (compétence morphosyntaxique et une compétence lexicale;

- Composante socioculturelle : il s'agit des savoirs culturels basés sur les connaissances des normes sociales et interactionnelles entre les sujets et les institutions de l'environnement d'apprentissage;

- Composante référentielle : il s'agit des savoirs concernant les objets du monde;

- Composante discursive : c'est la compétence pragmatique qui aide à produire un texte relatif à une situation de communication;

- Composante cognitive : il s'agit ici des compétences relatives au processus de l'instruction-apprentissage de la langue à enseigner/apprendre. 
Les apprenants(es) de FLÉ sont, donc, amené(es) à combiner les composantes déjà mentionnées pour pratiquer son travail comme scripteur. Lors du travail comme scripteur pour créer un texte, les apprenants(es) sont appelé(es) à enchevêtrer de telles composantes. Ce canevas de compétences se combinent donc pour adresser un message façonné au destinataire, comme a affirmé Corinne Weber (Weber C., 1993 : P. 62) en disant : l'apprenant(e) «doit façonner son message afin que le destinataire soit en mesure de comprendre sa pensée».

Selon Danielle Bailly (Bailly D., 1998), il existe une différence entre les deux termes; Production écrite et expression écrite. Le premier terme met l'accent sur l'émission de L2 dépourvue d'engagement tandis que le deuxième terme met en relief l'émission de L2 où l'émetteur s'exprime de façon modale. L'expression écrite, d'après lui, constitue la production personnelle d'un message écrit de façon énonciative. Bailly a déterminé rigoureusement les conditions essentielles de rédaction; il suffit d'avoir quelque chose à dire, savoir à qui le rédacteur va s'adresser pour le dire, et les raisons derrière ce qu'il veut dire. Elle (Bailly) a assuré que malgré les distances qui pouvaient être entre le destinateur et le destinataire, l'écriture constitue un acte de communication.

Julié Kathleen (Kathleen J., 1994) a déterminé ce qu'on désigne par le terme d'expression écrite en mettant l'accent sur les objectifs de l'écrit. Elle a confirmé qu'on écrit pour :

- Fixer ses savoirs; 
- Donner des informations;

- Transmettre des sentiments;

- Donner son avis;

- Véhiculer un sens;

- Commenter des évènements.

- Importance de l'expression écrite.

Il faut mentionner que l'oral et l'écrit sont les deux facettes de la même pièce. On n'imagine pas l'existence de l'un supprime l'autre. Denis Gérard (Gérard D., 1974) a confirmé que l'aspect écrit est essentiel pour renforcer l'aspect oral car il est la ressource de l'enrichissement linguistique.

L'écriture est la transposition de l'oral. S'on considère l'oral comme un mode de pensée, l'écrit constitue le mode créatif de pensée. L'expression écrite fait partie intégrale de la production et de la communication écrites; communiquer à l'écrit suppose qu'un scripteur rédige un message ou un document en vue de les adresser à un ou à des lecteurs. Les lecteurs et les scripteurs ont des intentions différentes des situations de communication écrites; les lecteurs sont toujours dans une situation de réception écrite alors que les scripteurs sont dans une situation de production écrite. 
Aperçu panoramique : les deux facettes de l'expression (orale-écrite) du point de vue des méthodologies et des approches.

Plusieurs précurseurs, chercheurs(euses) et didacticiens(nes) parmi lesquels on trouve les références de (Cornaire C., 1991), (Germain C., 1993) (Cornaire C., et Raymond P.-M., 1999) et (Watt L., 2002) et les recherches d'(Aslim-Yetis V., 2008), d'(Amel Oual, 2010), d'(Abdelaziz M. Latreche, 2015) et de (Karima Majouba, 2012). Ces références et recherches ont présenté une vision panoramique des compétences de l'expression (orale/écrite) traitées par les différentes méthodologies des langues étrangères en général et notamment de FLÉ.

- Les compétences de l'expression (orale/écrite) traitées par la méthodologie traditionnelle.

Cette méthodologie est intitulée la méthode «grammaire/Lecture» ou «grammaire/traduction». Elle était dominante entre la deuxième moitié du $18^{\text {ème }}$ siècle et tout au long $\mathrm{du} 19^{\text {ème }}$ siècle. Elle avait pour objet l'instruction/apprentissage du grec et du latin en mettant l'accent sur la lecture des textes littéraires pour que les apprenants(es) puissent établir des correspondances entre la langue maternelle et la langue cible (étrangère) à travers la traduction. Cette méthode visait essentiellement à faire les apprenants(es) acquérir une culture générale et une formation intellectuelle. Elle met également l'accent sur la forme des textes au dépens du sens. 
Elle a, donc, traité la langue non pas comme un moyen de communication mais comme une discipline interculturelle. Les compétences de l'expression écrite ont, donc, reçu un intérêt partiel mais les compétences de l'expression orale sont totalement négligées.

Malgré la concentration de la méthodologie traditionnelle sur l'aspect écrit de l'expression, on n'a pas touché un véritable apprentissage de l'expression écrite. Selon (Cornaire C., et Raymond P.-M., 1999), le processus de l'apprentissage reste modeste du raison que :

- Les activités de l'expression écrite dans la classe de langue demeurent modestes et insistent uniquement sur la traduction thème et version;

- Les exercices présentés dans le cadre de l'enseignement/ apprentissage portent uniquement sur quelques points grammaticaux vus nécessaires pour la didactique des textes littéraires. Plus les textes choisis sont normatifs, plus ils sont considérés comme des textes idéaux;

- Les exercices de l'expression écrite présentés dans la classe de langue demeurent artificiels et ne donnent aucune occasion aux apprenants(es) de pratiquer la communication réelle.

Cette méthodologie mettait l'oral en second degré mais l'écrit notamment l'écrit littéraire en premier plan. Les exercices et les activités présentés en classe de langue se font essentiellement à 
l'écrit et aucune place accordée à l'oral. Les rapports enseignant/apprenant en classe de langue reste dans le cadre traditionnel où on met l'accent sur l'enseignant en négligeant les apprenants(es). L'enseignant(e) a joué des rôles comme suit :

- Il(elle) est le dominant(e) dans la classe;

- Il(elle) est la ressource du savoir et de l'autorité;

- Il(elle) est le correcteur essentiel des fautes et des erreurs des apprenants(es);

- Il(elle) est là pour respecter les normes.

Mais l'apprenant(e) a joué des rôles comme suit :

- Il(elle) est tout à fait passif(ve);

- Il(elle) est soumis(e) à l'enseignant(e);

- Il(elle) apprend par cœur avec une négligence totale de la créativité;

- Il(elle) travaille de façon individuelle.

En un mot, les exercices présentés dans le cadre de la méthodologie traditionnelle font uniquement des traducteurs de textes littéraires et ne sont pas valables pour un enseignement/ apprentissage des compétences de deux facettes de l'expression (orale/écrite). 
- Les compétences de l'expression (orale/écrite) traitées par la méthodologie directe.

Selon la définition du dictionnaire pratique de didactique de FLÉ de Jean-Pierre Robert (Robert J.,-P., 2002), la méthodologie directe refuse les apports sous-jacents de la méthodologie traditionnelle (dite grammaire-traduction) et plonge l'apprenant(e) dans ce qu'on intitule «bain de langue». Cette méthodologie a été apparue au début du $19^{\text {ème }}$ siècle comme une réaction contre la méthodologie traditionnelle «dite indirecte». Elle met l'accent sur les performances orales des apprenants(es). Du point de vue de Christian Puren (Puren C., 1998) c'est la première méthode spécialisée dans le domaine de l'enseignement des langues vivantes étrangères car elle répond à un besoin plus pratique que littéraire dans le domaine de l'enseignement des langues étrangères. Cette méthodologie voulait employer la langue comme un instrument de communication avec l'autrui. Cette méthodologie a été considérée comme une approche naturelle pour ce qui concerne l'instruction/apprentissage des langues vivantes étrangères. Cette méthode est basée sur l'accès direct à la langue étrangère sans intermédiaire de la langue maternelle. Elle emploie des gestes, des images, des objets et des mimiques pour donner le sens des mots (le vocabulaire). On attribue des dénominations variées à cette méthode; méthode active, méthode orale et méthode directe.

À travers la pratique d'une telle méthode, le(la) maître(esse)enseignant(e) peut jouer des rôles comme : 
- Il(elle) parle tout le temps en langue étrangère dans la classe de langue;

- Il(elle) n'a jamais recours à la langue maternelle;

- Il(elle) emploie des objets, des gestes et des images pour accéder au sens (il emploie des outils non-verbaux);

- Il(elle) met l'accent sur les activités orales au dépens de celles de l'écrit.

Cependant, l'apprenant(e) peut jouer des rôles comme :

- Il(elle) devient le responsable de son apprentissage;

- Il(elle) devient tout à fait actif(ve) et motivé(e);

- Il(elle) prend part à toutes les représentations contribuant à son apprentissage;

- Il(elle) répond à toutes les questions posées par le(la) maître(esse)-enseignant(e);

- Il(elle) emploie les mouvements corporels pour réaliser la lecture expressive;

- Il(elle) participe à toutes les activités tenues dans la classe sous la direction du(de la) maître(esse)-enseignant(e);

- Il(elle) déploie des efforts personnels pour comprendre.

En synthèse, la méthodologie directe est vraiment une réaction radicale contre la méthode dite grammaire-traduction du raison que : 
- La méthode directe s'intéresse à l'expression orale mais la méthode traditionnelle s'intéresse à l'expression écrite;

- Cette méthode directe accorde une importance à la prononciation, à l'intonation et au rythme mais la méthode traditionnelle les néglige;

- Cette méthode directe favorise les activités basées sur les questions-réponses dirigées par le(la) maître(esse)enseignant(e);

- Cette méthode directe motive les apprenants(es) à répondre aux questions posées par l'enseignant(e);

- Cette méthode directe traite l'écrit comme un «oral scripturé»» mais la méthode traditionnelle s'intéresse à l'écrit littéraire.

\section{- Les compétences de l'expression (orale/écrite) traitées} par la méthodologie audio-orale.

Née pendant la deuxième guerre mondiale, la méthodologie audio-orale (MAO) s'appuie sur les théories psychologiques et linguistiques de l'époque comme le béhaviorisme et le structurisme. Selon (Cornaire C., et Germain C., 1998), cette méthodologie a comme théories de référence : le distributionalisme linguistique et le conditionnement de Skinner associés au modèle structuraliste de Bloomfield. Cette méthode pousse les apprenants(es) des langues vivantes étrangères à produire des comportements langagiers proches comme se passant dans les situations de la vie réelle. 
L'apprentissage selon cette méthode se fait de manière mécanique selon le modèle de Skinner (stimulus-réponserenforcement). Ce processus se fait par des répétions opérées des automatismes linguistiques afin de les fixer dans la mémoire des apprenants(es). Cette méthode a profité de l'évolution technologique de l'époque où elle a exploité les supports audiovisuels, les cassettes magnétiques et les labos de langue.

L'objectif majeur derrière l'emploi d'une telle méthode (La méthode MAO) est de développer les quatre compétences de base de la langue (compréhension orale et écrite et expression orale et écrite). Ce développement des compétences déjà mentionnées est radical pour la communication quotidienne.

Comme dans le cas de la méthodologie directe, cette méthodologie audio-orale (MAO) donne la priorité à l'aspect oral au dépens de l'aspect écrit. D'après (Cornaire C., et Raymond P.M., 1999), l'écrit dans la méthode s'est limité a :

- Quelques exercices modestes en quantité et en qualité;

- Quelques exercices de substitution et de transformation dont le sens est en second plan;

- Quelques exercices de composition de reprendre les structures automatistes présentés à l'oral.

- Les compétences de l'expression (orale/écrite) traitées par la méthodologie SGAV.

C'est à l'Institut de phonétique de l'université de Zagreb sous la direction de Peter Guberina, la méthode audio visuelle (dite 
SGAV) a été née. Cette méthodologie visait à développer l'apprentissage de la communication quotidienne. D'après (Cornaire C., 1993), cette méthode constitue essentiellement un moyen de communication et d'expression orale. lorsqu'on emploie cette méthode dans le processus d'instruction/ apprentissage (dans la classe de langue), on met l'accent sur la perception du sens global de la structure en exploitant les éléments auditifs et visuels qui facilitent l'apprentissage. Les situations de communication se font, selon cette méthode, à travers des conversations enregistrées et accompagnées des images ou des films fixes.

Il est à noter que dans une telle méthode, l'oral prime l'écrit et se présente à travers l'aspect auditif et l'aspect visuel de façon simultanée comme on a déjà mentionné. Le structuralisme sert de référence en ce qui concerne l'aspect grammatical. L'écrit se présente sous la forme des exercices de dictée dans une visée de renforcer l'aspect phonique et l'aspect graphique.

- Les compétences de l'expression (orale/écrite) traitées par l'approche communicative.

Intitulée «approche communicative», cette méthodologie est apparue pendant les années soixante-dix et a continué jusqu'aujourd'hui. Cette méthode a été considérée comme une réaction contre toutes les méthodes précédentes notamment la méthode audio-orale (MAO) et la méthode Structuro globale audio visuelle (SGAV). Elle est basée sur des principes théoriques empruntés de différentes disciplines; l'ethnographie 
de la communication, la psycholinguistique, la sémantique, la sociolinguistique ...etc. c'est pourquoi elle est intitulée «approche» plutôt que «méthodologie».

En fait, cette approche n'est qu'une remise en question des méthodologies suivantes notamment les méthodes (audio-orale et audio-visuelle)(Karima Majouba, 2012). Cette approche a rejeté les apports béhavioristes en adoptant la psychologie cognitive. Elle a refusé l'idée de considérer les savoirs comme des automatismes présentés aux apprenants(es) et elle a défendu l'idée de faire les apprenants(es) travailler sur des énoncés auxquels ils(elles) peuvent attribuer un sens. (Bérari E., 1991).

C'est la première fois, avec cette approche, qu'on commence entendre le concept de «compétence de communication» dans le domaine de la didactique des langues. Cette approche a considéré que la langue est non seulement l'instrument de communication mais également un instrument d'interaction sociale. (Aslim-Yetis V., 2008).

Cette approche est basée sur la collaboration entre l'enseignant(e) et les apprenants(es). Il faut montrer que l'apprenant(e), suivant cette approche, joue le rôle essentiel car il est le responsable de son apprentissage. l'apprenant(e) est toujours actif(ve) dans toutes les étapes de l'apprentissage à partir de la recherche des savoirs jusqu'à l'évaluation des acquis de cet apprentissage.

Suivant Sophie Moirand (Moirand S., 1982), cette approche est basée sur ce qu'on intitule «la compétence de 
communication». Celle-ci identifie quatre composantes essentielles :

- Composante dite linguistique;

- Composante discursive;

- Composante socioculturelle;

- Composante pragmatique.

Pour clôturer cette partie, on doit noter que l'approche communicative s'intéresse aux compétences orales (compréhension orale et expression orale) au même titre les compétences écrites (compréhension écrite et expression écrite) car les quatre compétences sont élémentaires dans le cadre de la communication quotidienne constituant l'objectif majeur de l'approche communicative.

Rapports entre savoir-être et les compétences de l'expression orale et écrite.

\section{Savoir-être : de quoi s'agit-il?}

Des concepteurs, et des didacticiens(nes) ont travaillé sur les comportements et les attitudes (les savoir-être) comme : (Kopiac M., et Howden J., 2000), (Cuq J.-P., 2003), (Gauvin C., et Laforge É., 2006), et (Fatiha Boudebouda, 2010). Ces spécialistes nous ont clarifié ce qu'on désigne par le concept de «savoir-être».

Les savoir-être sont préalablement les comportements et les attitudes manifestés de la part des apprenants(es) envers telle ou 
telle activité d'apprentissage, envers les travaux de l'autre et envers les activités pratiquées dans l'environnement d'apprentissage. D'après ces chercheurs et chercheuses, ces concepteurs dans le domaine de la didactique de FLÉ comme : Clémence Gauvain et Émilienne Laforge (Gauvain C., et Laforge É., 2006), les savoir-être constituent tout ce que l'on «sait être» au plan personnel. C. à. d., tout ce qu'on a comme attitudes, valeurs, et besoins lors de l'interaction avec les autres et avec l'environnement en entourage. Ces chercheuses donnent des exemples pour faciliter la compréhension du concept; lorsqu'un sujet travaille telle ou telle activité avec un autre sujet différent, le premier doit manifester un respect envers le deuxième malgré ses valeurs et ses aptitudes qui semblent différentes à lui. Alors, lorsqu'on accepte de travailler avec des apprenants(es) ayant des valeurs différentes des siennes, on doit savoir être respectueux avec eux(elles). Dans ce cadre, l'acquisition des savoir-être nous donnent un type de souplesse face à des individus ayant un rythme différent que le nôtre.

D'après Jean-Pierre Cuq (Cuq J.-P., 2003), le concept de savoir-être a trouvé une nouvelle vigueur. Celle-ci fait que le «savoir-être» est remplacé par le «savoir se comporter». Dans ce sens, les apprenants(es) se mettent en relation avec les autres; du point de vue culturel et linguistique en même temps. l'auteur a ici ajouté que les apprenants(es) sont toujours invités(es) à être ouverts(es) vers d'autres cultures mais en prenant en considération sa propre identité culturelle. L'école est donc 
l'endroit où l'on peut acquérir les savoirs, les savoir-faire et les savoir-être. (Fatiha Boudebouda, 2010).

Les savoir-être sont, du point de vue du (CÉCRL) (Conseil de l'Europe, 2001), à considérer comme des dispositions individuelles, des traits de personnalité, des dispositifs d'attitudes, qui touchent, par exemple, à l'image de soi et des autres [.....]. le savoir-être recouvre, donc, tous les aspects non langagiers notamment tout ce qui concerne les attitudes, le système de valeurs internes ou externes, les motivations, les traits de la personnalité, les compétences d'autonomie ...etc.

Les savoir-être constituent un état d'esprit acquis d'une personne à l'égard de son soi et de son environnement entouré qui incite dans cette même personne un état d'agir de telle ou telle manière face à une situation particulière. Dans ce sens, les savoir-être sont étroitement liés aux comportements et aux attitudes manifestés envers les situations quotidiennes rencontrées par les personnes. Dans ce cadre, le Socle commun nous a donné que l'intérêt pour le développement des compétences de la langue (des savoir-faire) génère la puissance affective et émotive de la langue et l'ouverture au débit, au dialogue et à la communication (verbale - non verbale).

Alors, les savoir-être ne sont que des attitudes nécessaires pour l'individu tout au long de sa vie; il doit être ouvert aux différents points de vue présentés, il doit accepter les autres malgré les différences individuelles qui pourraient être existantes, il doit manifester un respect de son niveau intellectuel 
et celui des autres, il doit être curieux en ce qui concerne les connaissances, les savoirs, les savoir-faire, il doit être créateur...etc.

En un mot, le savoir-être constitue l'aspect affectif dans le processus de l'enseignement/apprentissage en général et particulièrement en FLÉ. Les savoir-être ne sont que les traits généraux composant la personnalité de l'apprenant(e); sa motivation, ses besoins, ses goûts, ses valeurs et ses émotions. Tous ces traits tracent la personnalité de l'apprenant(e) dans ses rapports avec soi-même, avec les autres individus (ses pairs) et avec le monde.

Savoirs, savoir-faire et savoir-être : composantes de la notion de compétence.

Plusieurs chercheurs(ses), précurseurs, concepteurs et didacticiens(nes) comme : (Le Boterf G., 1995), (Perrenoud P., 1997), (Kopiac M., et Howden J., 2000), (Cuq J.-P., 2003), (Gauvin C., et Laforge É., 2006), (Fatiha Boudebouda, 2010), et (Smuk M., 2014) ont rigoureusement distingué les différents aspects du terme «compétence»; savoirs, savoir-faire et savoirêtre.

\section{Savoirs.}

Selon la recherche de (Fatiha Boudebouda, 2010), les savoirs constituent les connaissances cognitives influençant sur toutes les activités cognitives achevées par les apprenants(es). Ces savoirs cognitifs sont, au fur et à mesure, emmagasinés dans la mémoire à long terme. Selon la chercheuse, ils (les savoirs 
cognitifs) participent à la formation de nos objectifs, à leur évaluation, ainsi à leur abandon. L'individu doit avoir la capacité à reprendre tels savoirs pour faire face aux différentes situations et résoudre les situations problématiques.

Guy Le Boterf (Le Boterf G., 1995) a distingué deux types de savoirs; savoirs théoriques liés à la compréhension et à l'interprétation et savoirs procéduraux liés aux procédures. D'après cette distinction de Guy Le Boterf, les savoirs théoriques sont les connaissances que chacun acquiert tout au long de sa vie dans les différents domaines. Les savoirs procéduraux ne sont que les règles procédurales employées pour présenter les savoirs théoriques de façon minutieuse et normative.

Un nombre infini des spécialistes sont, donc, d'accord sur une idée centrale confirmant que les savoirs ne sont que des connaissances institutionnalisées et organisées transmises à travers un établissement scolaire. Ces savoirs sont acquis, élaborés soit par l'étude dans un domaine donné, soit par l'expérience; ces savoirs sont le résultat des activités d'apprentissage. On peut, donc, dire que ces savoirs ne se transmettent pas mais s'actualisent à travers les situations d'apprentissage et les pratiques dans le réel. Lorsqu'on emploie des connaissances pour traiter une situation problématique donnée pour le résoudre, on a l'habitude de réutiliser ces mêmes connaissances pour résoudre une autre situation semblable. 


\section{Savoir-faire.}

S'on considère les savoirs comme des connaissances déclaratives ou bien conceptuelles liées à un domaine donné, les savoir-faire ne sont qu'une sorte de savoirs procéduraux liés au domaine de règles employées pour présenter les connaissances conceptuelles de façon réglementaire. Par ex. (lorsqu'on se met à parler en français comme langue étrangère, on a besoin de connaissances déclaratives (conceptuelles) liées à la langue (des termes, des expressions) et de connaissances procédurales liées à la grammaire, à la sémantique, à la phonologie ....etc. pour bien parler dans la situation).

Des études et recherches antérieures, comme la recherche de Fatiha Boudebouda (Fatiha Boudebouda, 2010) s'accordent avec cette distinction entre les termes de savoirs et savoir-faire. La chercheuse a confirmé que si les savoirs sont liés aux connaissances langagières, les savoir-faire sont liés à l'ordre du discours.

D'après Perrenoud P., (Perrenoud P., 1997), les savoir-faire ne sont que des compétences élémentaires employées pour présenter les connaissances conceptuelles. À ce propos, il confirme que les savoir-faire sont «un savoir comment faire, un savoir y faire et une compétence élémentaire».

On peut donc dire, les savoir-faire ne sont que les compétences acquises dans un domaine donné comme (dans la grammaire, dans la phonétique ...etc.). les compétences ne sont, donc, innées. Le fait d'être un individu compétent dans un tel ou 
tel domaine, nécessite qu'il doit maîtriser des outils et des opérations intellectuels relatifs à ce domaine. $\mathrm{Si}$ les connaissances conceptuelles (les savoirs) sont disponibles à tout le monde dans tous les domaines, on acquiert les savoir-faire à travers un entraînement dans un établissement scolaire à travers l'observation de différentes situations filtrées. il faut signaler que l'apprentissage des compétences aident les apprenants(es) à les réemployer ultérieurement dans de nouveaux contextes et dans des nouvelles situations.

Les apprenants(es) des langues vivantes étrangères sont appelés(es) d'apprendre à développer ces savoir-faire à côté d'enrichir leurs savoirs dans les deux codes de la langue; code oral et code écrit. Les savoir-faire dans le domaine de l'expression orale et écrite constituent les compétences de ces deux facettes d'expression. L'essentiel est de découvrir les compétences nécessaires pour chaque niveau langagier car la réussite du travail compte sur le bon choix de telles compétences (on choisit les compétences convenables à chaque niveau d'apprentissage).

En bref, les trois concepts (savoirs - savoir-faire - et savoirêtre) sont des trois dimensions composantes le concept de compétence. C.- à- d., telle ou telle compétence se compose de trois dimensions importantes; la dimension épistémologique relative aux connaissances (les savoirs), la dimension procédurale relative aux habiletés (les savoir-faire) et la dimension affective relative aux attitudes (les savoir-être). 
Signalons qu'il est presque impossible de développer telle ou telle compétence (en compréhension orale et écrite, en expression orale et écrite) sans prendre en compte les trois aspects des savoirs (savoirs - savoir-faire - et savoir-être).

\section{Savoir-être et expression (orale - écrite).}

Le processus d'enseignement /apprentissage consiste, au fur et à mesure, à développer le niveau des apprenants(es) en général et plus particulièrement leur niveau en FLÉ; leur niveau dans toutes les compétences langagières et linguistiques au même titre leurs attitudes et leurs traits de personnalité contribuant à faire de nos apprenants(es) des sujets autonomes.

Plusieurs chercheurs(ses), linguistes, didacticiens(nes) comme : (Péris E., 2009) et (Smuk M., 2014) sont presque d'accord sur la nécessité de développer les savoir-être chez nos apprenants(es). Ces savoir-être, d'après ces spécialistes, peuvent contribuer à construire des traits d'autonomie, d'autoanalyse, d'autorégulation et d'autoévaluation chez un(e) apprenant(e) de FLÉ. Ces attitudes sont vues essentielles pour tous les types de compétences (soit les compétences de compréhension orale et écrite, soit les compétences de l'expression orale et écrite).

Autrement dit, ces traits déjà mentionnés font partie intégrante de l'enseignement/apprentissage de toutes les compétences d'une langue étrangère (c.-à-d., les compétences de la compréhension orale et écrite et l'expression orale et écrite). Notre travail focalise sur les compétences de l'expression orale et écrite. 
Pour l'apprentissage de la langue étrangère et de ses compétences parmi lesquelles, on trouve les compétences de l'expression orale et écrite, l'apprenant(e) doit être en mesure de :

- Déterminer, nommer et identifier ses atouts d'apprentissage en général;

- Déterminer, nommer et identifier ses atouts d'apprentissage de la langue et de ses compétence (dans notre cas celles de l'expression (orale et écrite));

- Déterminer, nommer et identifier ses points faibles concernant le processus d'apprentissage en général;

- Déterminer, nommer et identifier ses points faibles concernant le processus d'apprentissage de la langue et de ses compétences (dans notre cas celles de l'expression (orale et écrite));

- Déterminer et saisir les traits personnels constituant une entrave à la perfection de telle ou telle compétence et dans certains cas l'accepter;

- Intégrer des connaissances sur le soi dans la conception de son processus d'apprentissage et du choix des stratégies adoptées pour atteindre ses objectifs;

- Délimiter les champs d'intérêt liés au processus de l'enseignement/apprentissage de la langue;

- Faire des choix au sein des moyens, des outils et des matériaux les plus appropriés à ses objectifs et à ses besoins; 
- Déterminer ses sources de satisfaction;

- Déterminer et identifier les sources des difficultés lors d'exécuter les activités en général et notamment celles qui sont liées aux caractéristiques individuelles;

- Apprécier le degré de difficulté de chaque activité et expliquer les raisons de cette difficulté;

- Choisir les meilleurs moyens de faire face à chaque type de difficulté. 


\section{Étude du champs.}

La recherche en cours vise essentiellement à développer les compétences de deux facettes d'expression (orale et écrite), et les savoir-être nécessaires pour les apprenants(es) de FLÉ au niveau secondaire par la voie d'employer les activités théâtrales. Afin d'atteindre les objectifs de cette recherche, on a conçu des outils et des instruments nombreux comme :

- Élaboration d'une liste de compétences de l'expression (orale/ écrite) vue nécessaire pour les apprenants de FLÉ au niveau secondaire;

- Élaboration d'une liste de savoir-être vue nécessaire pour les sujets de ce niveau d'apprentissage;

- Élaboration d'un test de compétences de deux facettes d'expression orale et écrite pour contrôler le niveau des sujets de ce niveau d'apprentissage avant et après l'intervention;

- Élaboration d'une grille d'observation pour contrôler le degré des savoir-être chez les sujets de ce niveau d'apprentissage pour contrôler leur niveau avant et après la tentative;

- Élaboration d'une grille d'évaluation pour contrôler le niveau des apprenants de FLÉ dans les compétences de l'expression orale; 
- Conception d'un cahier d'activités en employant des activités théâtrales pour développer les compétences de deux facettes d'expression et les savoir-être relatifs à ces types de compétences;

\section{Les outils et les procédures de la recherche actuelle en détail.}

Élaboration d'une liste de compétences de l'expression (orale/ écrite) vue nécessaire pour les apprenants(es) de FLÉ au niveau secondaire.

\section{Objectif de la liste.}

Tout d'abord, cette liste a constitué une procédure de recherche essentielle. Elle a pour objectif la découverte de compétences de deux facettes d'expression (orale et écrite). Cette liste, dans sa forme initiale, a été présentée aux membres de jury. Cette liste a été évaluée suivant une échelle de degré d'importance (très important, important, pas important). Les juges l'ont appréciée et ont proposé quelques modifications dont le chercheur a pris en considération dans la forme définitive. Cette liste, dans sa forme définitive, ( $C f$., Annexe No. (1)) a compris deux compétences essentielles et dix sous-compétences portant sur l'expression correcte (oralement et par écrit) dans des situations de la vie personnelle, sociale, professionnelle et familiale quotidiennes. Les sous-compétences ont mis l'accent sur les différentes phases de l'expression soit à l'oral, soit à l'écrit; concernant l'oral, les phases traitées ont porté sur la prononciation, l'intonation, le contenu lexical, le contenu contextuel, et les règles grammaticales, concernant l'écrit, les 
phases traitées ont porté sur la ponctuation, le contenu lexical, le contenu contextuel, les règles grammaticales et orthographiques.

\section{Importance de la liste.}

Cette liste était importante dans la mesure de mettre en relief les compétences de deux facettes d'expression (orale/écrite) nécessaires pour les apprenants de FLÉ de ce niveau d'apprentissage. Elle a constitué une procédure de recherche de base pour traiter la problématique de la recherche actuelle.

\section{Élaboration d'une liste de savoir-être vue nécessaire pour les sujets de ce niveau d'apprentissage.}

\section{Objectif de la liste.}

Cette liste a été également considérée comme une procédure de la recherche. Elle a été comme un point de départ pour concevoir la grille d'observation employée dans le cadre de la recherche actuelle. Elle a donc visé à découvrir les savoir-être vus nécessaires pour les sujets de ce niveau d'apprentissage (niveau secondaire). Cette liste, dans sa forme initiale, a été présentée aux membres de jury pour valider son contenu. Les juges l'ont appréciée et ont proposé quelques modifications dont le chercheur a pris en compte dans la forme finale. La liste initiale a été évaluée suivant une échelle de trois valeurs suivant le seuil d'importance (très importante - importante - pas importante). La liste, dans sa forme définitive ( $C f$., Annexe No. (2)), a compris dix savoir-être vus nécessaires pour les apprenants de FLÉ de ce niveau d'apprentissage. Les savoir-être ont essentiellement porté sur la capacité de joindre la parole aux 
signes non-verbaux, la capacité de s'enthousiasmer et d'enthousiasmer ses pairs, la confiance en soi, la communication facile avec les autres, le respect du niveau langagier de ses collègues, la capacité d'assumer une responsabilité collective, la précision de ses côtés faibles et forts en expression ...etc.

\section{Importance de la liste.}

Cette liste était importante dans le cadre du développement de quelques uns des savoir-être vus nécessaires pour les apprenants de FLÉ de ce niveau d'apprentissage (le niveau secondaire). Elle a été constituée comme une procédure de recherche de base. Ces savoir-être constituent le noyau de pratiquer les activités théâtrales employées pour développer les compétences de deux facettes d'expression.

Élaboration d'un test de compétences de deux facettes d'expression (orale et écrite) pour contrôler le niveau des sujets de ce niveau d'apprentissage avant et après

\section{l'intervention.}

\section{Objectif du test.}

Ce test de compétences de deux facettes d'expression (orale / écrite) a pour objet le contrôle du niveau des apprenants(es) de FLÉ, à la $2^{\text {ème }}$ année du cycle secondaire avant et après l'intervention. Ce test a été présenté à quelques juges, spécialistes de méthodologie, de didactique de FLÉ, et de linguistique pour valider son contenu. Dans sa forme définitive (Cf., Annexe No. (4)), il s'est composé de deux parties; la première partie est consacrée à l'aspect oral (cette partie a 
compris deux questions essentielles), la deuxième partie est consacrée à l'aspect écrit (cette partie a compris cinq questions essentielles). Signalons que l'aspect oral a été corrigé suivant une grille d'évaluation conçue à ce propos $(C f$., Annexe No. (8)). Le tableau suivant met l'accent sur l'aspect descriptif du test de compétences de deux facettes d'expression.

\section{Tableau No. ( 1 ).}

L'aspect descriptif des items du test de compétences de l'expression orale et écrite ( $C f$., Annexe No. (4)).

\begin{tabular}{|c|c|c|c|c|c|}
\hline No. & $\begin{array}{c}\text { Les } \\
\text { questions } \\
\text { du test } \\
\text { (orales et } \\
\text { écrites). }\end{array}$ & $\begin{array}{c}\text { Les } \\
\text { aspects } \\
\text { mesurés } \\
\text { par les } \\
\text { question. }\end{array}$ & $\begin{array}{c}\text { Les } \\
\text { items de } \\
\text { chaque } \\
\text { question. }\end{array}$ & $\begin{array}{c}\text { Les phases } \\
\text { relatives aux } \\
\text { items. }\end{array}$ & $\begin{array}{c}\text { Les compétences } \\
\text { mesurées. }\end{array}$ \\
\hline 1. & $\begin{array}{c}1^{\text {ère }} \\
\text { question. }\end{array}$ & & $\begin{array}{l}\text { Un seul } \\
\text { item. }\end{array}$ & $\begin{array}{c}\text { Toutes les } \\
\text { phases de } \\
\text { l'aspect oral. }\end{array}$ & $\begin{array}{c}\text { Toutes les sous- } \\
\text { compétences de } \\
\text { l'aspect oral. }\end{array}$ \\
\hline 2. & $\begin{array}{c}2^{\text {ème }} \\
\text { question. }\end{array}$ & $\begin{array}{l}\text { Aspect } \\
\text { oral. }\end{array}$ & $\begin{array}{l}\text { Un seul } \\
\text { item. }\end{array}$ & $\begin{array}{c}\text { Toutes les } \\
\text { phases de } \\
\text { l'aspect écrit. }\end{array}$ & $\begin{array}{c}\text { Toutes les sous- } \\
\text { compétences de } \\
\text { l'aspect oral. }\end{array}$ \\
\hline 3. & $\begin{array}{c}3^{\text {ème }} \\
\text { question. }\end{array}$ & $\begin{array}{l}\text { Aspect } \\
\text { écrit. }\end{array}$ & $\begin{array}{l}\text { Plusieurs } \\
\text { items. }\end{array}$ & $\begin{array}{c}\text { Phase de } \\
\text { ponctuation et } \\
\text { d'orthographe. }\end{array}$ & $\begin{array}{c}\text { Respecter les } \\
\text { marques de } \\
\text { ponctuation lors } \\
\text { de l'écriture./ } \\
\text { Respecter les } \\
\text { règles } \\
\text { d'orthographe lors } \\
\text { d'écrire. }\end{array}$ \\
\hline
\end{tabular}




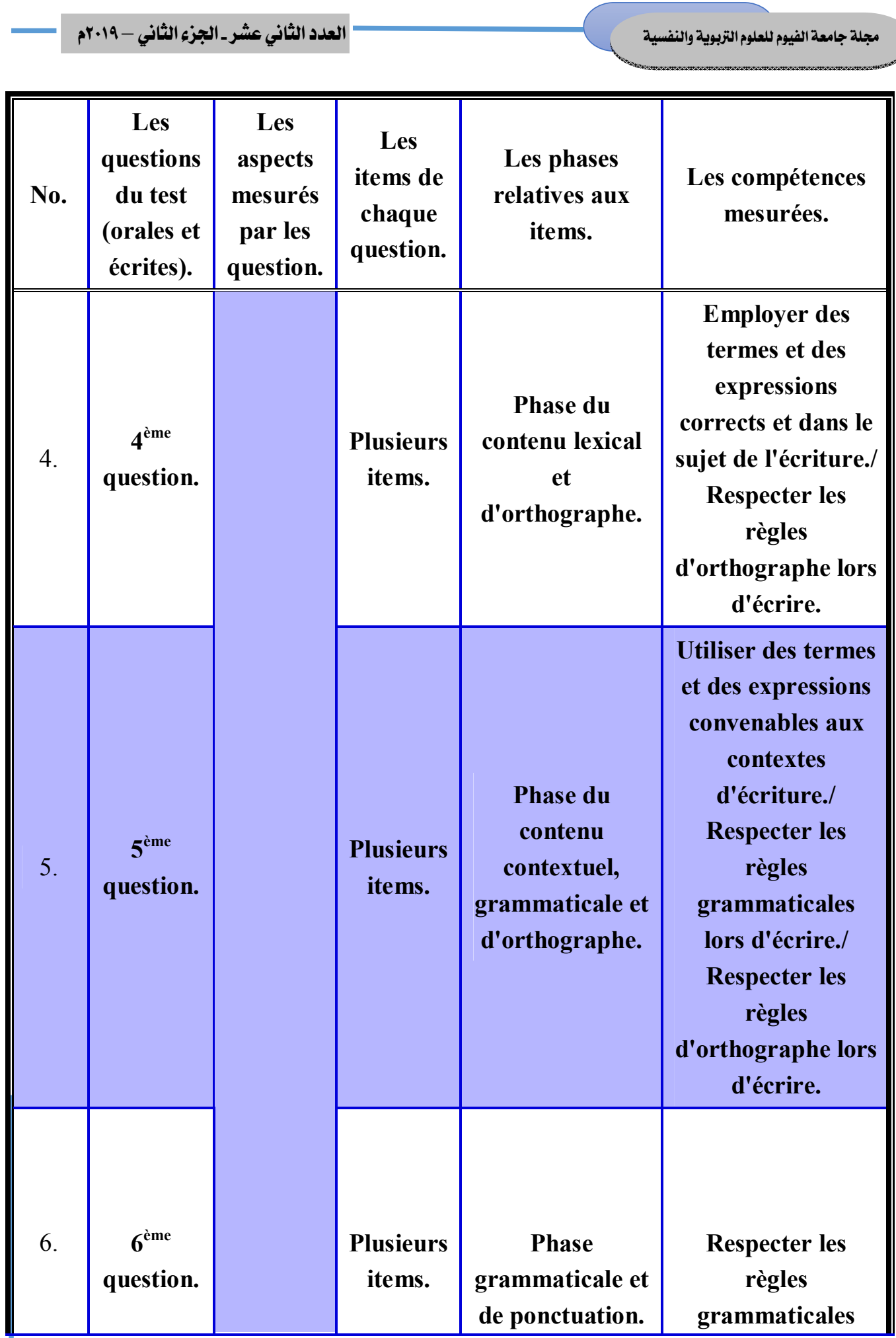




\begin{tabular}{|c|c|c|c|c|c|}
\hline No. & $\begin{array}{c}\text { Les } \\
\text { questions } \\
\text { du test } \\
\text { (orales et } \\
\text { écrites). }\end{array}$ & $\begin{array}{c}\text { Les } \\
\text { aspects } \\
\text { mesurés } \\
\text { par les } \\
\text { question. }\end{array}$ & $\begin{array}{c}\text { Les } \\
\text { items de } \\
\text { chaque } \\
\text { question. }\end{array}$ & $\begin{array}{c}\text { Les phases } \\
\text { relatives aux } \\
\text { items. }\end{array}$ & $\begin{array}{l}\text { Les compétences } \\
\text { mesurées. }\end{array}$ \\
\hline & & & & & $\begin{array}{c}\text { ponctuation lors } \\
\text { d'écrire. }\end{array}$ \\
\hline 7. & $\begin{array}{c}7^{\text {ème }} \\
\text { question. }\end{array}$ & & $\begin{array}{l}\text { Plusieurs } \\
\text { items. }\end{array}$ & $\begin{array}{c}\text { Phase } \\
\text { orthographique, } \\
\text { lexicale et } \\
\text { grammaticale. }\end{array}$ & $\begin{array}{c}\text { Respecter les } \\
\text { règles } \\
\text { d'orthographe lors } \\
\text { d'écrire./ } \\
\text { Employer des } \\
\text { termes et des } \\
\text { expressions } \\
\text { corrects et dans le } \\
\text { sujet de l'écriture./ } \\
\text { Respecter les } \\
\text { règles } \\
\text { grammaticales } \\
\text { lors d'écrire. }\end{array}$ \\
\hline
\end{tabular}

\section{Importance du test.}

L'importance de ce test est de découvrir les lacunes des apprenants(es) de FLÉ dans les compétences de l'expression orale et écrite. Il a été employé comme un outil de mesure dans le cadre de contrôler le niveau des apprenants de FLÉ (les sujets du groupe de l'étude avant et après l'intervention).

\section{Passation pilote du test.}

Le chercheur a opéré une application pilote du test de compétences de deux facettes d'expression afin de calculer : 


\section{Durée du test;}

Pour calculer la durée de l'aspect écrit du test, on a suivi la technique statistique ci-dessous :

Durée du test $=$

Total des temps pris par chacun des sujets du groupe de l'étude pilote.

Durée du test $=(90)$ minutes +5 minutes consacrées aux consignes du test $=(95)$ minutes.

\section{Fidélité du test;}

Le chercheur a appliqué et a réappliqué le test dans un intervalle de (15) jours, ensuite il a utilisé la technique statistique de (SPSS) pour calculer le coefficient de corrélation entre les deux applications. Il a trouvé que l'indice de fidélité est (0.907). F. $=0.907$.

Donc, le test est fidèle.

\section{Validité du test;}

Le chercheur a calculé la validité à partir de la fidélité comme suit :

Donc, la validité $=$ Fidélité $\sqrt{=(0.952)}$.

Donc, le test est valide.

\section{L'indice de facilité/difficulté du test.}

Pour calculer l'indice de facilité / difficulté du test de compétences de l'expression orale et écrite à employer dans le cadre de l'étude actuelle, le chercheur a appliqué l'indice pour chacun des items du test, puis il l'a fait pour le test en entier. Il a 
trouvé que l'indice pour le test et ses items est entre $(0.25 \&$ 0.80 ) et ces résultats sont suffisants pour que l'indice de facilité/difficulté du test et de ses items soit valide.

Donc, le test est valide à l'échelle de facilitéldifficulté.

\section{Critères de notation.}

Le test de compétences de l'expression orale et écrite se compose de (7) questions dont (2) questions sont consacrées à l'aspect oral et (5) questions sont consacrées à l'aspect écrit. On a consacré (10) points pour chacun des questions de l'aspect oral (Cf. Annexe No. (8)) pour évaluer les phases composantes l'aspect oral : phase du contenu, phase lexicale, phase grammaticale, phase phonologique : on a consacré (4) points pour la phase du contenu et (6) points pour les autres. Or, (2) points pour chacune d'autres phases. Pour l'aspect écrit, on a consacré (4) points pour chaque question pour évaluer les différentes phases de l'aspect écrit : phase de ponctuation, phase du contenu lexical et contextuel, phase de règles grammaticales et phase d'orthographe. Or, la note totale du test $=(40)$ points.

Élaboration d'une grille d'observation pour contrôler le degré des savoir-être chez les sujets de ce niveau d'apprentissage pour contrôler leur niveau avant et après la tentative.

\section{Objectif de la grille d'observation.}

Cette grille d'observation a visé à contrôler les savoir-être nécessaires pour les apprenants(es) de FLÉ au niveau 
secondaire. On a employé cette grille avant et après l'intervention. Cette grille d'observation nous a donnés l'occasion de surveiller le progrès fait au sein des savoir-être chez nos apprenants(es). La forme initiale de cette grille a été présentée à un jury composé de spécialistes de méthodologie, de didactique de FLÉ, et de spécialistes en linguistique pour la valider du point de vue du contenu. La forme définitive a compris dix items focalisant sur les savoir-être nécessaires pour ce niveau d'apprentissage $(C f$., Annexe No. (5)). À travers cette grille d'observation, les apprenants(es) de FLÉ ont été évalués(es) selon une échelle de trois degrés de maîtrise (3 (degré maximal), 2 (degré moyen) et 1 (degré faible)). La note totale de cette grille $=30$ points et la note minimale $=10$ points. Le tableau cidessous (Tableau No. (5)) met l'accent sur l'aspect descriptif de la grille d'observation.

\section{Validation de la grille d'observation.}

Le chercheur a opéré une application pilote dans une visée de valider la grille d'observation avant l'application dans le cadre de la tentative. Afin de valider le contenu, il a suivi des procédures comme la présentation de la grille à un jury composé de méthodologues, didacticiens(nes), linguistes de français. Ils(elles) ont proposé quelques modifications dont le chercheur a pris en considération. Le chercheur a vérifié également la fidélité, et la validité en employant la technique statistique (SPSS). 
- Indice de fidélité calculée $=(0.9188)$ et il l'a trouvé suffisant pour que la grille soit fidèle.

- Indice de validité calculée $=\quad$ Fidélité $=\sqrt{(0.9585) \text { et }}$ cette valeur a été suffisante pour que la grille soit valide. À la lueur des avis des membres de jury, le chercheur a groupé les (10) savoir-être de la forme définitive de la grille en (cinq) dimensions dont les détails existent dans le tableau ci-dessous.

Tableau No. ( 2 ).

L'aspect descriptif des savoir-être contenus dans la grille d'observation ( $C f$., Annexe No. (5)).

\begin{tabular}{|c|c|c|}
\hline No. & $\begin{array}{l}\text { Les dimensions } \\
\text { des savoir-être. }\end{array}$ & $\begin{array}{l}\text { Les comportements relatifs à } \\
\text { chacune des dimensions. }\end{array}$ \\
\hline \multirow[t]{2}{*}{1.} & \multirow{2}{*}{$\begin{array}{c}1^{\text {ère }} \text { dimension : la dimension } \\
\text { de manifester l'ouverture de } \\
\text { l'esprit. }\end{array}$} & $\begin{array}{l}\text { - Joindre la parole aux signes } \\
\text { non-verbaux dans le cadre } \\
\text { de l'activité. }\end{array}$ \\
\hline & & $\begin{array}{l}\text { - Surmonter les obstacles lors } \\
\text { d'exécuter les activités. }\end{array}$ \\
\hline \multirow[t]{2}{*}{2.} & \multirow{2}{*}{$\begin{array}{c}2^{\text {ème }} \text { dimension : la dimension } \\
\text { de manifester l'adaptabilité et } \\
\text { la flexibilité. }\end{array}$} & $\begin{array}{l}\text { - Respecter les opinions et les } \\
\text { décisions prises dans le } \\
\text { cadre du groupe. }\end{array}$ \\
\hline & & $\begin{array}{l}\text { - } \text { Etre ouvert aux suggestions, } \\
\text { aux différentes façons } \\
\text { d'agir. }\end{array}$ \\
\hline
\end{tabular}




\begin{tabular}{|c|c|c|}
\hline No. & $\begin{array}{l}\text { Les dimensions } \\
\text { des savoir-être. }\end{array}$ & $\begin{array}{l}\text { Les comportements relatifs à } \\
\text { chacune des dimensions. }\end{array}$ \\
\hline \multirow{2}{*}{3.} & \multirow{2}{*}{$\begin{array}{l}3^{\mathrm{ème}} \text { dimension : la dimension } \\
\text { de manifester la conscience de } \\
\text { son identité personnelle. }\end{array}$} & $\begin{array}{c}\text { - Avoir confiance en soi lors } \\
\text { d'exécuter les activités. }\end{array}$ \\
\hline & & $\begin{array}{c}\text { - Assumer une responsabilité } \\
\text { collective. }\end{array}$ \\
\hline \multirow[t]{2}{*}{4.} & \multirow[t]{2}{*}{$\begin{array}{l}4^{\text {ème }} \text { dimension : la dimension } \\
\text { de manifester son autonomie. }\end{array}$} & $\begin{array}{l}\text { - Préciser ses côtés forts et } \\
\text { faibles en ce qui concerne } \\
\text { les compétences de } \\
\text { l'expression. }\end{array}$ \\
\hline & & $\begin{array}{l}\text { - Préciser ses atouts pour ce } \\
\text { qui concerne les } \\
\text { compétences } \\
\text { l'expression. }\end{array}$ \\
\hline \multirow[t]{2}{*}{5.} & \multirow{2}{*}{$\begin{array}{c}5^{\mathrm{ème}} \text { dimension : la dimension } \\
\text { de manifester sa coopération } \\
\text { et sa collaboration avec ses } \\
\text { pairs. }\end{array}$} & $\begin{array}{l}\text { - Se communiquer facilement } \\
\text { avec une variété de } \\
\text { personnes. }\end{array}$ \\
\hline & & $\begin{array}{l}\text { S'enthousiasmer et } \\
\text { enthousiasmer les autres } \\
\text { dans le groupe du travail. }\end{array}$ \\
\hline
\end{tabular}

\section{Importance de la grille de l'observation.}

Cette grille d'observation était, donc, importante dans la mesure de découvrir le jusqu'à quel point les apprenants de FLÉ au niveau secondaire maîtrisent-ils ces savoir-être?. Elle était donc destinée à mesurer les savoir-être avant et après la tentative. 
Élaboration d'une grille d'évaluation pour contrôler le niveau des apprenants de FLÉ dans les compétences de l'expression orale.

\section{Objectif de la grille d'évaluation.}

Cette grille d'évaluation a été conçue dans une visée d'évaluer les compétences de l'expression orale de façon objective. Cette grille est, en effet, une échelle d'évaluation employée pour mesurer les différentes phases des compétences de l'expression orale ( $C f$., Annexe No. (8)). Les phases évaluées sont : phase du contenu, phase lexicale, phase grammaticale, phase phonologique. On a consacré (10) points pour chaque question de l'expression orale; on a consacré (4) points pour la phase de contenu et (6) points pour les autres. Or, (2) points pour chacune d'autres phases.

\section{Importance de la grille de l'évaluation.}

Cette grille d'évaluation a tiré son importance pour contrôler, de façon objective, le niveau des apprenants de FLÉ au cycle secondaire avant et après l'intervention. Cette grille nous a aidés à savoir le progrès fait au sein du développement des savoir-être.

Conception d'un cahier d'activités en employant les activités théâtrales pour développer les compétences de deux facettes d'expression et les savoir-être relatifs à ces types de compétences.

Introduction du cahier d'activité : dans cette petite introduction, le chercheur a clarifié ce qu'on désigne par les 
activités et les représentations théâtrales pour le développement des compétences de l'expression orale et écrite chez les apprenants de FLÉ au cycle secondaire et le développement des savoir-être chez les mêmes sujets. le chercheur a conçu les exercices relatifs aux compétences de l'expression orale et écrite du livre scolaire en employant les activités théâtrales.

Objectifs généraux du cahier d'activités : dans cette partie, le chercheur a mis l'accent sur les objectifs généraux de ce cahier d'activités comme suit :

- S'exprimer correctement à l'oral en parlant dans des sujets de la vie familiale, sociale, professionnelle et quotidienne.

- S'exprimer correctement à l'écrit dans des sujets de la vie familiale, sociale, professionnelle et quotidienne.

- Développer les savoir-être nécessaires pour les apprenants(es) de FLÉ de ce niveau d'apprentissage.

Objectifs spécifiques du cahier d'activités : dans cette partie, le chercheur a focalisé sur les objectifs opérationnels de toutes les leçons du livre scolaire notamment ceux qui sont relatifs aux compétences de l'expression orale et écrite et également aux savoir-être nécessaires pour les apprenants(es) de ce niveau d'apprentissage. Ces compétences et ces savoir-être ont été comme suit :

- Prononcer correctement les sons français constituant des difficultés pour les arabophones comme le son $[\mathrm{P}]$, le son $[\mathrm{Y}]$, le son $[\mathrm{U}] \ldots$...etc. 
- Respecter, lors de parler, les types de phrases; phrases affirmatives, interrogatives, exclamatives ...etc.

- Employer des termes et des expressions corrects et dans le sujet de l'expression présenté.

- Utiliser des termes et des expressions dans un contexte oral correct.

- Respecter les règles grammaticales lors de parler.

- Fonctionner correctement, lors d'écrire, les marques de ponctuation comme (. - , - : - ; ? - ! ...etc.).

- Employer des termes et des expressions corrects et dans le sujet d'écriture.

- Respecter les règles grammaticales lors d'écrire.

- Utiliser des termes et des expressions dans leur contexte correct lors d'écrire.

- Écrire des mots et des phrases corrects du point de vue orthographique.

- Savoir joindre la parole aux signes non-verbaux dans les différentes situations.

- Savoir s'enthousiasmer et enthousiasmer les autres dans un groupe donné.

- Avoir confiance en soi dans un groupe donné.

- Fréquenter facilement les groupes sociaux. 
- Participer activement aux activités collectives.

- Assumer une responsabilité collective.

- Se communiquer facilement avec tous les membres d'un groupe.

- S'impliquer dans les discussions opérées dans un groupe.

- Respecter les décisions prises dans le cadre d'un groupe donné.

- Préciser ses atouts pour ce qui concerne les compétences de l'expression;

- Préciser ses côtés forts et faibles en ce qui concerne les compétences de l'expression.

Préparation de contenu du cahier d'activités : dans cette partie, le chercheur a reformulé les exercices du livre scolaire notamment ceux qui sont relatifs aux compétences de deux facettes d'expression et aux savoir-être visés. Le chercheur a intégré les activités théâtrales dans les activités langagières contenues dans le livre scolaire pour développer les compétences et les savoir-être visés. Le déroulement des activités se sont faites comme suit :

- Étape de déterminer les objectifs et les matériaux nécessaires.

- Étape de réviser les savoirs (les connaissances linguistiques à développer), les savoir-faire (les 
compétences de l'expression orale - écrite) et les savoirêtre.

- Étape de représenter les spectacles et les actes théâtraux.

- Étape de discuter les savoirs (les connaissances linguistiques développées), les savoir-faire développés (les compétences de l'expression orale et écrite), et les savoir-être (les comportements observés).

Évaluation au sein du cahier des activités : dans cette partie, le chercheur a employé les deux modalités d'évaluation; évaluation formative et évaluation sommative. L'évaluation formative s'est faite pendant et à la fin des activités présentées pour aborder les exercices de chaque leçon à travers un test élaboré à ce propos (Cf. Annexe No. ( 7 )). L'évaluation sommative s'est faite avant et après l'intervention pour contrôler le niveau des apprenants de FLÉ avant la tentative, pour savoir le degré de leur progrès et pour assurer l'efficacité, de façon quantitative, des activités théâtrales dans le développement des compétences et des savoirêtre visés ( $C f$. Annexes No. (4) et ( 5 )). Les deux modalités d'évaluation sont complémentaires dans la mesure de l'analyse (mixte); quantitative et qualitative des résultats obtenus.

\section{Choix de l'échantillon et exécution de la tentative de la recherche :}

Public visé : le chercheur a choisi son groupe de la recherche parmi les apprenants de FLÉ de la $2^{\text {ème }}$ année secondaire à l'école de (Khausos de jeunes garçons) au gouvernorat du Caire pendant le deuxième semestre de 
l'année scolaire 2018/2019 (pendant les deux mois de Mars et d'Avril). Il a commencé la tentative le dimanche 3 mars 2019 et a fini le jeudi 26 Avril 2019, avec un nombre de (35) apprenants. Il a travaillé le cahier d'activités élaboré en employant les activités théâtrales.

$\checkmark$ Pré-application des outils de la recherche : pour s'assurer du niveau des sujets du groupe de l'étude avant l'intervention, le chercheur a appliqué les outils de la recherche; le test des compétences de l'expression orale et écrite, la grille d'observation pour contrôler les savoir-être avant la tentative. Cette pré-application des outils de la recherche a contribué à contrôler le niveau des apprenants de FLÉ avant la tentative, comme un point de départ pour commencer le processus d'enseignement par l'emploi des activités théâtrales.

$\checkmark$ Enseignement du cahier d'activités : tout d'abord, le chercheur a distribué le cahier d'activités aux apprenants du groupe de l'étude. Pour garder l'objectivité du travail, un formateur de FLÉ a fait la tentative sous la direction du chercheur; le chercheur a surveillé ce formateur pendant la période de la tentative comme un guide du travail. il a assisté à toutes les sessions consacrées à la tentative pour s'assurer à l'application idéale des activités proposées. L'enseignement a duré ( 16 semaines/ environ 2 mois y compris la pré-application et la post-application des outils de la recherche). 
Post-application des outils de la recherche : après avoir terminé la tentative, le chercheur a fait la post-application des outils de la recherche (le test des compétences de l'expression orale et écrite et la grille d'observation élaborée pour contrôler le niveau des apprenants dans les savoir-être). Le chercheur a inscrit les notes brutes obtenues et a opéré le traitement statistique pour s'assurer l'efficacité des activités théâtrales pour le développement des compétences de l'expression orale et écrite et le développement des savoir-être chez les sujets du groupe de l'étude au niveau secondaire. Cette analyse des résultats a fait partie intégrale de la partie suivante de la recherche. 


\section{Étude expérimentale.}

\section{Les résultats de la recherche.}

Notre recherche actuelle a pour objet le développement des compétences de l'expression orale et écrite et les savoir-être par l'emploi des activités et des représentations théâtrales. Afin d'atteindre ces objectifs, le chercheur a élaboré quelques instruments (une liste de compétences de l'expression orale et écrite, une liste de savoir-être, un test de compétences de l'expression orale et écrite, une grille d'observation des savoirêtre, une grille d'évaluation employée pour contrôler le jusqu'à quel point les apprenants de FLÉ au niveau secondaire maîtrisent-ils les savoir-être ?...etc.). Le chercheur a validé ces instruments par les techniques statistiques convenables à ce propos. L'analyse statistique a visé à savoir si $/ \mathrm{s}^{\prime}$ :

- Il existe une différence statistiquement significative entre les moyennes des notes des sujets du groupe de l'étude dans tous les items du test de compétences de l'expression (orale - écrite) entre la pré et la post application du test en faveur de la post application au seuil de 0.01 .

- Il existe une différence statistiquement significative entre les moyennes des notes des sujets de l'étude dans les compétences de l'expression orale contenues dans le test des compétences de l'expression (orale et écrite) entre la pré et la post application du test en faveur de la post application du test au seuil de 0.01 . 
- Il existe une différence statistiquement significative entre les moyennes des notes des sujets de l'étude dans toutes les sous-compétences de l'expression orale contenues dans le test de compétences de l'expression (orale et écrite) entre la pré et la post application du test en faveur de la post application du test au seuil de 0.01 .

- Il existe une différence statistiquement significative entre les moyennes des notes des sujets du groupe de l'étude dans les items du test de compétences de l'expression (orale - écrite) en ce qui concerne les compétences de l'expression écrite entre la pré et la post application du test en faveur de la post application du test au seuil de 0.01 .

- Il existe une différence statistiquement significative entre les moyennes des notes des sujets de l'étude dans toutes les sous-compétences de l'expression écrite contenues dans le test des compétences de l'expression (orale et écrite) entre la pré et la post application du test en faveur de la post application du test au seuil de 0.01 .

- Il existe une différence statistiquement significative entre les moyennes des notes des sujets du groupe de l'étude dans la pré-post application des items de la grille d'observation concernant les savoir-être en faveur de la post application au seuil de 0.01 . 
Vérifier la première hypothèse de la recherche.

Pour vérifier la première hypothèse : «Il existe une différence statistiquement significative entre les moyennes des notes des sujets du groupe de l'étude dans tous les items du test de compétences de l'expression (orale - écrite) entre la pré et la post application du test en faveur $d$ et la post application du test au «seuil de $0.01 »$, le chercheur a employé le baguage statistique «SPSS». Après avoir appliqué cette technique statistique, on a obtenu le tableau ci-dessous :

\section{Tableau ( 3 ).}

Résultats relatifs au test en entier des compétences de l'expression orale et écrite chez les apprenants de FLÉ (au niveau secondaire).

\begin{tabular}{|c|c|c|c|c|c|c|c|}
\hline Test & $\mathbf{N}$ & M & É.T. & DL. & $\begin{array}{c}\text { « } \mathbf{T} » \\
\text { calculé }\end{array}$ & $\eta^{2}$ & S./NS. \\
\hline $\begin{array}{c}\text { Pré- } \\
\text { application. }\end{array}$ & & 16.46 & 3.119 & & & & \\
\hline $\begin{array}{l}\text { Post- } \\
\text { application. }\end{array}$ & 35 & 36.86 & 1.833 & 34 & 29.26 & 0.96 & \\
\hline
\end{tabular}

\section{Commentaire du tableau.}

S'on remarque le tableau ci-dessus, on trouve que le nombre des sujets du groupe de l'étude est $(\mathrm{N}=35)$, la moyenne des notes des sujets du groupe de l'étude dans les résultats de la préapplication du test est $(\mathrm{M}=16.46)$, la moyenne des notes des sujets du même groupe de la post-application du test est $(\mathrm{M}=$ 
36.86), l'écart type pour les sujets du même groupe dans les résultats de la pré-application du test est (É.T. = 3.119), l'écart type pour les sujets du même groupe de la post-application du test est $($ É.T. $=1.833)$, le degré de liberté est $(\mathrm{DL}=(\mathrm{N}-1)=$ 34), la valeur de «T» calculé est $(\mathrm{T}=29.26)$, le carré d'Éta est $\left(\eta^{2}=0.96\right)$, ainsi le seuil de signifiance est (S. au seuil de 0.01). Tous ces résultats ont clairement montré que les activités théâtrales étaient efficaces dans le développement des compétences de l'expression orale et écrite en entière.

Figure No. ( 1 ).

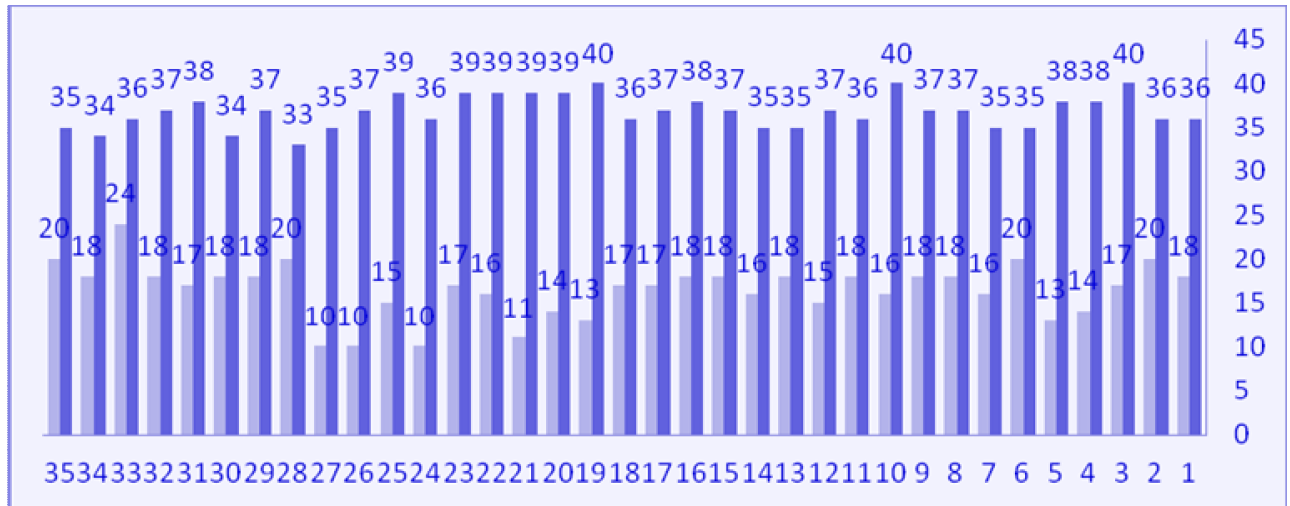

Pré 밀

\section{Analyse qualitative et interprétation des résultats.}

\section{Avant l'intervention.}

Après avoir analysé les résultats quantitativement, on les a analysés de façon qualitative comme suit :

- La majorité des sujets du groupe de l'étude $(100 \%),(\mathrm{N}=$ $35 / 35$ ) ont manifesté une faiblesse absolue en ce qui concerne toutes les compétences de l'expression orale et écrite. 
- Des apprenants (8.57\%), $(\mathrm{N}=3 / 35)$ sont énormément faibles dans les compétences de l'expression orale et écrite dans sa totalité; ils ont obtenu (moins de 10 notes sur 40 comme degré maximal) avant l'intervention;

- Des apprenants $(14.28 \%),(\mathrm{N}=5 / 35)$ sont très faibles dans les compétences de l'expression orale et écrite en entier; ils ont obtenu (de 10 à moins de 15 notes sur 40 comme degré maximal) avant l'intervention;

- Le nombre majoritaire des apprenants (77.14\%), $(\mathrm{N}=27 / 35)$ sont faibles dans les compétences de l'expression orale et écrite en entier; ils ont obtenu (moins de 20 notes sur 40 comme degré maximal) avant la tentative.

\section{Après l'intervention.}

- Tous les sujets du groupe de l'étude (100\% N = 35/35) sont améliorés dans toutes les compétences de l'expression orale et écrite.

- Peu d'apprenants $(\mathrm{N}=7 / 35)$ deviennent très bien dans ces compétences de l'expression orale et écrite; ils sont remarquablement améliorés et ont obtenu (de 33 à 35 notes sur 40 comme degré maximal) après l'intervention;

- Le nombre majoritaire des apprenants $(\mathrm{N}=28 / 35)$ deviennent excellents dans ces compétences de l'expression orale et écrite; ils sont énormément améliorés et ont obtenu (de 35 à 40 notes sur 40 comme degré maximal) après la tentative; 
- En un mot, les sujets du groupe de l'étude sont remarquablement améliorés dans toutes les compétences de l'expression orale et écrite. Cette amélioration est due de l'efficacité des activités théâtrales employées dans le cadre de l'étude actuelle.

\section{Vérifier la deuxième hypothèse de la recherche.}

Pour vérifier la deuxième hypothèse : «Il existe une différence statistiquement significative entre les moyennes des notes des sujets de l'étude dans les compétences de l'expression orale contenues dans le test entre la pré et la post application du test en faveur de la post application du test au seuil de $« 0.01 »$, le chercheur a employé le baguage statistique «SPSS». Après avoir appliqué cette technique statistique, on a obtenu le tableau cidessous :

\section{Tableau ( 4 ).}

Résultats relatifs au test des compétences de l'expression orale contenues dans le test de compétences de l'expression chez les apprenants de FLÉ (au niveau secondaire).

\begin{tabular}{|c|c|c|c|c|c|c|c||}
\hline Test & $\mathbf{N}$ & $\mathbf{M}$ & É. T. & DL. & $\begin{array}{c}\text { « T » } \\
\text { calculé }\end{array}$ & $\boldsymbol{\eta}^{2}$ & S./NS. \\
\hline $\begin{array}{c}\text { Pré- } \\
\text { application. }\end{array}$ & & 9.26 & 2.005 & & 27.211 & 0.956 & $\begin{array}{c}\text { S. au } \\
\text { seuil de } \\
0.01\end{array}$ \\
\cline { 1 - 4 } $\begin{array}{c}\text { Post- } \\
\text { application. }\end{array}$ & \multirow{2}{*}{35} & 18.91 & 1.040 & 34 & & & \\
\cline { 2 - 7 }
\end{tabular}




\section{Commentaire du tableau.}

S'on remarque le tableau ci-dessus, on trouve que le nombre des sujets du groupe de l'étude est $(\mathrm{N}=35)$, la moyenne des notes des sujets du groupe de l'étude dans les résultats de la préapplication du test est $(\mathrm{M}=9.25)$, la moyenne des notes des sujets du même groupe dans la post-application du test est $(\mathrm{M}=$ 18.91), l'écart type pour les sujets du même groupe dans les résultats de la pré-application du test est $(E ́ . T .=2.005)$, l'écart type pour les sujets du même groupe de la post-application du test est $($ É.T. $=1.040)$, le degré de liberté est $(\mathrm{DL}=(\mathrm{N}-1)=$ $34)$, la valeur de «T» calculé est $(\mathrm{T}=27.211)$, le carré d'Éta est $\left(\eta^{2}=0.956\right)$, ainsi le seuil de signifiance est (S. au seuil de 0.01). Tous ces résultats ont clairement montré que les activités théâtrales étaient efficaces dans le développement des compétences de l'expression orale contenues dans le test de compétences de l'expression orale et écrite.

Figure No. ( 2 ).

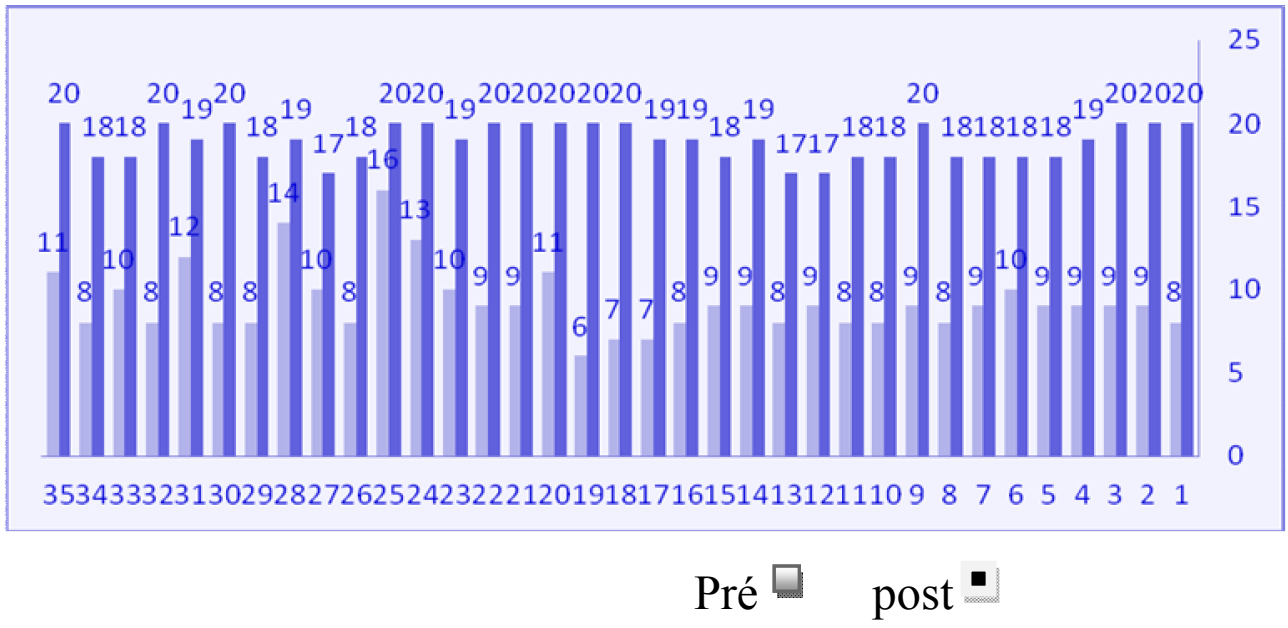




\section{Analyse qualitative et interprétation des résultats.}

\section{Avant l'intervention.}

Après avoir analysé les résultats quantitativement, on les a analysés de façon qualitative comme suit :

- Un nombre énorme d'apprenants (74.28\% N $\quad \mathrm{N}=26 / 35)$ ont été très faibles dans les compétences globales de l'expression orale contenues dans le test de l'expression orale et écrite; ils ont obtenu (de 5 à moins de 10 sur 20 comme degré maximal) avant l'intervention;

- Peu d'apprenants (11.42\% N = 4/35) ont manifesté un niveau un peu moyen dans le compétences de l'expression orale en gros notamment lorsqu'il s'agit de se présenter uniquement (c.à.d., dans les compétences de la vie personnelle); ils ont obtenu (10 notes sur 20 comme degré maximal) avant l'intervention;

- Tous les apprenants (100\% N = 35/35) ont manifesté une faiblesse remarquable dans les autres compétences de l'expression orale (c.à.d., dans les compétences de la vie sociale, familiale et professionnelle) avant la tentative.

\section{Après l'intervention.}

- Un nombre satisfaisant d'apprenants du groupe de l'étude (37.14\% $\mathrm{N}=13 / 35)$ deviennent aptes à s'exprimer oralement de façon considérable dans les situations de la vie personnelle, familiale, sociale et professionnelle; ils 
ont obtenu (de 16 à 18 sur 20 comme degré maximal) après l'intervention;

- Un nombre majoritaire d'apprenants du groupe de l'étude (62.85\% $\mathrm{N}=22 / 35)$ deviennent excellents(es) dans les compétences de l'expression orale; ils ont obtenu (de 19 à 20 sur 20 comme degré maximal) après l'intervention;

- Il est remarquable que tous les membres du groupe de l'étude $(100 \% \mathrm{~N}=35 / 35)$ deviennent aptes à s'exprimer dans presque toutes les situations proposées soit par leurs collègues soit par les formateurs notamment dans les dernières séances de la tentative. Ce qui a confirmé que les activités théâtrales employées au sein de l'entraînement ont été efficaces dans le développement des compétences de l'expression orale.

\section{Vérifier la troisième hypothèse de la recherche.}

Pour vérifier la troisième hypothèse : «Il existe une différence statistiquement significative entre les moyennes des notes des sujets de l'étude dans toutes les sous-compétences de l'expression orale contenues dans le test de compétences de l'expression orale et écrite entre la pré et la post application du test en faveur de la post application du test au seuil de «0.01», le chercheur a employé le baguage statistique «SPSS». Après avoir appliqué cette technique statistique, on a obtenu le tableau cidessous : 
Tableau ( 5 ).

Résultats relatifs au test des compétences de l'expression orale et écrite en ce qui concerne les sous-compétences de l'expression orale chez les apprenants de FLÉ (au niveau secondaire).

\begin{tabular}{||c|c|c|c|c|c|c|c||}
\hline $\begin{array}{c}\text { Les } \\
\text { compétences } \\
\text { de l'expression } \\
\text { orale } \\
\text { mesurées. }\end{array}$ & $\begin{array}{c}\text { Moyennes } \\
\text { pour la pré- } \\
\text { application. }\end{array}$ & $\begin{array}{c}\text { Moyennes } \\
\text { pour la } \\
\text { post- } \\
\text { application. }\end{array}$ & $\begin{array}{c}\text { É.T. pour la } \\
\text { pré- } \\
\text { application. }\end{array}$ & $\begin{array}{c}\text { É.T. pour la } \\
\text { post- } \\
\text { application. }\end{array}$ & $\begin{array}{c}\text { Valeur } \\
\text { de «T» } \\
\text { calculée. }\end{array}$ & $\eta^{2}$ & S./NS. \\
\hline \hline $\begin{array}{c}\text { Le contenu } \\
\text { contextuel. }\end{array}$ & 3.20 & 8.00 & 1.37 & 0.000 & 20.76 & 0.926 & $\begin{array}{c}\text { S. au } \\
\text { seuil } \\
\text { de } \\
\text { o.01 }\end{array}$ \\
\hline $\begin{array}{c}\text { Le } \\
\text { vocabulaire. }\end{array}$ & 1.97 & 3.74 & 0.618 & 0.443 & 16.23 & 0.885 & $\begin{array}{c}\text { S. au } \\
\text { seuil } \\
\text { de } \\
0.01\end{array}$ \\
\hline $\begin{array}{c}\text { La phase } \\
\text { phonologique. }\end{array}$ & 1.69 & 3.43 & 0.583 & 0.502 & 12.62 & 0.824 & $\begin{array}{c}\text { S. au } \\
\text { seuil } \\
\text { de } \\
0.01\end{array}$ \\
\hline $\begin{array}{c}\text { La phase } \\
\text { grammaticale. }\end{array}$ & 2.11 & 3.77 & 0.583 & 0.426 & 15.34 & 0.873 & $\begin{array}{c}\text { S. au } \\
\text { seuil } \\
\text { de } \\
\text { o.01 }\end{array}$ \\
\hline
\end{tabular}

\section{Commentaire du tableau.}

Suivant les données statistiques quantitatives présentées dans le tableau ci-dessus, on a remarqué que la valeur de «T» sont : concernant le contenu contextuel est (20.76), concernant le vocabulaire est (16.23), concernant la phase phonologique est (12.62), et la phase grammaticale est (15.34) et le seuil de signifiance est ( S. au seuil de 0.01). Sans entrer dans des détails statistiques, toutes les valeurs contenues dans le tableau cidessus ont confirmé l'efficacité des activités théâtrales dans le développement des compétences de l'expression orale en gros. 
Analyse qualitative et interprétation des résultats.

\section{Avant l'intervention.}

Après avoir analysé les résultats quantitativement, on les a analysés de façon qualitative comme suit :

- En ce qui concerne le contenu contextuel, presque tous les apprenants $(100 \% \mathrm{~N}=35 / 35)$ ont manifesté une faiblesse remarquable lors de s'exprimer dans les situations proposées (situations de la vie personnelle, sociale, familiale et professionnelle); ils ont obtenu (moins de 4 notes sur 8 comme note maximale) avant l'intervention;

- Concernant le vocabulaire, le nombre majoritaire des apprenants $(91.42 \% \mathrm{~N}=$ plus de $32 / 35)$ ont été, tout à fait, faibles soit dans le champs du choix du vocabulaire convenable aux situations proposées, soit dans le champs de l'emploi de ce vocabulaire; ils ont obtenu (moins de 2 points sur 4 points comme note maximale) avant la tentative;

- Pour ce qui concerne la phase phonologique, la plupart des apprenants (94.28\% $\mathrm{N}=33 / 35)$ ont été remarquablement faibles dans la prononciation de presque tous les sons français notamment les sons constituant des difficultés pour les arabophones comme : le son $/ \mathrm{P} /$, les voyelles orales et les voyelles nasales, dans l'intonation et dans le rythme; ils ont obtenu (moins de 2 points sur 4 comme point maximal) avant l'intervention; 
- Quant à la phase grammaticale, la plupart des apprenants (85.71\% $\mathrm{N}=30 / 35)$ ont été presque moyens sur le plan d'employer les règles grammaticales dans leurs discours; ils ont obtenu (de 0 à 2 points sur 4 comme point maximal) avant la tentative.

\section{Après l'intervention.}

Il est à remarquer que les apprenants ont été améliorés après avoir terminé la tentative comme suit :

- En ce qui concerne le contenu contextuel, presque tous les apprenants $(100 \% \quad \mathrm{~N}=35 / 35)$ deviennent aptes à s'exprimer correctement dans les différentes situations de la vie personnelle, sociale, familiale et professionnelle proposées. Les notes des apprenants se sont élevées et deviennent entre ( 7 et 8 notes sur 8 comme note maximale);

- Concernant le vocabulaire, tous les apprenants $(100 \% \mathrm{~N}$ $=35 / 35)$ deviennent capables d'employer un vocabulaire correct pour s'exprimer dans toutes les situations proposées. Les notes des apprenants se sont également élevées et deviennent entre ( 3 et 4 sur 4 comme note maximale);

- Pour ce concerne la phase phonologique, les apprenants $(100 \% \mathrm{~N}=35 / 35)$ deviennent capables de parler avec une prononciation et une intonation correctes dans toutes les situations proposées. Ils ont pu facilement prononcer les 
sons constituant une difficulté pour les arabophones et ils ont pu distinguer oralement leurs énoncés de façon compréhensible. Les notes des apprenants deviennent entre ( 3 et 4 sur 4 comme note maximale);

- Quant à la phase grammaticale, les apprenants se sont considérablement améliorés sur le plan d'employer les règles grammaticales de façon correcte lors de parler.

\section{Vérifier la quatrième hypothèse de la recherche.}

Pour vérifier la quatrième hypothèse : «Il existe une différence statistiquement significative entre les moyennes des notes des sujets du groupe de l'étude dans les items du test de compétences de l'expression en ce qui concerne les compétences de l'expression écrite entre la pré et la post application en faveur de la post application du test au seuil de «0.01», le chercheur a employé le baguage statistique «SPSS». Après avoir appliqué cette technique statistique, on a obtenu le tableau ci-dessous :

\section{Tableau ( 6 ).}

Résultats relatifs au test des compétences de l'expression orale et écrite en ce qui concerne les compétences de l'expression écrite. (au niveau secondaire).

\begin{tabular}{|c|c|c|c|c|c|c|c|}
\hline Test & $\mathbf{N}$ & $\mathbf{M}$ & É.T. & DL. & $\begin{array}{l}\text { «T» } \\
\text { calculé }\end{array}$ & $\eta^{2}$ & S./NS. \\
\hline Pré & \multirow[t]{2}{*}{35} & 8.34 & 1.878 & \multirow{2}{*}{34} & \multirow{2}{*}{25.91} & \multirow{2}{*}{0.95} & \multirow{2}{*}{$\begin{array}{c}\text { S. au } \\
\text { seuil de } \\
0.01\end{array}$} \\
\hline Post & & 18.30 & 1.158 & & & & \\
\hline
\end{tabular}




\section{Commentaire du tableau.}

S'on remarque le tableau ci-dessus, on trouve que le nombre des sujets du groupe de l'étude est $(\mathrm{N}=35)$, la moyenne des notes des sujets du groupe de l'étude dans les résultats de la préapplication du test est $(\mathrm{M}=8.34)$, la moyenne des notes des sujets du même groupe de la post-application du test est ( $\mathrm{M}=$ 18.30), l'écart type pour les sujets du même groupe dans les résultats de la pré-application du test est (É.T. $=1.878)$, l'écart type pour les sujets du même groupe de la post-application du test est (É.T. $=1.158)$, le degré de liberté est $(\mathrm{DL}=(\mathrm{N}-1)=$ 34), la valeur de «T» calculé est $(\mathrm{T}=25.91)$, le carré d'Éta est $\left(\eta^{2}=0.95\right)$, ainsi le seuil de signifiance est (S. au seuil de 0.01$)$. Tous ces résultats ont clairement montré que les activités théâtrales étaient efficaces dans le développement des compétences de l'expression écrite.

Figure No. ( 3 ).

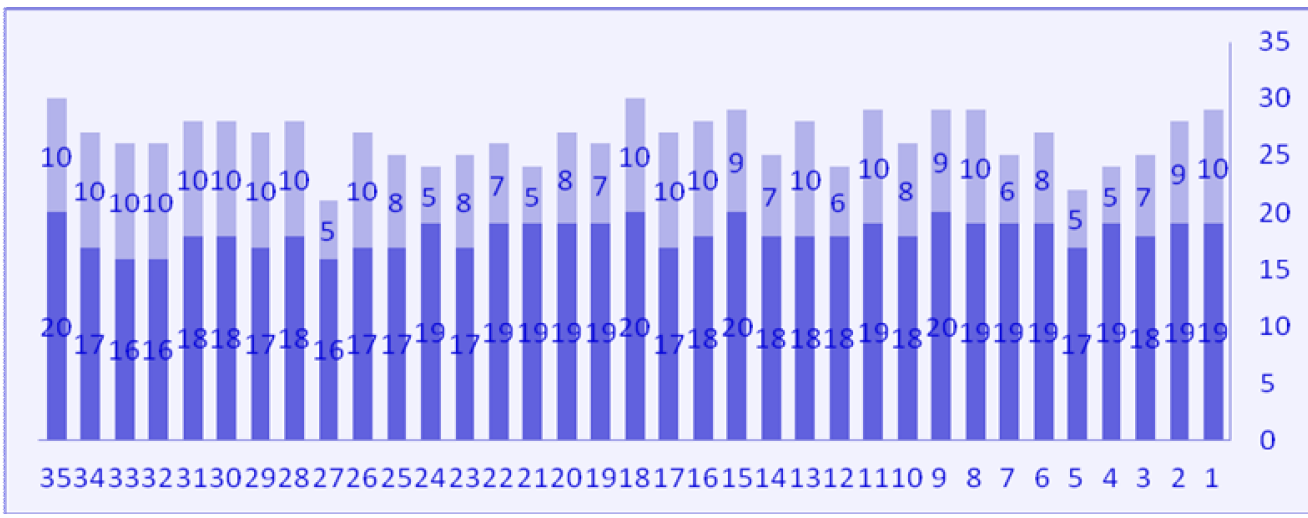

$$
\text { Pré } \square \text { post }-
$$

Analyse qualitative et interprétation des résultats. 


\section{Avant l'intervention.}

Après avoir analysé les résultats quantitativement, on les a analysés de façon qualitative comme suit :

- Un nombre d'apprenants du groupe de l'étude $(14.28 \% \mathrm{~N}$ $=5 / 35)$ ont été énormément faibles dans les compétences de l'expression écrite. Ils n'ont pas pu s'exprimer par écrit en général; ils ont obtenu des notes faibles dans tous les items des questions et tests consacrés à l'aspect écrit, ils ont le plus souvent obtenu (moins de 5 points sur 20 points comme point maximal) avant l'intervention;

- Le reste d'apprenants du groupe de l'étude $(85.71 \% \mathrm{~N}=$ 30/35) ont été faibles dans ces compétences de l'expression écrite. Ils ont obtenu des scores insatisfaisants dans tous les items et les tests consacrés à l'aspect écrit. Ces scores étaient (de 5 points jusqu'à moins de 10 points sur 20 points comme point maximal) avant l'intervention;

- Tous les apprenants ont manifesté une faiblesse lors de s'exprimer dans les différentes situations sauf les situations personnelles. Ils ont employé un vocabulaire incorrect, ils n'ont pas respecté les règles grammaticales, les règles d'orthographe et les marques de ponctuation. Ce qui a confirmé qu'ils ont été faibles dans toutes les phases de l'expression écrite avant la tentative. 


\section{Après l'intervention.}

On a remarqué que la situation a totalement changé après l'intervention comme suit :

- Un nombre considérable d'apprenants du groupe de l'étude $(48.57 \% \mathrm{~N}=17 / 35)$ ont manifesté une amélioration remarquable pendant et après la tentative. Ils deviennent capables de s'exprimer par écrit dans toutes les situations proposées (situations de la vie personnelle, familiale, sociale et professionnelle). Ces apprenants ont obtenu (de 16 à 18 points sur 20 points comme point maximal) après l'intervention;

- Le reste des apprenants (51.42\% $\mathrm{N}=18 / 35)$ ont été améliorés de façon remarquable. Ils ont obtenu des scores très élevés dans tous les items et les questions consacrés à l'aspect écrit. Ils ont obtenu (19 et 20 sur 20 points comme score maximal) après la tentative;

- Tous les apprenants du groupe de l'étude $(100 \% \mathrm{~N}=$ 35/35) deviennent excellents dans toutes les compétences de l'expression écrite.

\section{Vérifier la cinquième hypothèse de la recherche.}

Pour vérifier la cinquième hypothèse : «Il existe une différence statistiquement significative entre les moyennes des notes des sujets de l'étude dans toutes les sous-compétences de l'expression écrite entre la pré et la post application du test en faveur de la post-application du test au seuil de «0.01», le 
chercheur a employé le baguage statistique «SPSS». Après avoir appliqué cette technique statistique, on a obtenu le tableau cidessous :

Tableau ( 7 ).

Résultats relatifs au test des compétences de l'expression orale et écrite en ce qui concerne les sous-compétences de l'expression écrite. (au niveau secondaire).

\begin{tabular}{|c|c|c|c|c|c|c|c|}
\hline $\begin{array}{c}\text { Les } \\
\text { compétences de } \\
\text { l'expression } \\
\text { orale mesurées. }\end{array}$ & $\begin{array}{l}\text { Moyennes } \\
\text { pour la pré- } \\
\text { application. }\end{array}$ & $\begin{array}{c}\text { Moyennes } \\
\text { pour la } \\
\text { post- } \\
\text { application. }\end{array}$ & $\begin{array}{c}\text { É.T. pour } \\
\text { la pré- } \\
\text { application. }\end{array}$ & $\begin{array}{c}\text { É.T. pour } \\
\text { la post- } \\
\text { application. }\end{array}$ & $\begin{array}{c}\text { Valeur } \\
\text { de «T» } \\
\text { calculée. }\end{array}$ & $\eta^{2}$ & S./NS. \\
\hline $\begin{array}{c}\text { Le contenu } \\
\text { contextuel et le } \\
\text { vocabulaire. }\end{array}$ & 2.54 & 7.69 & 0.919 & 1.095 & 17.877 & 0.90 & $\begin{array}{c}\text { S. au } \\
\text { seuil } \\
\text { de } \\
0.01\end{array}$ \\
\hline La ponctuation. & 3.00 & 7.69 & 1.213 & 0.530 & 19.38 & 0.928 & $\begin{array}{c}\text { S. au } \\
\text { seuil } \\
\text { de } \\
0.01\end{array}$ \\
\hline $\begin{array}{c}\text { La phase } \\
\text { orthographique. }\end{array}$ & 5.71 & 14.80 & 2.334 & 1.491 & 20.20 & 0.92 & $\begin{array}{c}\text { S. au } \\
\text { seuil } \\
\text { de } \\
0.01\end{array}$ \\
\hline $\begin{array}{c}\text { La phase } \\
\text { grammaticale. }\end{array}$ & 3.80 & 10.60 & 1.491 & 0.812 & 23.272 & 0.94 & $\begin{array}{c}\text { S. au } \\
\text { seuil } \\
\text { de } \\
0.01\end{array}$ \\
\hline
\end{tabular}

\section{Commentaire du tableau.}

Suivant les données statistiques quantitatives présentées dans le tableau ci-dessus, on a remarqué que la valeur de «T» sont : concernant le contenu contextuel et le vocabulaire est (17.877), concernant la ponctuation est (19.38), concernant la phase orthographique est (20.20), et la phase grammaticale est (23.272) et le seuil de signifiance est ( $\mathrm{S}$. au seuil de 0.01). Sans entrer 
dans des détails statistiques, toutes les valeurs contenues dans le tableau ci-dessus ont confirmé l'efficacité des activités théâtrales dans le développement des compétences de l'expression écrite en général.

\section{Analyse qualitative et interprétation des résultats.}

\section{Avant l'intervention.}

Après avoir analysé les résultats quantitativement, on les a analysés de façon qualitative comme suit :

- En ce qui concerne le contenu contextuel et le vocabulaire, la plupart des apprenants $(100 \% \mathrm{~N}=35 / 35)$ ont manifesté une faiblesse remarquable lors de s'exprimer par écrit dans toutes les différentes situations proposées. Ils ont trouvé des difficultés d'employer un vocabulaire convenable aux différents contextes proposés. Ils ont obtenu (moins de 4 points sur 8 points comme point maximal) avant l'intervention;

- Concernant la ponctuation, Tous les apprenants $(100 \% \mathrm{~N}$ $=35 / 35$ ) ont manifesté une faiblesse remarquable soit sur le plan de choisir la marque de ponctuation convenable, soit sur le plan de l'emploi de cette marque; ils ont obtenu (moins de 0 point à 4 points sur 8 points comme note maximale) avant la tentative;

- Pour ce qui concerne la phase orthographique, la plupart des apprenants $(97.14 \% \mathrm{~N}=34 / 35)$ ont été très faibles dans l'écriture de plusieurs graphèmes notamment les 
graphèmes semblables comme (ei - ai - ein - ain - ou eau - au ...etc.); ils ont obtenu (moins de 9 points sur 16 points comme point maximal) avant l'intervention;

- Quant à la phase grammaticale, la plupart des apprenants (82.85\% $\mathrm{N}=29 / 35)$ ont été faibles sur le plan de choisir la forme et le temps convenables pour s'exprimer par écrit. Ils n'ont pas été capables d'employer les règles grammaticales dans leurs rédactions; ils ont obtenu (de 0 à 6 points sur 12 points comme point maximal) avant la tentative.

\section{Après l'intervention.}

Il est à remarquer que tous les apprenants du groupe de l'étude ont été améliorés après avoir terminé la tentative comme suit :

- En ce qui concerne le contenu contextuel et le vocabulaire, la plupart des apprenants (94.28\% $\mathrm{N}=33 / 35)$ deviennent aptes à s'exprimer correctement par écrit dans les différentes situations de la vie personnelle, sociale, familiale et professionnelle proposées. Ils ont remarquablement pu employer un champs lexical convenable aux différents contextes proposés. Les notes des apprenants se sont élevées et deviennent entre (de 6 à 8 notes sur 8 points comme note maximale);

- Concernant la ponctuation, tous les apprenants $(100 \% \mathrm{~N}$ $=35 / 35$ ) deviennent capables non uniquement de choisir les marques convenables mais également d'employer 
chacune de ces marques au sein des phrases écrites pour s'exprimer dans toutes les situations proposées. Les notes des apprenants se sont également élevées et deviennent entre (de 14 à 16 points sur 16 points comme note maximale);

- Pour ce concerne la phase orthographique, la majorité des apprenants $(85.71 \% \quad \mathrm{~N}=30 / 35)$ deviennent capables de distinguer les graphèmes de la langue française notamment les graphèmes identiques. Ils deviennent aptes à écrire correctement les graphies différentes. Leurs phrases deviennent correctes. Les notes des apprenants deviennent entre ( 3 et 4 points sur 4 points comme note maximale);

- Quant à la phase grammaticale, la plupart des apprenants ( $\mathrm{N}=33 / 35)$ se sont considérablement améliorés soit sur le plan de choisir le temps et le mode convenable soit sur le plan d'employer ces règles grammaticales pour s'exprimer par écrit de façon correcte lors de rédiger.

\section{Vérifier la sixième hypothèse de la recherche.}

Pour vérifier la sixième hypothèse : «Il existe une différence statistiquement significative entre les moyennes des notes des sujets du groupe de l'étude dans la pré-post application des items de la grille d'observation concernant les savoir-être entre la pré et la post application de la grille d'observation en faveur de la post application de la grille au seuil de «0.01», le chercheur a 
employé le baguage statistique «SPSS». Après avoir appliqué cette technique statistique, on a obtenu le tableau ci-dessous :

Tableau ( 8 ).

Résultats relatifs à la grille d'observation en ce qui concerne les savoir-être nécessaires chez les apprenants de FLÉ. (au niveau secondaire).

\begin{tabular}{|c|c|c|c|c|c|c|c||}
\hline Test & N & M & É.T. & DL. & $\begin{array}{c}\text { «T } \\
\text { calculé }\end{array}$ & $\boldsymbol{\eta}^{2}$ & S./NS. \\
\hline \hline $\begin{array}{c}\text { Pré- } \\
\text { application. }\end{array}$ & \multirow{2}{*}{35} & 13.11 & 1.937 & & & & \\
\cline { 1 - 6 } $\begin{array}{c}\text { Post- } \\
\text { application. }\end{array}$ & & 25.46 & 1.633 & 34 & 30.899 & 0965 & $\begin{array}{c}\text { S. au } \\
\text { seuil de } \\
0.01\end{array}$ \\
\hline
\end{tabular}

\section{Commentaire du tableau.}

S'on remarque le tableau ci-dessus, on trouve que le nombre des sujets du groupe de l'étude est $(\mathrm{N}=35)$, la moyenne des notes des sujets du groupe de l'étude dans les résultats de la préapplication du test est $(\mathrm{M}=13.11)$, la moyenne des notes des sujets du même groupe de la post-application du test est $(\mathrm{M}=$ 35.46), l'écart type pour les sujets du même groupe dans les résultats de la pré-application du test est (É.T. = 1.937), l'écart type pour les sujets du même groupe de la post-application du test est $($ É.T. $=1.633)$, le degré de liberté est $(\mathrm{DL}=(\mathrm{N}-1)=$ 34), la valeur de «T» calculé est $(\mathrm{T}=30.933)$, le carré d'Éta est $\left(\eta^{2}=0.965\right)$, ainsi le seuil de signifiance est (S. au seuil de 0.01). Tous ces résultats ont clairement montré que les activités 
théâtrales étaient efficaces dans le développement des savoir-être en entier.

\section{Figure No. ( 4 ).}

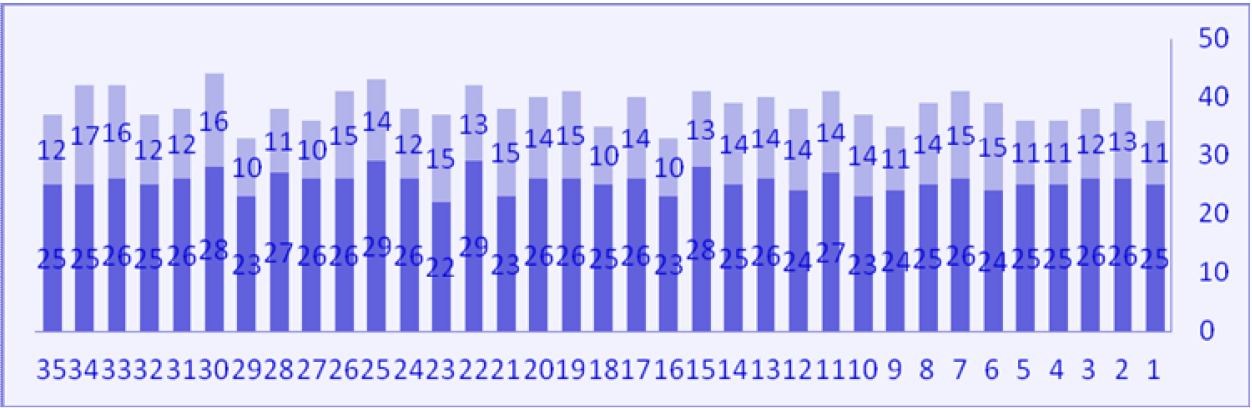

\section{Pré $\square \quad$ post}

\section{Analyse qualitative et interprétation des résultats.}

\section{Avant l'intervention.}

Après avoir analysé les résultats quantitativement, on les a analysés de façon qualitative comme suit :

- Tous les apprenants du groupe de l'étude $(100 \% \mathrm{~N}=$ 35/35) ont été faibles dans toutes les dimensions de savoir-être. Les apprenants ont manifesté une faiblesse remarquable dans tous les comportements en général : manifester l'ouverture de l'esprit, manifester l'adaptabilité et la flexibilité, manifester la conscience de son identité personnelle, manifester son autonomie, et manifester sa coopération et sa collaboration avec ses pairs;

- Ces apprenants ont obtenu des scores modestes sur la grille d'observation pour toutes les dimensions de savoir- 
être (moins de 15 points sur 30 points comme point maximal) avant la tentative;

- Il est à noter que ces apprenants ont été faibles dans des comportements essentiels comme : joindre la parole aux signes non-verbaux lors de parler, assumer une responsabilité collective, s'enthousiasmer et enthousiasmer les autres, se communiquer facilement avec les autres en groupe, préciser ses atouts et ses objectifs pour ce qui concerne les compétences de l'expression, préciser ses côtés faibles et ses côtés forts lors de développer ses compétences en expression.

\section{Après l'intervention.}

Il est à remarquer que tous les apprenants du groupe de l'étude ont été améliorés après avoir terminé la tentative comme suit :

- Tous les apprenants du groupe de l'étude $(100 \% \mathrm{~N}=$ 35/35) se sont améliorés de façon remarquable dans toutes les dimensions de savoir-être pendant les dernières séances et après avoir terminé l'entraînement en employant les activités théâtrales;

- Ils deviennent coopératifs, autonomes, sociables...etc. après l'entraînement;

- Ils ont obtenu des scores plus élevés qu'auparavant; leurs scores deviennent (de 25 à 28 points sur 30 points comme point maximal) après l'intervention; 
- Ces apprenants se sont développés dans toutes les dimensions de savoir-être. Cela se voit clairement dans tous les items de la grille d'observation;

- Ce développement s'est fait grâce aux répétitions opérées tout au long des séances de la tentative. Ce qui a confirmé que les activités théâtrales employées dans le cadre de l'étude en cours ont été efficaces pour le développement des savoir-être chez les sujets du groupe de l'étude.

\section{Discussion des résultats.}

Après avoir exposé et analysé quantitativement et qualitativement les résultats de la recherche, le chercheur peut présenter une brève discussion de ces résultats. Tout d'abord, l'étude actuelle a cherché la question du développement des compétences de l'expression orale et écrite et les savoir-être relatifs à ces compétences chez les apprenants de FLÉ de la $2^{\text {ème }}$ année au cycle secondaire en employant les activités théâtrales. Les résultats ont confirmé clairement que les activités théâtrales sont efficaces dans le domaine du développement des compétences visées et des savoir-être visés.

Cette recherche s'est accordée avec plusieurs recherches antérieures, comme : la recherche d'(Aliaa Mohammed, 2003), celle d'(Asma El-Dib, 2015), celle de (Taje El-Dine Mohammed, 2013), celle de (Passant Kamal, 2018), et celle de (Mohammed Fathi, 2018). Ces recherches ont déjà recommandé la nécessité du développement des compétences de l'expression orale et 
écrite chez les apprenants de FLÉ et notamment chez les débutants.

Également, cette recherche s'est accordée avec plusieurs recherches et œuvres antérieures, comme : (Kopiac M., et Howden J., 2000), (Cuq J.-P., 2003), (Gauvin C., et Laforge É., 2006), (Fatiha Boudebouda, 2010), (Péris E., 2009) et (Smuk M., 2014)). Ces recherches et œuvres ont mis l'accent sur l'importance du développement des savoir-être chez les apprenants de la langue étrangère et notamment ceux de la langue française comme langue étrangère (FLÉ).

Ensuite, cette recherche s'est accordée avec un nombre énorme des recherches antérieures comme : la recherche de (Balazard S., Gentet-Ravasco E., 2011), celle de (De Bouter P., 2015), celle de (Marjolaine P., et Treffandier F., (2012), et celle de (Payet A., 2010). Ces recherches et œuvres ont assuré l'efficacité de l'emploi des activités théâtrales comme démarches et outils pédagogiques. Ces recherches ont recommandé la nécessité d'employer ces activités théâtrales dans la classe de langue avec les apprenants de FLÉ de tous les niveaux langagiers.

Les résultats obtenus ont assuré l'efficacité des activités théâtrales dans le développement des compétences de l'expression orale. Les pourcentages de différentes compétences de l'expression orale avant la tentative étaient : une faiblesse totale au niveau du contenu contextuel $(100 \%)$, une faiblesse remarquable au niveau du vocabulaire choisi et employé 
(91.4\%), une faiblesse au niveau de la phase phonologique (94.2\%), une faiblesse au niveau de la phase grammaticale $(85.7 \%)$. Le chercheur a touché une amélioration considérable à tous les niveaux après la tentative. Les pourcentages ont totalement changé et deviennent : (de 80\% à 100\%) développement à tous les niveaux; niveau du contenu contextuel, niveau du vocabulaire, niveau de la phase phonologique, et niveau de la phase grammaticale.

Après avoir terminé les séances de l'entraînement, le chercheur a remarqué que les apprenants deviennent aptes à s'exprimer oralement dans les différentes situations proposées. Ils ont pu choisir leur vocabulaire, prononcer les phonèmes constituant des difficultés pour eux, distinguer oralement les différentes phrases employées pour s'exprimer (phrase affirmative, interrogative, impérative ou exclamative), respecter les règles grammaticales lors de parler.

Les résultats obtenus ont également assuré l'efficacité des activités théâtrales dans le développement des compétences de l'expression écrite. Les pourcentages de différentes compétences de l'expression écrite avant la tentative étaient : une faiblesse totale au niveau du contenu contextuel et du vocabulaire (100\%), une faiblesse remarquable au niveau de la ponctuation (100\%), une faiblesse au niveau de la phase orthographique (97\%), une faiblesse au niveau de la phase grammaticale (82.8\%). Le chercheur a touché une amélioration considérable à tous les niveaux après la tentative. Les pourcentages ont totalement 
changé et deviennent : (94.2\%) de développement au niveau du contenu contextuel et du vocabulaire, $(100 \%)$ au niveau de la ponctuation, (85.7\%) au niveau de la phase orthographique, et $(94.2 \%)$ au niveau de la phase grammaticale.

Après avoir terminé les séances de l'entraînement, le chercheur a remarqué que les apprenants deviennent capables de s'exprimer dans les différentes situations de l'écrit. Ils deviennent capables de bien choisir le vocabulaire adéquat aux différents contextes, bien faire son choix au sein des marques de ponctuation et bien les employer, bien rédiger et bien distinguer les différents graphèmes lors d'écrire et bien choisir et employer les différentes règles grammaticales.

Au même titre, les résultats obtenus ont assuré l'efficacité des activités théâtrales dans le développement des savoir-être. Le pourcentage de différentes dimensions des savoir-être étaient modestes avant la tentative. Mais après la tentative, le chercheur a touché un développement énorme au niveau de toutes les dimensions. Les apprenants deviennent plus autonomes, plus coopératifs, plus responsables qu'auparavant.

Le chercheur a remarqué que les apprenants deviennent capables de déterminer leurs atouts, leurs objectifs, leurs côtés forts et faibles pour ce qui concerne les compétences de l'expression orale et écrite.

Ce progrès remarquable au sein des compétences de l'expression orale /écrite et des savoir-être relatifs à ces compétences est due à : 
- L'activité des apprenants du groupe de l'étude au cours de pratiquer les représentations théâtrales employées dans le cadre de la recherche;

- La spontanéité des apprenants du groupe de l'étude au cours des activités théâtrales; les apprenants se sont sentis à l'aise lors de se mettre à parler en public;

- La convenance des activités proposées au niveau langagier des apprenants du groupe de l'étude;

- La convenance des savoirs et des savoir-faire contenus dans les activités proposées au niveau langagier des sujets du groupe de l'étude;

- La simplicité des consignes données au niveau des participants aux activités;

- La convenance des savoir-être aux besoins psychopédagogiques des apprenants du groupe de l'étude de ce niveau d'apprentissage;

- La clarté des étapes procédurales suivies par les participants pour exécuter les activités théâtrales.

En un mot, les résultats ont confirmé clairement que les activités théâtrales étaient efficaces en vue de développer les compétences de l'expression orale et écrite et en vue de développer les savoir-être relatifs à ces compétences chez les apprenants débutants au niveau secondaire. 
Acquis d'apprentissage réalisés par les apprenantsparticipants après avoir terminé la tentative.

Après avoir terminé la tentative, le chercheur et ses collaborateurs ont remarqué que :

- La majorité des sujets du groupe de l'étude deviennent plus aptes à s'exprimer oralement et par écrit qu'auparavant dans les différentes situations de la vie personnelle, familiale, sociale et professionnelle; ils deviennent capables de se présenter et de présenter leurs collègues, de prendre spontanément la parole en public, de décrire simplement les petits évènements, de décrire ses objects...etc.

- La plupart des sujets du groupe de l'étude deviennent plus aptes à distinguer les sons du français qu'auparavant; ils deviennent capables de distinguer les consonnes constituant des obstacles pour les arabophones comme : les consonnes $/ \mathrm{P} /$ et $/ \mathrm{b} /$, les $/ \mathrm{f} /$ et $/ \mathrm{v} /$, les $/ \mathrm{s} /$ et $/ \mathrm{z} /$, à distinguer les voyelles orales et les voyelles nasales.

- Tous les sujets du groupe de l'étude deviennent plus capables de respecter les règles grammaticales lors de parler et lors d'écrire qu'auparavant; les apprenants deviennent capables de choisir et d'employer les modes et les temps des verbes convenables, de choisir et d'employer les articles convenables, d'employer les conjugaisons correctes des verbes...etc. 
- Tous les sujets du groupe de l'étude deviennent plus capables de respecter l'intonation qu'auparavant; le chercheur a vraiment remarqué que les apprenantsparticipants deviennent aptes à distinguer les différents types de phrases en parlant : phrases affirmatives, impératives, exclamatives, et interrogatives.

- Tous les sujets du groupe de l'étude deviennent plus capables de faire attention aux rapports phonèmesgraphèmes qu'auparavant; ils deviennent aptes à écrire des phrases correctes du point de vue orthographique.

- Tous les sujets du groupe de l'étude deviennent plus aptes à choisir et à employer les marques de ponctuation convenables lors de s'exprimer par écrit qu'auparavant; ils deviennent capables de distinguer au niveau du choix au même titre au niveau d'emploi les marques convenables et de les employer correctement.

- La majorité des sujets du groupe de l'étude deviennent plus autonomes, coopératifs, sociables qu'auparavant; ils deviennent capables de fréquenter les différentes situations en parlant, de prendre la parole spontanément, de surmonter leur peur, leur honte et leur hésitation en parlant, de joindre leur parole aux gestes et aux mimiques (les signes non-verbaux).

- En un mot, les sujets du groupe de l'étude se sont améliorés de façon satisfaisante dans leurs performances 
(orale et écrite) après avoir terminé les séances de la tentative.

\section{Conclusion.}

L'étude actuelle a visé au développement des compétences de l'expression orale et écrite et au développement des savoir-être chez les apprenants de FLÉ au cycle secondaire en employant les activités et les représentations théâtrales. Afin d'atteindre les objectifs, le chercheur a élaboré quelques outils de recherche comme : un test de compétences de l'expression orale et écrite et une grille d'observation pour contrôler les savoir-être avant et après la tentative. Il a élaboré un cahier d'activités et des exercices en employant les activités et des représentations théâtrales.

Le chercheur a commencé son intervention par une préapplication des outils de recherche (le test de compétences de deux facettes d'expression et la grille d'observation). Il a guidé la tentative; le formateur de la classe a exécuté les activités élaborées sous les yeux du chercheur. Les apprenants de FLÉ à ce niveau d'apprentissage (niveau secondaire) ont travaillé avec enthousiasme; ils ont été actifs et ont participé activement aux activités parce qu'ils se sont sentis gais pendant toutes les étapes de la tentative. Leur niveau langagier s'est progressé de façon graduelle.

Le chercheur a fait l'application des instruments de la recherche avant, pendant et après la tentative (évaluation formative et évaluation sommative) et a traité les notes brutes 
régulièrement en employant les techniques statistiques appropriées.

Après avoir opéré l'analyse statistique, il a présenté une interprétation des résultats obtenus et a présenté une discussion de ces résultats. Tous les résultats ont assuré l'efficacité des activités théâtrales pour le développement des compétences de l'expression orale et écrite et le développement des savoir-être chez les apprenants de FLÉ de la $2^{\text {ème }}$ année au cycle secondaire. Il a avancé des recommandations à la lueur des résultats obtenus et il a suggéré des recherches futures.

\section{Recommandations.}

À la lueur des résultats obtenus, le chercheur a recommandé que :

- Les maîtres(ses)-enseignants(es) de FLÉ doivent employer en permanence les activités théâtrales dans les classes de langue avec les apprenants(es) de tous les niveaux d'apprentissage;

- Ils(elles) doivent exploiter ces activités théâtrales pour le développement des différentes compétences de la langue soit les compétences de la réception, soit les compétences de la production chez leurs apprenants(es) de tous les niveaux de la langue française;

- Les spécialistes et les didacticiens(nes) de FLÉ doivent s'orienter vers ces activités théâtrales lors de leurs entraînements dans le cadre de développer les 
compétences langagières et professionnelles chez maîtres(ses)-enseignants(es) de FLÉ;

- Les didacticiens(ennes) et les méthodologues de FLÉ doivent focaliser sur les rôles de l'enseignant(e), ceux de l'apprenant(e) et les scénarios d'enseignement /apprentissage concernant les activités théâtrales non seulement lors des cours théoriques consacrés à la matière de didactique de FLÉ mais également lors des séances du stage pratique pendant la formation de futurs(es) enseignants(es) dans les facultés de pédagogie.

\section{Propositions.}

À la lueur des résultats obtenus, le chercheur peut suggérer des recherches futures :

- Mener un nombre énorme de recherches en didactique de FLÉ pour développer toutes les compétences de la compréhension auditive en employant les activités et les représentations théâtrales chez les apprenants(es) de FLÉ de tous les niveaux d'apprentissage;

- Employer les activités et les représentations théâtrales pour entraîner les apprenants(es) de FLÉ notamment les adolescents(es) débutants(es) à maîtriser la performance orale;

- Exploiter les activités et les pratiques théâtrales pour développer les compétences de la communication verbale 
et non-verbale chez les élèves des cycles primaire et préparatoire en français langue étrangère;

- Mener un nombre énorme de recherches en didactique de FLÉ pour le développement de compétences de compréhension (orale et écrite) notamment chez les apprenants(es) de FLÉ dans tous les niveaux d'apprentissage.

- Effectuer des recherches successives en employant les activités théâtrales en vue de développer et d'enrichir le vocabulaire chez les apprenants(es) de FLÉ au cycle secondaire. 


\section{Bibliographie.}

\section{Références en langue francaise.}

Abdelaziz M. Latreche, (2015). L'expression orale : pratiques et difficultés en classe de FLÉ, «cas des étudiants de la $1^{\text {ère }}$ année LMD français», mémoire de master, Université d'El-Oued, Algérie.

Albert A.-C., (1998). Évaluer les productions écrites des apprenants, le français dans le monde, NovembreDécembre.

Aliaa Mohammed, (2003). Efficacité de quelques stratégies d'apprentissage sur le développement de certaines compétences auditives et orales chez les étudiants nonspécialisés, section de français, à la lueur de l'approche communicative, thèse de magistère, Faculté de pédagogie, Université de Hélouân.

Alix Ch., et al., (2013). Didactique du français langue étrangère par la pratique théâtrale, Université de Savoie.

Amel Oual, (2010). Les activités orales au cycle moyen, (Cas de classes de : 2 et 3 A. M), Mémoire de magistère, Faculté des lettres et des langues, Université de Constantine 1, Algérie.

Amina Souhila Hadjar, (2015). L'enseignement /apprentissage de l'expression orale, exemple des apprenants de $5^{\text {ème }}$ année primaire, mémoire de magistère, Université d'Oran 2. 
Aslim-Yetis V., (2008). Enseignement/apprentissage de l'expression écrite en FLÉ, environnement numérique de travail et Internet : le cas de l'université Anadolu en Turquie, thèse de PHD., Université Lyon 2.

Asma El-Dib, (2015). Programme enrichissant basé les jeux dramatiques pour le développement de quelques compétences de l'expression orale chez les élèves du cycle primaire aux écoles françaises, thèse de magistère, Faculté de pédagogie, Université d'Ain Chams.

Bailly D., (1998). Les mots de la didactique des langues, le cas de l'anglais, Ophrys.

Balazard S., et Gentet-Ravasco E., (2011). Faire du théâtre avec ses élèves : techniques théâtrales et expression orale, Hachette éducation.

Barth B.-M., (2006). Les stratégies d'enseignement et d'apprentissage en français langue seconde, Commission scolaire Kativik, services éducatifs, Juin.

Bee H., (1997). Psychologie du développement, Éditions de De BoecK.

Bérari E., (1991). L'approche communicative : théorie et pratique, clé International, Paris.

Berlin C., et Hornbeck K., (2005). Guide de formation en techniques de théâtre, UNFPA. 
Bernard I., (2010). Pratique théâtrale et insécurité linguistique, un exemple d'enseignement du FLÉ en Jordanie, Synergies Algérie, No. 10, PP. 225-231.

Besse H., et al., (1975). Pratique de la classe audio-visuelle au niveau 1, CRÉDIF, Paris.

Billières M., (1988). Le statut de l'intonation dans l'évolution de l'enseignement/apprentissage de l'oral en F.L.É., un article, Université de Toulouse-le Mirail-in Élisabeth Lhote.

Blanche-Benvéniste C., (1998). La langue parlée, genres et parodies, dans la revue de Repères, recherches en didactique du français langue maternelle, l'oral pour apprendre, INRP, No. 17.

Boisvert A., (2006). La communication participative au théâtre : le cabaret de la fausse représentation, mémoire de maîtrise, Université du Québec à Montréal.

Buysse A., (2007). Le théâtre, au-delà du jeu : une exploration de la forme théâtrale comme médiation de l'apprentissage autorégulé, cahiers de la section des sciences de l'éducation, No. 114, Université de Genève.

Catach N., (1975). Écrit et graphie dans l'enseignement du français, dans «l'apprentissage de l'écrit».

Cellier H., et Pourtier P., (2013). Réussite éducative : une expérience sociale à Romans-sur-Isère, l'Harmattan, Paris. 
Centre international d'études pédagogiques, (2015). La pratique théâtrale au service de l'enseignement du FLÉ, centre de ressources et d'ingénierie documentaires, disponible sur www.ciep.fr

Charvet P., et al., (1986). Pour pratiquer le texte du théâtre, De Boeck, Bruxelles.

CLB., (2012). Niveaux de compétence linguistique canadiens, Ontario, Canada.

Conseil de l'Europe, (2001). Cadre européen commun de référence pour les langues : apprendre, enseigner, évaluer, Les Éditions Didier, Paris.

Cormanski A., (2005). Techniques dramatiques : activités d'expression orale, Hachette FLE,Vanves.

Cornaire C., (1991). Le point sur la lecture en didactique, CÉC (centre éducatif et culturel), France.

Cornaire C., et Germain C., (1998). La compréhension orale, Clé International, Paris.

Cornaire C., et Rymond P.-M., (1999). La production écrite, clé international, Paris.

Cuq J.,-P., (2003). Dictionnaire de didactique du français langue étrangère et seconde, CLÉ International, Paris.

De Bouter P., (2015). À l'école du théâtre : dossier, cahiers pédagogiques, PP. 15-57. 
Derkaoui L., et Legros D., (2015). L'activité interprétative d'un texte et le développement de la fluidité de l'expression orale, Les neurosciences aujourd'hui, développement et perspectives de recherche, $3^{\text {ème }}$ Congrès International de Neurosciences, 24-25 octobre, Université de Constantine 2, Algérie.

Doaa Sayed, (2011). L'effet d'un programme proposé basé sur l'activité théâtrale pour développer quelques compétences de la communication orale du français chez les étudiants de la première année secondaire générale, thèse de magistère, Faculté de pédagogie, Université de Beni-Suef.

Dubois J., (1994). Dictionnaire de linguistique et des sciences du langage, Ed. Larousse Bordas, Québec.

Dubos C., (2014). Jeu de théâtre en classe, Formation Alliance Française de Turin, Turin.

Fanchini A., (2016). Les compétences sociales et la réussite scolaire de cycle III. L'effet de l'accompagnement scolaire, thèse de PHD., Université de Bourgogne Franche-Comté. disponible sur https://halshs.archives-ouvertes.fr/tel$\underline{01380965}$.

Fatiha Boudebouda, (2010). L'approche par compétences : une stratégie pour réinvestir ses acquis en français langue étrangère; cas des élèves de troisième année secondaire série Langues Étrangères du lycée «CHERAITIA Youcef», El Aouana-Jijel , mémoire de magistère, École de Doctorale Algéro-Française, Antenne de SETIF. 
Fraile P., (2014). Pratiques théâtrales en milieu scolaire, quels apports pour le développement social des élèves de cycle 3?, mémoire de master, Université d'Orléans.

Galisson R., et Coste D., (1976). Dictionnaire de didactique des langues, Librairie Hachette, Paris.

Gauvin C., et Laforge É., (2006). La formation universitaire vise habituellement des acquisitions au niveau des savoirs : les habiletés de savoir-être, Université de Québec en Abitibi-Témiscamingue, Version modifiée, Mai.

Gérard D., (1974). Les langues vivantes, Larousse.

Germain C., (1993). Évolution de l'enseignement des langues : 5000 ans d'histoire, CLÉ International, Paris.

Goody G., (1979). La raison graphique, Édition de minuit, Paris.

Goullier F., (2005). Les outils du conseil de l'Europe en classe de langue, cadre européen commun et portfolios, Didier.

Hagaar Khalil, (2005). Effet d'employer le brainstorming sur le développement des compétences de l'expression orale en français chez les étudiants des écoles secondaires des langues, Thèse de Magistère, Faculté de pédagogie, Université de Zagazig.

Hakima Abdelloui, (2012). Contribution de la communication non-verbale dans l'enseignement/ apprentissage du FLÉ, cas des élèves de la $3^{\text {ème }}$ année primaire de la wilaya de 
Biskra, mémoire de master, Université Mohamed Kheider, Biskra.

Halima Saadia Charif, (2015). Développer la compétence de l'expression orale par la pratique théâtrale, cas de $2^{\text {ème }}$ année moyenne, CEM El-Arabi Ben Mehidi, ElMeKhadma, Ouargla, Faculté des lettres et des langues, Université d'Hamma Lakhdar, El-Oued, Algérie.

Hartmann S., (2012). La pédagogie de projet : facteur de motivation et d'efficacité pour les élèves, mémoire de master, IUFM, Centre de Val de Loire.

Hassan Marai, (2002). Le théâtre scolaire, Dar El-Hilal, Beyrouth.

Hernandez Alarcon M., (2001). Proposition instructionnelle pour développer la compétence de production écrite des étudiants de la licence de FLÉ à l'université de Veracruz, Collection pédagogique universitaire, No. 36, Décembre.

Hilton H., (2011). Psycholinguistique de la production orale, aisance et diffluences en L2, Dans Goutéraux P., Intégration de l'altérité dans l'apprentissage des langues : formes didactiques et procédures psycholinguistiques, L'Harmattan, Paris, PP. 75-96.

Karima Cheriet, (2014). Pour un enseignement/apprentissage efficient de l'oral chez les élèves de $1^{\text {ère }}$ année moyenne en FLÉ : cas du C.E.M. Chergui Mecki, Zéribet-El-Oued, 
Wilaya de Biskra, Mémoire de magistère, Université de Mohammed Khider, Biskra.

Karima

Majouba,

(2012).

Stratégies

d'enseignement/apprentissage de la production écrite en classe de FLÉ, cas de la $1^{\text {ère }}$ année moyenne, mémoire de magistère, Université d'Oran, Algérie.

Kopiac M., et Howden J., (2000). Ajouter aux compétences, Chenelière/McGraw-Hill.

Kathleen J., (1994). Enseigner l'anglais, Hachette, Paris.

Kowzan T., (1997). Sémiologie du théâtre, Nathan, Paris.

Lang J., (2000). Présentation de la mission pour l'éducation artistique et culturelle, Paris.

Lartigue R., (1992). La maîtrise de la langue à l'école, C.N.D.P., Paris.

Le Boterf G., (1995). De la compétence : essai sur un attracteur étrange, Éd., d'organisation, Paris.

Lepoutre G., (2007). En quoi la théâtralisation peut-elle faciliter l'entrée dans le monde de l'écrit ?, IUFM, Bourgogne.

Lilia Boumendjel, (2005). Identification des difficultés a l'oral de FLÉ a partir d'interactions en classes de (3 AM) et propositions de remédiation, mémoire de magistère en didactique, École doctorale de français, Université Mentouri Constantine 1. 
Linten L., (1988). Recherche sur l'acquisition du langage, Presse de la Sorbonne Nouvelle, Paris.

Louys G., Leeman D., (2013). Le vécu corporel dans la pratique d'une langue, dans langages, no. 192.

Naglaa Fathi, (2006). L'effet d'un programme proposé basé sur le jeu de rôles dans l'enseignement de la langue française pour développer quelques compétences de la communication orale chez les étudiants de la première année à la faculté de pédagogie de Minia, thèse de Magistère, Faculté de pédagogie, Université de Minia.

Nesma Mohammed, (2015). Utilisation d'une stratégie actionnelle proposée pour développer les compétences de la communication orale des futurs enseignants de FLÉ à la faculté de pédagogie, thèse de Magistère, Faculté de pédagogie, Université de Damiette.

Marjolaine P., et Treffandier F., (2012). Jeux de théâtre, PUG, Grenoble.

Maurie F., (1992). Les langues vivantes à l'école, SyrosAlternatives.

Megrier D., (2004). Pratiquer le théâtre à l'école : cycle 3, Édition Retz, Paris.

Meunier Ch., (2010). Production et perception de la parole, laboratoire parole et langage, Aix-en-Provence, France. Disponible sur http://www.lpl.univ-aix.fr 
Ministère de l'Éducation de l'Ontario, (2008). Guide d'enseignement efficace de la communication orale, de la maternelle à la $3^{\text {ème }}$ année, Imprimeur de la Reine à l'Ontario, Canada.

Ministère de l'éducation nationale, (2009). Comment faire maîtriser l'expression écrite et orale par chaque élève, Bureau des programmes d'enseignement / Ressources pour le collège, Éduscol.

Ministère de l'éducation nationale, (2013). Repères pour mettre en cuvre «les activités pédagogiques complémentaires», MEN-DEGSCO, Éduscol.

Mohammed Fathi, (2018). Efficacité d'un programme proposé basé sur l'approche actionnelle en vue de développer les compétences de la compréhension auditive et de l'expression orale chez les étudiants du cycle secondaire, thèse de PHD., Faculté de pédagogie, Université de Hélouân.

Moirand S., (1982). Enseigner à communiquer en langue étrangère, Hachette, Paris.

Mongenot Ch. et De Peretti I., (2013). Pour l'enseignement du théâtre, le français d'aujourd'hui, no. 180.

Morlaix S., (2015). Les compétences sociales : quels apports dans la compréhension des différences de réussite à l'école primaire?, les documents de travail de l'IREDU, no. 2015- 
2, disponible sur https://halshs.archives-ouvertes.fr/halshs$\underline{01111163}$.

Page Ch., (1997). Éduquer par le jeu dramatique : pourquoi? Comment?, ESF éditeur, Paris.

Passant Kamal, (2018). Utilisation de l'approche actionnelle pour développer quelques compétences de l'expression orale chez les futurs-enseignants du français aux facultés de pédagogie, thèse de Magistère, Faculté de pédagogie, Université de Damiette.

Payet A., (2010). Activités théâtrales en classe de langue, CLÉ International, Paris.

Péris E., (2009). L'éducation pour l'autonomie : un nouveau modèle d'enseignement?, Dans : Lions-Olivieri, M.-L., Liria, P. (coord.). L'approche actionnelle dans l'enseignement des langues, Onze articles pour mieux comprendre et faire le point, Maison des Langues, PP. 101-118, Barcelone.

Perrenoud P., (1997). Construire des compétences dès l'école, ESF, Paris.

Pieera G., (2011). Pratique théâtrale en F.L.É. : spécificités d'une recherche action en didactique, synergies Chine, No. 6, PP. 105-114.

Pieera G., (2006). Le corps, la voix, le texte : arts du langage en langue étrangère, L'Harmattan, Paris. 
Pieera G., (2001). Une esthétique théâtrale en langue étrangère, L'Harmattan, Paris.

Pouliot M., (1993). Discours explicatif écrit en milieu universitaire, F.D.M., Recherches et applications, numéro spécial, Février - Mars, PP. 120 - 128.

Puren C., (1988). Histoire des méthodologies de l'enseignement des langues, CLÉ International, Nathan, Paris. Disponible sur www.christianpuren.com.

Raymond R., (2002). Apprentissage d'une langue étrangère/seconde, Vol. 2, La phonétique verbo-tonale, De Boeck Larcier s. a., Bruxelles.

Robert J.,-P., (2002). Dictionnaire pratique de didactique $d u$ $F L E$, $1^{\text {ère }}$ édition, l'essentiel français, Ophrys, Paris.

Roxane G., (2011). L'improvisation théâtrale au service de l'expression orale et écrite et de son enseignement, Revue suisse des sciences de l'éducation, no. 33, vol. 2, PP. 251265.

Runtz-Christan E., (2000). Enseignant et comédien, un même métier? Issy-les-Moulineaux, ESF.

Samira Moutakil, (2012). le théâtre dans un cours de langue pour les futurs guides touristiques, Synergies Corée, No. 3, PP. $21-31$.

Smuk M., (2014). Le savoir-être de l'apprenant au service du processus d'autonomisation, Synergie chine, No. 9, PP. 4151. 
Sorez H., (1995). Prendre la parole, Hatier, Paris.

Tagliante C., (2006). La classe de langue, nouvelle édition, CLÉ International, Paris.

Taje-El-Dine Mohammed, (2013). Effet d'un programme basé sur l'utilisation de l'enseignement actif sur le développement de quelques notions culturelles et des compétences de l'expression orale et écrite en français chez les élèves du cycle secondaire, Thèse de PHD., Faculté de pédagogie, Université de Minia.

Thao N., (2007). Les pratiques de classe, Disponible sur http://www.ctu.edu.vn/coursewares/supham/ppgdphap/cha pitre3.htm.

Toastmasters international, (2013). Le langage corporel : chaque geste est parole, traduit de l'Américain par la Banque Royale du Canada et Comité de Traduction District 61, traduit en 1998, version 1/2013. Disponible sur www.toastmasters.org/members.

Trendel E., (2008). Projet interculturel à l'école primaire de Mayotte et apprentissage de l'argumentation orale, thèse de PHD., Université de la Réunion.

Vercollier A., Vercollier G., (2013). L'acquisition du français langue seconde par les techniques théâtrales, Éducation permanente, Mars, PP. 51-58. 
Verdelhan-Bourgade M., (2002). Le français de scolarisation pour une didactique réaliste, Presses Universitaires de France.

Vinh S., (2001). La gestion de l'oral dans une classe indisciplinée, l'oral est un outil de démocratisation?, Mémoire, académie de Montpelier.

Watt L., (2002). L'apprentissage du français langue étrangère facilité par la technologie, thèse de PHD., Université de Pretoria.

Disponible sur http://upted.uo.ac.za/thesis/available/etd-02182003151147unrestricted/00dissertation.pdf

Weber C., (1993). L'écrit, un système d'opérations et de représentations, F.D.M., Recherches et applications, Numéro spécial, PP. 62 - 71, Février - Mars.

Wel Ch., (2008). Un regard nouveau sur le théâtre en tant que support pédagogique du FLÉ, Synergie Chine, No. 4.

\section{Sites d'Internet.}

https://www.ciep.fr

www.christianpuren.com.

http://www.ctu.edu.vn/coursewares/supham/ppgdphap/cha pitre3.htm

https://halshs.archives-ouvertes.fr/halshs-01111163.

https://halshs.archives-ouvertes.fr/tel-01380965.

http://www.lpl.univ-aix.fr 
WWW.toastmasters.org/members.

http://upted.uo.ac.za/thesis/available/etd-02182003-

151147unrestricted/00dissertation.pdf 